\title{
Government Structure and Equity in Access to Psychotherapy: A Study of Canada, with Comparisons to Australia and the United Kingdom
}

\author{
by \\ Mary Bartram
}

A thesis submitted to the Faculty of Graduate and Postdoctoral Affairs in partial fulfillment of the requirements for the degree of

Doctor of Philosophy

in

Public Policy

Carleton University

Ottawa, Ontario

(C) 2017, Mary Bartram 


\begin{abstract}
Gaps in mental health funding and insurance coverage have resulted in significant unmet need and inequities in access. Both Australia and the United Kingdom have expanded public funding for psychotherapy over the past decade, and it remains to be seen how far the new federal transfer of $\$ 5$ billion over ten years will go toward improving equity in access in Canada.
\end{abstract}

This four-paper dissertation examines how the exclusion of psychotherapy came about in Canada and why it has persisted, the extent to which access currently depends on how rich or poor you are, and what could be done to change this in the Canadian context in light of lessons learned from Australia and the United Kingdom.

The first paper analyses parliamentary debates to trace the role of Canada's decentralized government structure in constraining federal transfers. The evidence suggests that Canada's decentralized form of government has been at the heart of its inability thus far to introduce significant reforms. The primary contribution of other factors (such as stigma and cost) has been their influence over whether or not mental health has been enough of a national priority to warrant the use of federal spending power.

The second and third papers are large- $\mathrm{N}$ studies using data from Canadian and Australian population health surveys to measure the extent to which access to psychotherapy and other mental health services varies by income. Income-based inequities in utilization and unmet need are found to be significant problems in Canada, particularly for psychologist services. In Australia, inequities in utilization are found to be less of a concern than in Canada, but unmet need for psychotherapy is more inequitable, suggesting a possible backlog effect with the expansion of public funding in 2006.

The fourth paper uses interviews with key informants in Australia, the United Kingdom and Canada to delve more deeply into the relationship between government structure, service system design and equity in access to psychotherapy. The key finding is that while more centralized governments have greater capacity for reform, achieving equity in access requires explicit focus regardless of government structure, service system design or social insurance model. 


\section{Acknowledgements}

Writing a dissertation is a rather solitary endeavour and I could not have done it without support and encouragement from many quarters. First, I would like to thank my dissertation committee members: Allan Maslove, for his steady encouragement and insightful guidance from our first discussion to the completion of this dissertation; Jennifer Stewart, for inspiring the inequity research and for her invaluable assistance in puzzling it all through; and Vandna Bhatia, for strengthening the dissertation's approach to theory and for her excellent editorial suggestions. Thanks are also due to Saul Schwartz, for getting me off to a good start by asking so many fundamental questions during the proposal stage.

This dissertation had its genesis in my work with the Mental Health Strategy team at the Mental Health Commission of Canada between 2008 and 2012. By focusing this dissertation on government structure and equity in access to psychotherapy, I was able to bring together policy questions from my earlier career as a family therapist with a deep curiosity about the role of jurisdictional dynamics in mental health policy. The mentors, friends and colleagues I was fortunate enough to work with at that time have continued to support and challenge my development as a researcher throughout the dissertation journey: Howard Chodos, Gillian Mulvale, Francine Knoops, Susan Hardie, Steve Lurie and Mary-Pat MacKinnon, among others. I would also like to thank friends who have provided essential feedback and support along the way, whether by providing comments on short notice or an encouraging ear, or by being an accountability buddy: Katherine Scott, Lara Stefanovich-Thomson, Sophia Murphy, and Elen Lemaitre-Curri.

A special thank you goes to the twenty-two key informants in Australia, the United Kingdom and Canada who were so generous with their time and insights. Our conversations were in many ways the highlight of this whole enterprise.

I would also like to thank the faculty and staff at the School of Public Policy and Administration for fostering a welcoming and productive environment, as well as the Macodrum librarians for their expert knowledge of parliamentary records. Carleton's bootcamps were a boon, and Queen's University's Lakeshift PhD retreat on the shores of Opinicon Lake provided a much-needed boost in the home stretch.

On a personal note, I would like to thank my family for their unconditional encouragement. My mother, Ann Evans, who walked many steps of this journey with me. My father and step-mother, Bill Bartram and Janet Bartram-Thomas, who are always cheering me on. My brother and sister-in-law, David Bartram and Cheryl McGowan, for always having my back. And my in-laws, for always being willing to lend a hand. 
My partner Chris Forbes has been my biggest supporter from day one, with his steady encouragement to pursue this dream even when it seemed most impractical, and with his optimism about my potential to contribute to meaningful policy change. Thanks go as well to our kids, Henry, Nora and Miranda, for giving up a corner of the couch to my home office, and for sharing their perspectives on mental health and public policy. 


\section{Preface}

Mary Bartram set up and conducted the research in this dissertation, including obtaining the data and analyzing the results, with guidance and support from co-supervisors Allan Maslove and Jennifer Stewart. Paper \#3 was co-authored with Jennifer Stewart: Mary Bartram was the principal author, and led the process of setting up and conducting the research, obtaining Canadian data, analyzing the results, and preparing and writing the material presented in the paper; Jennifer Stewart led the process of obtaining and analyzing the Australian data.

Paper \#1 was first published (following peer-review) in How Ottawa Spends 2016-17 as "A Targeted Federal Mental Health Transfer: Are Prospects Better under the Trudeau Liberals?" It is reprinted with permission of Christopher Stoney (Editor), with some modifications in order to make the paper less policy-oriented and more research-oriented, as appropriate for inclusion in a dissertation.

This dissertation should be cited as: Bartram, Mary. (2017). Government structure and equity in access to psychotherapy: A study of Canada, with comparisons to Australia and the United Kingdom (Unpublished doctoral dissertation). Carleton University, Ottawa, Ontario. 


\section{Table of Contents}

\section{Front Matter:}

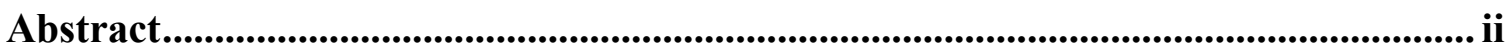

Acknowledgements ............................................................................................................ iii

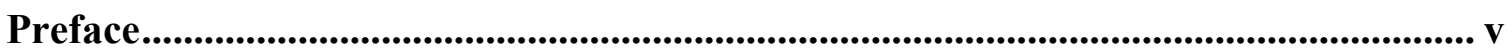

Table of Contents ........................................................................................................ vi

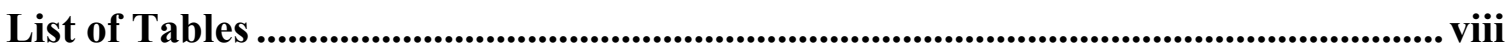

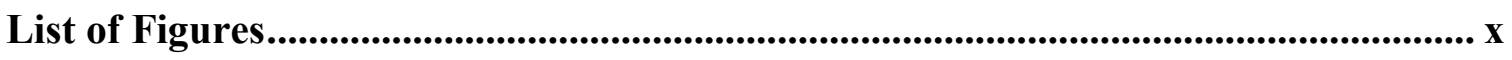

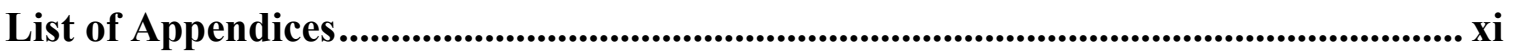

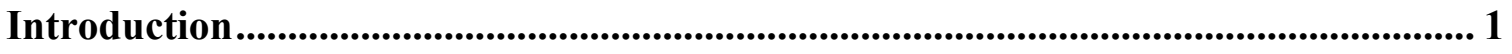

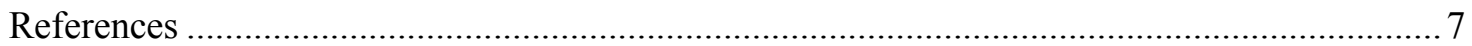

\section{Paper \#1: Prospects for a Federal Mental Health Transfer in the Canadian Context}

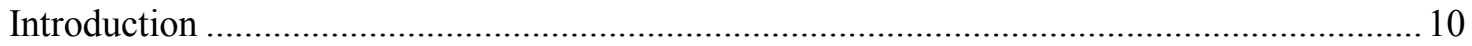

Mental Health Funding in the Context of Fiscal Federalism and the Federal

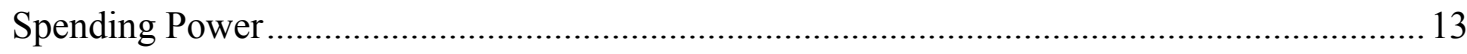

Further Federal Neglect and Disproportionate Gaps in Mental Health Funding ......................20

A Concluding Political Analysis on the Near-Term Prospects for a Targeted

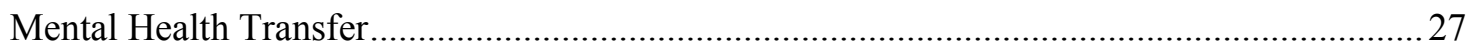

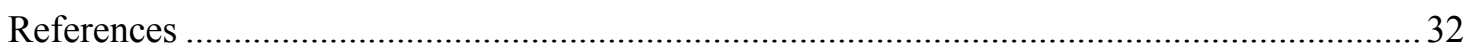

\section{Paper \#2: Income-Based Inequities in Access to Psychotherapy and other Mental}

\section{Health Services in Canada}

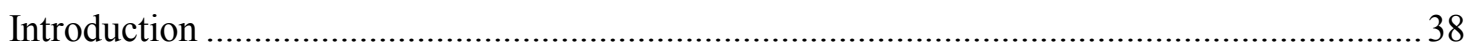

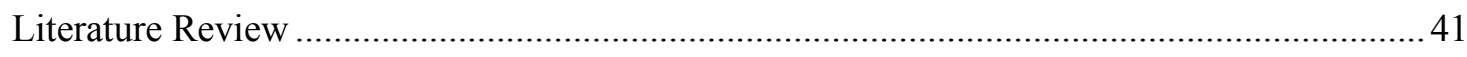

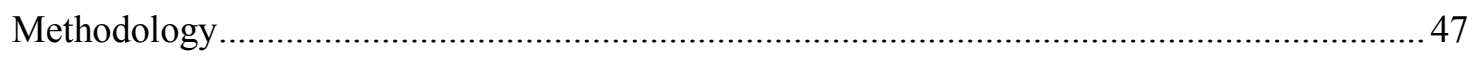

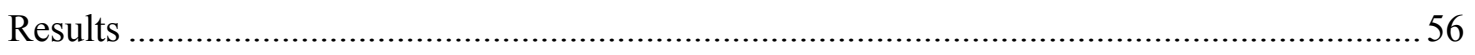

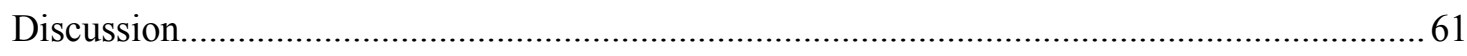

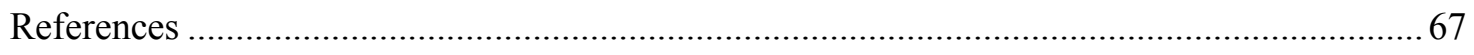

Appendix A: Calculating Need-Standardized Income-Based Inequities in Access to

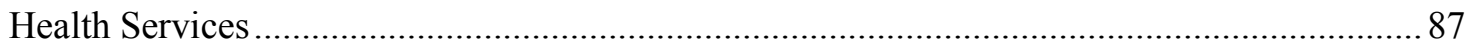

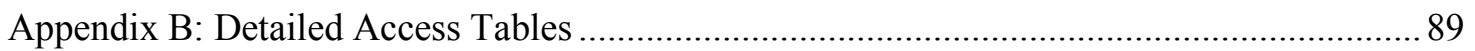

\section{Paper \#3: Income-Based Inequities in Access to Psychotherapy and other Mental}

\section{Health Services in Canada and Australia}

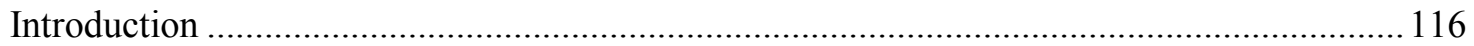

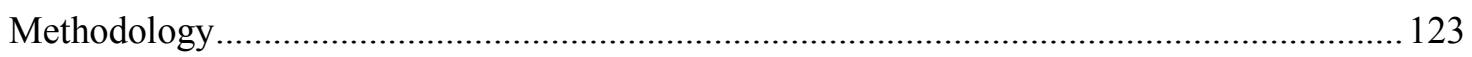

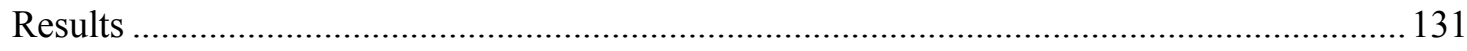

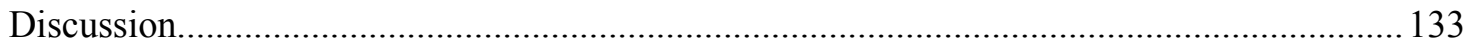

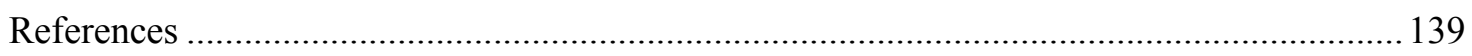




\section{Paper \#4: Government Structure, Service System Design and Equity in Access to} Psychotherapy

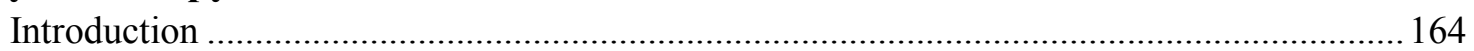

Guiding Literature regarding Government Capacity and Equitable Access......................... 165

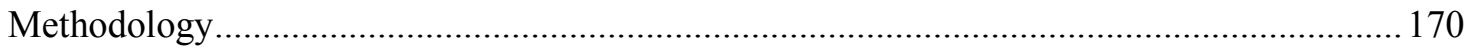

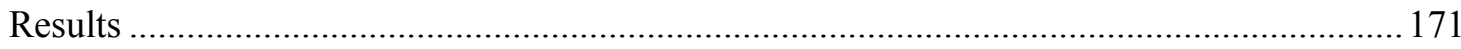

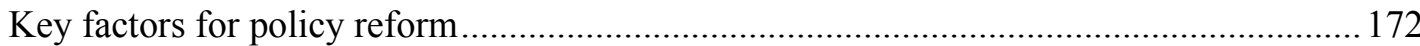

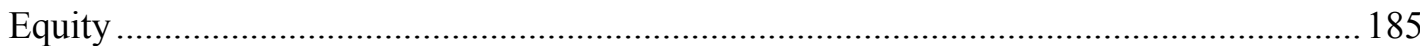

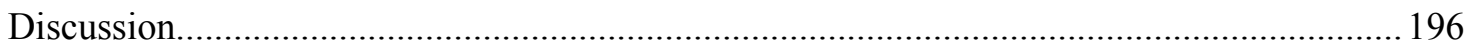

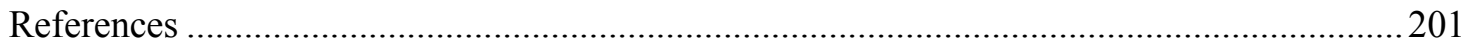

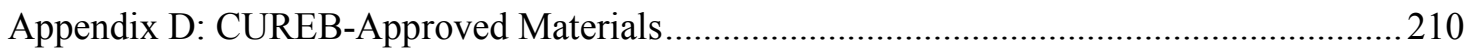

Conclusion

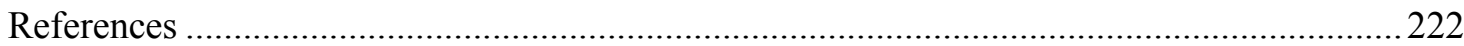




\section{List of Tables}

Paper \#2

Table 1 Outcome Variable Frequencies: Utilization .................................................. 73

Table 2 Outcome Variable Frequencies: Unmet Need .............................................. 74

Table 3 Need Variable Frequencies ............................................................................ 75

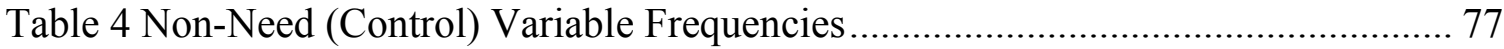

Table 5 Equivalized Household Income .......................................................................... 78

Table 6 Distribution of Mental Health Need Across Income Deciles ............................ 79

Table 7 CIs for Utilization ........................................................................................... 80

Table 8 Sensitivity Analysis of Various Mental Health Need Variables......................... 81

Table 9 CCHS MH 2012: CIs for Unmet Need for Mental Health Services................... 82

Table 10 CCHS Annual: CIs for Unmet Need for Healthcare...................................... 83

Appendix B: Detailed Access Tables

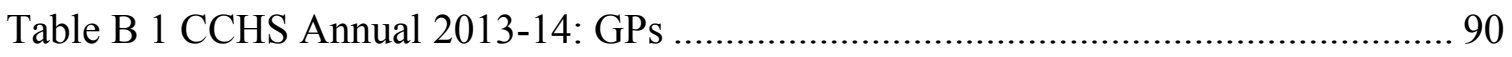

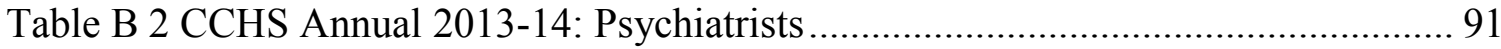

Table B 3 CCHS Annual 2013-14: Psychologists ....................................................... 92

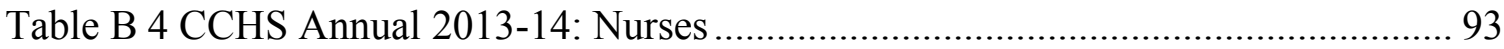

Table B 5 CCHS Annual 2013-14: Social Workers ........................................................ 94

Table B 6 CCHS Annual 2013-14: Any Professional Other than Psychologists ............ 95

Table B 7 CCHS Annual 2011-12: GPs ................................................................... 96

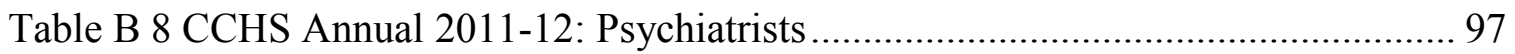

Table B 9 CCHS Annual 2011-12: Psychologists ........................................................... 98

Table B 10 CCHS Annual 2011-12: Social Workers .................................................... 99

Table B 11 CCHS Annual 2011-12: Any Professional other than Psychologists .......... 100

Table B 12 CCHS MH 2012: GP Sensitivity Analysis ........................................... 101

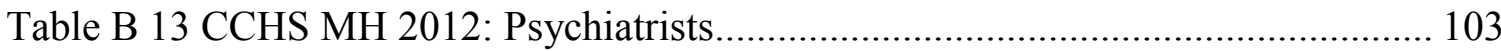

Table B 14 CCHS MH 2012: Psychologist Sensitivity Analysis .................................. 104

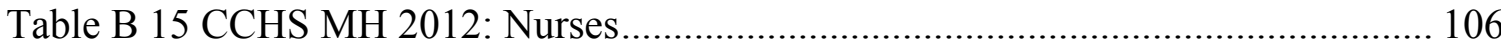

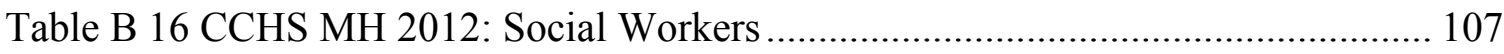

Table B 17 CCHS MH 2012: Any Professional other than Psychologists .................... 108

Table B 18 CCHS MH 2012: Unmet Need for Counselling ....................................... 109

Table B 19 CCHS MH 2012: Unmet Need for Medication.......................................... 110

Table B 20 CCHS MH 2012: Unmet Mental Health Service Need .............................. 111

Table B 21 CCHS Annual 2013-14: Unmet Need for Physical Health Problems .......... 112

Table B 22 CCHS Annual 2013-14: Unmet Need for Mental Health Problems ............. 113

Table B 23 CCHS Annual 2011-12: Unmet Need for Physical Health Problems .......... 114

Table B 24 CCHS Annual 2011-12: Unmet Need for Mental Health Problems ............ 115 


\section{Paper \#3}

Table 11 Price Faced by Service Users 145

Table 12 Outcome Variable Frequencies ................................................................. 146

Table 13 Need Variables Frequencies ...................................................................... 147

Table 14 Non-Need (Control) Variable Frequencies................................................ 148

Table 15 Equivalized Household Income ....................................................................... 149

Table 16 Concentration Indices for Self-Reported Mental Health .............................. 150

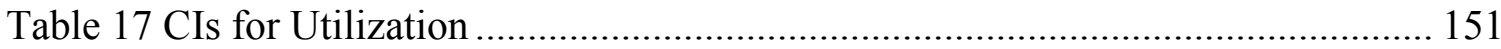

Table 18 CIs for Unmet Need for Psychotherapy...................................................... 152

Appendix C: Detailed Access Tables

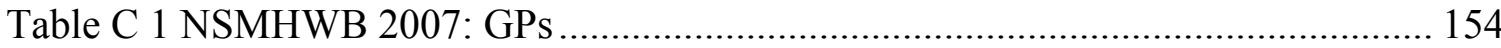

Table C 2 CCHS Annual 2011-12: GPs ................................................................ 155

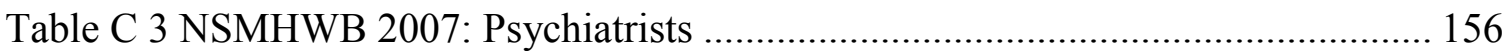

Table C 4 CCHS Annual 2011-12: Psychiatrists .......................................................... 157

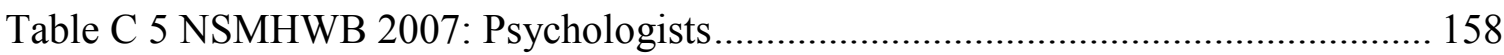

Table C 6 CCHS Annual 2011-12: Psychologists ........................................................ 159

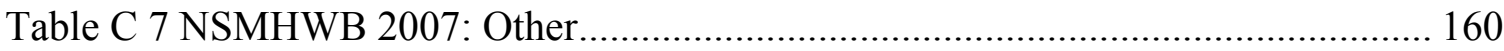

Table C 8 CCHS Annual 2011-12: Other ..................................................................... 161

Table C 9 NSMHWB 2007: Unmet Need for Psychotherapy ...................................... 162

Table C 10: CCHS MH 2012: Unmet Need for Psychotherapy ................................... 163

Paper \#4

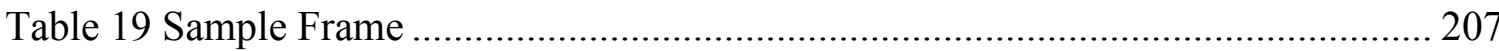

Table 20 Key Factors for Policy Reform - Summary of Results ................................. 208

Table 21 Equity and Access to Psychotherapy - Summary of Results ........................ 209 


\section{List of Figures}

Figure 1 Illustrative Example of Concentration Curves and Indices .............................. 84

Figure 2 Need-Standardized Concentration Curves for Utilization of GPs vs

Psychologists, 2011-12 85

Figure 3 Need-Standardized Concentration Curves for Unmet Need for Healthcare (Physical vs Mental Health Problems), 2011-12 


\section{List of Appendices}

Appendix A: Calculating Need-Standardized Income-Based Inequities in Access

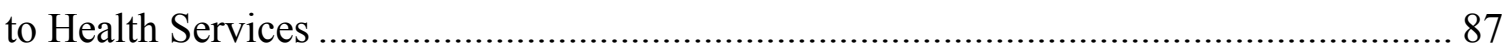

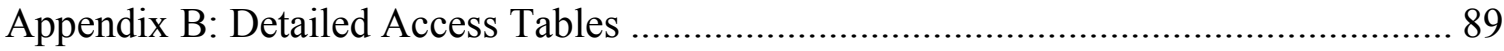

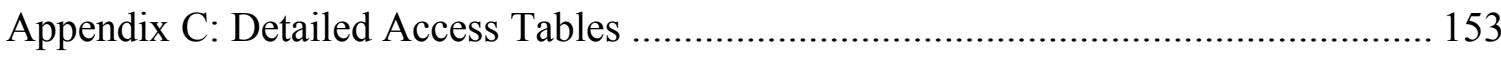

Appendix D: CUREB-Approved Materials .......................................................... 210 


\section{Introduction}

Mental health problems and illnesses affect one in five Canadians in any given year, with the combined cost to the economy (from both lost productivity and direct service provision) estimated at more than $\$ 50 \mathrm{~B}$ annually (Lim, Jacobs, Ohinmaa, Schopflocher, \& Dewa, 2008; Mental Health Commission of Canada, 2012; Smetanin et al., 2011). Nevertheless, there are significant gaps and inequities in Canadian mental health policy. Public spending on mental health in Canada is only $7 \%$ of public spending on health overall (Jacobs et al., 2010), well short of the $9 \%$ called for in the Changing Directions, Changing Lives: The Mental Health Strategy for Canada (Mental Health Commission of Canada, 2012). This percentage is also well short of the disease burden comprised by mental illnesses, which ranges from $13 \%$ globally (WHO, 2011) to $23 \%$ in the UK (OECD, 2014). By comparison, countries devote as much as $18 \%$ of their health spending to mental health, with the UK sitting at 13\% (OECD, 2014). Further, gaps in public insurance coverage have resulted in what is known as a two-tier system. Mental health services that are not provided in hospitals or by physicians are not covered by public health insurance in Canada. These excluded services include pharmaceutical treatments and psychotherapy, also known as psychological therapies, clinical counselling, and talk therapy. As a result, going to a general practitioner or psychiatrist for psychotherapy is covered by provincial and territorial health insurance plans, but going to a psychologist, clinical social worker, or other mental health professional is not.

These gaps in funding and insurance coverage are significant problems in Canadian society for three reasons. First, the gap in insurance coverage has resulted in significant unmet needs. Canadians identify a range of mental health service needs, 
including the need for information, medication and psychotherapy. Of these, psychotherapy is the need identified the most often, and is also the need that is least likely to be met (Sunderland \& Findlay, 2013). Second, the two-tier model raises financial barriers for equitable access to psychotherapy according to need. As was reported in a series in The Globe and Mail: "The treatment [many Canadians diagnosed with a mental illness] receive, and how much of it they get, will largely be decided not on evidence-based best practices but on their employment benefits and income level" (Anderssen, 2015, p. F1). Third, as the evidence base for psychotherapy has strengthened, this lack of public coverage has become increasingly questionable from a public policy perspective. Not only has psychotherapy been show to effectively reduce symptoms of common mental illness such as depression and anxiety (Canadian Psychiatric Association, 2001; Health Quality Ontario, 2016; National Institute for Health and Care Excellence, 2009), it has also been shown to reduce the economic impact of these illnesses by reducing acute care costs and improving workforce participation (Layard, Clark, Knapp \& Mayraz, 2007; Vasiliadis, Dezetter, Latimer, Drapeau, \& Lesage, 2017). While countries such as Australia and the United Kingdom (UK) have introduced significant reforms in the last decade to address similar gaps by expanding public funding for psychotherapy (Australia, 2015; NHS England, n.d.), Canada has not yet been able to follow suit. In March 2017, the Canadian federal government announced a targeted transfer of $\$ 5$ billion over ten years ( $\$ 500$ million per year on average, starting in 201718) to support provincial and territorial governments in improving access to mental health services (Finance Canada, 2017). It remains to be seen how far this new transfer will go 
oward improving access, and how much will go toward improving access to psychotherapy (Bartram \& Lurie, 2017).

This four-paper dissertation uses a mix of qualitative and quantitative methods to examine how the exclusion of psychotherapy came about in Canada and why it has persisted, the extent to which access currently depends on how rich or poor you are, and what could be done to change this in the Canadian context. The first paper analyses parliamentary debates and other historical policy records to trace the role of Canada's decentralized government structure in constraining federal funding for psychotherapy and other mental health services, and to assess prospects for a targeted federal transfer going forward from October 2016. The second paper is a large-N study using data from the Canadian Community Health Survey (CCHS) to measure the extent to which, with the financial barriers arising from these constrained policies, access to psychotherapy and other mental health services varies by income. The third paper uses similar methods to compare income-based inequities in access in Canada and Australia, two federal parliamentary systems with sharply contrasting responses to high rates of unmet need for psychotherapy. Building on the findings from the first three papers, the fourth paper uses interviews with key informants in Australia, the UK and Canada to delve more deeply into the relationship between government structure, service system design and equity in access to psychotherapy. The key findings from each paper are summarized briefly below.

The evidence from the review of the historical policy record in the first paper suggests that Canada's decentralized form of government has been at the heart of its inability thus far to introduce the kinds of reforms being implemented in Australia and 
the UK. Other factors have clearly played a role: early investments by colonial and then provincial governments in asylums, stigma, sticker shock from the high prevalence of mental illness in the population, the lack of effective treatments until the mid- $20^{\text {th }}$ century, and inter-professional struggles over turf have made it politically expedient for federal governments to evade and neglect mental health policy. However, the primary contribution of these other factors would appear to have been their influence over whether or not mental health has been enough of a national priority to warrant the use of federal spending power, with the threshold set by Canada's decentralized federal system. In the absence of such targeted federal transfers, provincial and territorial governments have been hard pressed to narrow the gap in funding for mental health services. This challenge is most acute for services that are not mandated for coverage under the Canada Health Act, such as psychotherapy provided by psychologists and clinical social workers.

The second paper found that income-based inequities in access to psychotherapy and other mental health services are indeed an issue in the Canadian context, with its absence of universal coverage of non-physician care. The two tiers exist, but apply mainly to the services of general practitioners (GPs) and psychologists. By standardizing for the higher concentration of mental health problems at lower income levels, this study was able to measure the relevant indicator, namely how much the distribution of access is even more inequitable than the distribution of need. While utilization of GP services for mental health problems was largely equitable (i.e. followed the same distribution as mental health need), utilization of psychologist services was more concentrated at higher income levels. The distribution of unmet need provided further evidence of income-based inequities in access. Unmet need for counselling and other mental health services was 
even more concentrated at lower income levels than mental health need itself. Further, after standardizing for need, unmet need for healthcare for mental health problems was more concentrated at lower income levels than unmet need for physical health problems.

By comparing income-based inequities in access to psychotherapy and other mental health services in Canada and Australia, the third paper was able to confirm that income-based inequities in the utilization of psychologist services were more of an issue in Canada in 2011-12 than in Australia in 2007, one year into the implementation of the Australian reform to improve access to psychological therapies. However, unmet need for psychotherapy and other mental health services was actually found to be more inequitable in Australia than in Canada, suggesting a possible backlog effect with the introduction of the Australian reform.

Through key informant interviews with researchers, policy-makers and stakeholders in Australia, the UK and Canada, two key findings emerged in the fourth paper. First, the comparative analysis confirmed the relationship between centralized government structures and capacity for policy reform (Banting \& Corbett, 2002; Pierson, 1995; Weaver \& Rockman, 1993), and also confirmed the first paper's finding regarding decentralization as the greatest barrier to reform in the Canadian context. With its most centralized government, reforms in the UK have had the strongest approach to accountability, the sharpest focus, and the strongest support for implementation. With its less centralized but still very strong federal system, Australian reforms have come close. Second, achieving equity in access requires explicit focus regardless of government structure, service system design or social insurance model. While the financial barriers to access under Canada's two-tier system were considered self-evident, key informants in 
Australia and the UK noted that removing financial barriers may increase absolute rates of access for all parts of the population but is no guarantee of equity. Rather, progress requires making equity an explicit objective and careful monitoring.

Each of the papers in this dissertation largely stand alone, either as the basis for a publishable journal article, or, in the case of the first paper, as a minor variation of a previously published paper (Bartram, 2016). In order to facilitate the coherence of the dissertation as a whole, some linking language is included at the outset of each paper and where called for to underscore a connection or reduce duplication. In particular, the third paper references the methodology and literature from the second paper. The strengths, limitations, recommendations for future research, and policy implications of this dissertation are discussed in the conclusion. 


\section{References}

Anderssen, E. (2015, May 22). We have the evidence...Why aren't we providing evidence-based care? The Globe and Mail, p. F1.

Australia. (2015). Better Access to Psychiatrists, Psychologists and General Practitioners through the MBS initiative [website]. Canberra: Author. Retrieved from http://www.health.gov.au/mentalhealth-betteraccess

Banting, K. G., \& Corbett, S. M. (2002). Health policy and federalism: An introduction. In K. G. Banting \& S. M. Corbett (Eds.), Health policy and federalism: A comparative perspective on multi-level governance (pp. 1-38). Kingston, ON: Institute of Intergovernmental Relations, Queen’s University.

Bartram, M. (2016). A targeted federal mental health transfer: Are prospects better under the Trudeau Liberals? In G. B. Doern \& C. Stoney (Eds.), How Ottawa Spends 20162017 (pp. 216-239). Ottawa: Carleton University.

Bartram, M., \& Lurie, S. (2017). Closing the mental health gap: The long and winding road? Canadian Journal of Community Mental Health, 1-14.

Canadian Psychiatric Association. (2001). Clinical guidelines for the treatment of depressive disorders. Canadian Journal of Psychiatry, 46(Supplement 1), 1S-90S.

Finance Canada. (2017). Building a strong middle class. Ottawa, ON: Author.

Health Quality Ontario. (2016). Major depression: Care for adults and adolescents [quality standard]. Retrieved from http://www.hqontario.ca/portals/0/documents/evidence/quality-standards/qsdepression-clinical-guide-1609-en.pdf 
Jacobs, P., Dewa, C., Lesage, A., Vasiliadis, H.-M., Escober, C., Mulvale, G., \& Yim, R. (2010). The cost of mental health and substance abuse services in Canada.

Edmonton: Institute of Health Economics.

Layard, R., Clark, D., Knapp, M., \& Mayraz, G. (2007). Cost-benefit analysis of psychological therapy. National Institute Economic Review, 202, 90-98.

Lim, K.-L., Jacobs, P., Ohinmaa, A, Schopflocher, D., \& Dewa, C. (2008). A new population-based measure of the economic burden of mental illness in Canada. Chronic Diseases in Canada, 28(3), 92-98.

Mental Health Commission of Canada. (2012). Changing directions, changing lives: The mental health strategy for Canada. Calgary: Author.

National Institute for Health and Care Excellence. (2009). Depression in adults: The treatment and management of depression in adults. London, UK: Author. Retrieved from http://www.nice.org.uk/guidance/cg90/chapter/key-prioritiesfor-implementation

NHS England. (n.d.). Adult Improving Access to Psychological Therapies programme [website]. London: Author. Retrieved from https://www.england.nhs.uk/mentalhealth/adults/iapt/

OECD. (2014). Focus on health: Making mental health count. Paris: Author. Retrieved from https://www.oecd.org/els/health-systems/Focus-on-Health-Making-MentalHealth-Count.pdf

Pierson, P. (1995). Fragmented welfare states: Federal institutions and the development of social policy. Governance, 8(4), 449 - 478. 
Smetanin, P., Stiff, D., Briante, C., Adair, C. E., Ahmad, S. \& Khan, M. (2011). The life and economic impact of major mental illnesses in Canada: 2011 to 2041. Risk Analytica, on behalf of the Mental Health Commission of Canada.

Sunderland, A. \& Findlay, L. C. (2013). Perceived need for mental health care in Canada: Results from the 2012 Canadian Community Health Survey-Mental Health. Statistics Canada Health Reports, 24(9), 3-9.

Vasiliadis, H.-M., Dezetter, A., Latimer, E., Drapeau, M., \& Lesage, A. (2017). Assessing the costs and benefits of insuring psychological services as part of Medicare for depression in Canada. Psychiatric Services, 68(9), 899-906.

Weaver, R. K., \& Rockman, B. A. (1993). Assessing the effects of institutions. In Do institutions matter? Government capabilities in the United States and abroad (pp. 1-41). Washington, DC: The Brookings Institution.

World Health Organization. (2011). Mental health atlas 2011. Geneva: Author. 


\section{Paper \#1: Prospects for a Federal Mental Health Transfer in the Canadian Context}

\section{Introduction}

Mental health problems and illnesses affect one in five Canadians in any given year, with the combined cost to the economy (from both lost productivity and direct service provision) estimated at more than $\$ 50 \mathrm{~B}$ annually (Lim, Jacobs, Ohinmaa, Schopflocher, \& Dewa, 2008; Mental Health Commission of Canada, 2012; Smetanin et al., 2011). However, significant gaps and inequities have arisen over the history of mental health policy in Canada. This paper leaves open the complex question of the extent to which addictions are considered to be a part of mental health policy.

With spending on mental health at only 7 per cent of public spending on health, Canada is far from keeping pace with the 10 to 11 per cent reached by counterpart countries such as the United Kingdom (UK) and New Zealand (Jacobs et al., 2010). Gaps in public insurance coverage have created inequities in access, with treatments people receive largely "decided not on evidence-based best practices but on their employment benefits and income level" (Anderssen, 2015, p. F1). For example, as will be demonstrated in the second paper of this dissertation, unmet needs for healthcare for mental health problems are more highly concentrated at lower levels of income than for physical health problems.

As documented below, the historical record shows that in the absence of targeted mental health transfers, provincial and territorial governments will continue to be hard pressed to narrow the gap in funding for mental health services. In Canada's highly decentralized federation, a very high bar is set for national priorities to justify the use of 
federal spending power in areas of provincial jurisdiction. Starting in the post-World War II era, broader health priorities met this bar; federal transfers have played a critical role in supporting provinces to better meet needs for health care through enhanced funding, and to reduce inequities in access to care through public health insurance. However, the history of federal transfers for mental health has been largely one of exclusion, evasion and neglect. Unmet needs for mental health care have just been too vast and expensive to take on, too jurisdictionally thorny to address, too politically expedient to evade, and too stigmatized to achieve the same priority status. While more centralized countries such as the UK and even Australia have introduced significant reforms in the last decade to address similar gaps by expanding public funding for psychotherapy services, Canada has not yet been able to follow suit (Australia, 2015; NHS England, n.d.).

Despite and to some extent because of this history, as of October 2016 prospects for a targeted mental health transfer are good, maybe even strong. In both the federal Minister of Health's mandate letter and the Liberal's first budget (Prime Minister of Canada, 2015; Finance Canada, 2016), the government has reconfirmed platform promises to negotiate a new Health Accord and improve access to mental health services. Changing Directions, Changing Lives: The Mental Health Strategy for Canada (MHS) recommended that public spending on mental health be increased from 7 to 9 per cent of all public spending on health, along with an equivalent increase in social spending and more effective use of current expenditures (Mental Health Commission of Canada, 2012). Support for mental health as a policy priority has grown over the past decade (Mulvale, Chodos, Bartram, MacKinnon, \& Abud, 2014), reflected in a wave of provincial and territorial mental health strategies and action plans, and increased attention from the 
public and the media. A recent survey found that $90 \%$ of Canadians support a targeted mental health transfer (Canadian Mental Health Association, 2015). The stage is thus set for renewed consideration of a targeted mental health transfer, to help close the gap in funding and inequities in access to services. Will it be possible to open a "policy window" (Kingdon, 1995) to advance this policy solution on the national agenda? In Canada's highly decentralized context, has mental health become a high-enough national priority to justify the use of federal spending power?

This chapter is divided into three sections. First, the potential for a targeted mental health is situated in the context of overall fiscal federalism and the nature of the federal spending power. This historical analysis uses data from debates in the House of Commons and recommendations from health commissions and stakeholder reports, and includes early criticism in Parliament and elsewhere of the failure to directly fund mental health. The second section draws from the political and policy record to explore more recent history extending to the very recent past, and shows further federal neglect and related disproportionate gaps in mental health funding due to shifts in the overall structure and nature of fiscal transfers in public health. The final conclusions of the chapter then offer an analysis of the current political environment, arguing that mental health may indeed have reached enough of a priority status to justify the use of federal spending power. The near-term prospects for a targeted mental health transfer are good and maybe even strong but also conditional given on-going tensions between federal, provincial and territorial governments in Canada's decentralized context. The conclusion also offers brief discussion of the forms that such a transfer could take. 


\section{Mental Health Funding in the Context of Fiscal Federalism and the Federal Spending Power}

The prospects for a targeted mental health transfer in Canada hang in large part on whether mental health is considered to be a national priority, thereby justifying the use of the federal spending power in an area of provincial/territorial jurisdiction. Broadly speaking, the distribution of tax room, tax revenue and spending responsibilities lies at the heart of federalism, with federal transfers as a critical distribution mechanism (Ouimet, 2014). Further, vertical fiscal imbalances tend to be built into fiscal federal arrangements, with federal governments holding back some fiscal room to deploy its federal spending power in order to promote national objectives through transfers (Boadway, 2001).

Canadian federalism is both highly decentralized and highly complex relative to other federal jurisdictions (Boadway \& Watts, 2004; Ouimet, 2014). Canadian history has been shaped by debates over vertical and horizontal fiscal imbalances and federal spending power, both the principles embodied in the constitution and the practices expressed through equalization payments and health and social transfers. What is more, the highly political nature of Canadian federalism may have played out most intensely in the health sector. According to Banting and Corbett (2002, p. 31), healthcare in Canada is "intensely politically salient," with "health politics influenc[ing] federalism as much as federalism influences health politics."

After 150 years of heated political debates over the distribution of resources and responsibilities, in general and as related to healthcare specifically, suffice it to say that the near-term prospects for a targeted mental health transfer will depend on the outcome 
of highly political negotiations between federal, provincial and territorial governments, not to mention other powerful interests such as the Canadian Medical Association. After the perceived failures of the 2004 Health Accord to buy change with increased but largely unconditional federal transfers (Health Council of Canada, 2014; Maslove, 2016), it remains to be seen how the new Liberal government will navigate the tricky political waters of a new Health Accord. Will it be more successful at tying transfers to specific targets and reforms, or will provincial autonomy prevail again? Thus far, mental health is perceived to be a national priority, after or perhaps alongside pharmacare and home care (which also confront significant gaps in public insurance coverage). Will that be enough for mental health to become enough of a national objective to justify the use of federal spending power? Even if negotiations bog down, could mental health be the exception that proves the rule?

\section{The Federal Role in Mental Health: Compounding Legacies of Exclusion}

The stage was set for mental health policy to fall outside of federal jurisdiction even before a federal government existed in Canada. The first asylum was established in Saint John in 1837, and by the time of confederation asylums had spread across North America such that they were explicitly named as an area of provincial jurisdiction in the Constitution Act of 1867: "The Establishment, Maintenance, and Management of Hospitals, Asylums, Charities, and Eleemosynary Institutions in and for the Province, other than Marine Hospitals" (Canada, 2012, s.92).

A mix of best intentions and political expediency drove this early spread of asylums. On the one hand, the beginning of colonial governments coincided with the emergence of the moral treatment movement in Europe and North America. Asylums 
were envisioned as an enlightened alternative to the warehousing of people with mental illness in jails or poorhouses, and as offering a well-ordered respite from the fast-paced, rapidly changing early $19^{\text {th }}$ century society (Brown, 1984; Rothman, 1990). On the other hand, asylums were a politically-expedient solution to a pressing public health and safety issue, providing a morally defensible method for getting unmanageable numbers of people affected by mental illness off of the streets regardless of the quality of care they received in asylums (Rothman, 1990). For example, the first asylum was established in Saint John, where higher rates of immigration made "the plight of the insane more evident and more urgent" (Francis, 1977, p. 26).

The intent to provide treatment in a therapeutic setting was overwhelmed by the reality of the high demand for this new institution. Asylums quickly became overcrowded (presumably because they provided a better alternative to jails, living in the streets, destitution, or family care). By 1891, the superintendent of the asylum in Saint John estimated that "of the 442 mental patients residing in the asylum, only 16 are expected to be restored to mental health" (New Brunswick, 2011, p. 4). Similarly by 1939 at the Ontario Hospital for the Insane in Whitby, Ontario, "the patient population swelled to 1,736 , bed capacity was 1,542 , and patients overflowed into the hallways" (Ontario Shores, n.d.). In the face of this increasing demand and overcrowding, the ideals of moral treatment gave way to warehousing, seclusion and restraints (Lurie \& Goldbloom, 2015).

\section{8-1972 National Health Programme: Targeted, Conditional Grants}

In the years following World War II, Canadian federalism became more centralized in the interests of national re-building and the development of a welfare state. Returning soldiers both exacerbated over-crowding in mental hospitals (as asylums were 
now called) and drew attention to the poor quality of care. The number of patients in mental hospitals grew from 31,686 in 1931 to 48,056 in 1945, making up 50\% of hospital patients in Canada (Canada, House of Commons, 1948, p. 6169). These urgent mental health needs compelled the federal government to use its federal spending power in a long-standing area of provincial jurisdiction. Targeted mental health grants were included under the National Health Programme in 1948 as one of a handful of national health priorities such as tuberculosis, venereal disease, and hospital construction. These grants were administered almost like contribution agreements, with provincial proposals reviewed by and held accountable to officials at the Department of National Health and Welfare in Ottawa. At $\$ 7 \mathrm{M}$ per year at the outset of the program, mental health was the largest grant targeted to a particular disease.

\section{7-1977 Cost-Shared Hospital and Medical Services Transfers}

Prime Minister Mackenzie King explicitly intended the National Health Programme grants to be "fundamental prerequisites of a nation-wide system of health insurance" (Canada, House of Commons, 1948, p. 3931). Nevertheless, when it came time to consider mental health in the context of health insurance debates in the 1950s and 1960s, the earlier investments (both the federal grant and provincial investments in asylums) provided an excuse for the decision to exclude mental hospitals. As argued by Paul Martin Sr., the then federal Minister of Health who introduced the Hospital Insurance and Diagnostic Services Act (HIDSA): "It would be wrong by any principle ... for us to include as part of the hospital insurance scheme ... mentally ill people who receive treatment in provincial institutions" (Canada, House of Commons, 1957, p. 2677). Further: 
No attempt is being made to discriminate against tuberculosis patients and those who suffer from mental illness ... This bill is designed to assist individuals in their individual hospital problems and not to subsidize provinces which are receiving assistance in other ways from the government. (Canada, House of Commons, 1957, p. 3384)

The federal government's position was extensively criticized by opposition parties, and a proposed amendment to re-consider including mental hospitals in HIDSA was debated right up until the final vote in 1957. According to Alexander Nicholson, Member of Parliament from Saskatchewan:

[I]t is most unfortunate that half of the people who are sick every day in the year are barred from the benefits of this so-called national health insurance plan... The cost per day for the patients in the mental hospitals of Canada [was] $\$ 2.70$ per patient per day in the mental hospitals ... and $\$ 10.77$ per day in the public hospitals. It now becomes clear why the minister is trying to get from under the responsibility of the federal government for this very large group. (Canada, House of Commons, 1957, p. 3382)

Erhart Regier, a Member of Parliament from British Columbia, couched the argument more in terms of the vertical fiscal imbalance: "This government gets over 70 per cent of every tax dollar; and simply because most of the provincial governments have now assumed full responsibility for mental care..., the federal government saw a way of saving some money" (Canada, House of Commons, 1957, p. 2667). John Diefenbaker (Leader of the Opposition) put it more colourfully:

Why is this? Why are these [mental] hospitals ... discriminated against? ...At the present time the provinces find themselves with a smaller and smaller share of the tax dollar and with an increasing problem intensified by our modern way of life which has resulted in the multiplication of the number of mental patients. This load of responsibility cannot be discharged properly by the provinces. (Canada, House of Commons, 1957, p. 3386)

These debates were revisited in the 1960s, with the Royal Commission on Health Services (the Hall Commission) and the introduction of the Medical Services Act (MSA). The Canadian Mental Health Association (1964) (CMHA) released its study, More for 
the Mind. This report recommended a shift from mental hospitals to care in general hospitals and communities in light of new treatment advances and concerns about stigma. However, the CMHA recommended that this shift be phased in:

The immediate scrapping of all old-style mental hospitals in favour of some new 'master plan' is not advocated, but planning at the regional and local levels can lead to the development of a new pattern of services which will better meet the needs of the mentally ill. (CMHA, 1964, p. 45)

Accordingly, the Hall Commission made a series of detailed recommendations designed to encourage the shift, but also recommended that HIDSA be expanded to cover mental hospitals in the meantime (Canada, Royal Commission on Health Services, 1964, p. 26). However, these nuances were ultimately overlooked as both federal and provincial governments appeared to latch onto the notion that mental illness could be most effectively treated in general hospitals; as these were already covered under HIDSA, little in the way of action was needed beyond encouraging the shift.

The federal government was again criticized for seeking to avoid shouldering an expensive responsibility. Harry Harley (Member of Parliament for Halton, Ontario) pointed out that psychiatric beds in general hospitals still only numbered 4,000 compared with the 68,000 beds in mental hospitals (a number that still totalled nearly half of hospital beds in Canada in 1967) (Canada, House of Commons, 1967, p. 1803). In one of his many speeches on this issue, David Orlikow (Member of Parliament for Winnipeg North) argued that the exclusion of mental hospitals resulted in "one type of treatment for people in the middle and upper income brackets" being far more likely to access higher quality care from psychiatrists and in general hospitals in urban centres, and "another and much poorer type of treatment for people in the low income brackets" (Canada, House of Commons, 1968, p. 3508). 
The federal government openly recognized the financial implications of expanding HIDSA, both in light of the high costs involved and in light of on-going fiscal federal negotiations. As recounted by federal Minister of Health Judy LaMarsh, during the 1964 federal/provincial conference on health:

[T] here was general acceptance of the principle of the integration of mental hospitals and tuberculosis sanatoria into the general hospital system. However, I did point out that the financial implications would need to be reviewed within the framework of the proposed study of the tax structure. (Canada, House of Commons, 1964, p. 5814)

Further, federal Parliamentary Secretary for Health Margaret Rideout argued that:

The question of extending federal contributions so as to include mental and tuberculosis hospitals is a financial question and is precisely the type of question which is now being studied in depth, along with other federal- provincial financial arrangements, by the tax structure committee. It is because of this, and pending a decision as to the future of federal-provincial programs such as hospital insurance, that the government does not propose to make any move at this time to include mental hospitals in the Hospital Insurance and Diagnostic Services Act. (Canada, House of Commons, 1967, pp. 1798-9)

The outcome of these considerations is telling: in 1967 the $M S A$ was voted in without expanding HIDSA to include mental hospitals. Certainly the MSA improved access and equity of access to mental health care provided by physicians, a significant policy achievement. However, the importance of this improvement was overshadowed by the hugely disproportionate number of people receiving sub-standard, uninsured services in mental hospitals. When the targeted mental health grant under the National Health Programme was dropped not long after in 1972 (National Health and Welfare, 1972), the federal role in mental health was further diminished. 


\section{Further Federal Neglect and Disproportionate Gaps in Mental Health Funding}

The more recent history shows federal neglect and related disproportionate gaps in mental health funding due to shifts in the overall structure and nature of fiscal transfers in public health. Two periods of change and complexity are examined below.

\section{8-1992 Block-Funded Transfers, De-Institutionalization and the Canada Health}

Act

Mental health policy faded further from view at the federal level over the next fifteen years. The shift to block-funding, the move toward de-institutionalization without the required investment in community services at the provincial level, and the unwillingness by either level of government to expand insurance coverage with the Canada Health Act (CHA) did nothing to address the long-standing gaps and inequities in mental health policy.

Mental health was largely absent from the debates about the Established Programs Financing (EPF) Act, introduced in 1978. The shift from cost-shared to blockfunded transfers was caught up in the broader dynamics of fiscal federalism, with provincial governments gaining more autonomy in the form of fewer conditions on federal transfers and a greater share of tax room, in exchange for greater budgetary certainty for the federal government (Ouimet, 2014). As argued by Maioni (2002), the $E P F$ tied federal transfers to the gross domestic product rather than actual health care costs, leaving provinces with greater responsibilities for growing health care costs.

These cost pressures combined with new opportunities for community-based treatment noted in the Hall Commission report to once again provide a recipe for political expediency. The move to close mental hospitals (known as de-institutionalization) that 
started in the 1970s was driven as much by the cost pressures on provincial health systems in the wake of $E P F$, as by the imperative to provide higher quality care for people living with mental health problems and illnesses. By the mid-20th century new pharmacological and psychotherapeutic treatments had opened up new opportunities for active treatment (as opposed to custodial care) and recovery of meaningful lives in the community for people living with mental health problems and illnesses (Canadian Medical Health Association, 1964). In combination with a new wave of advocacy to address deplorable conditions in mental hospitals, these treatment advances built public support for de-institutionalization (Mulvale, Abelson, \& Goering, 2007).

However, the promised re-allocation of funding from psychiatric institutions to community-based services was never fully realized (Lurie \& Goldbloom, 2015). According to Orlikow:

With the development of the tranquillizer drugs, many people who earlier spent years, if not their whole lives, in mental hospitals have been and are being released. The idea was that they would be serviced outside in the community which would help them in the transition years. ... [E]ven in a city like Toronto there are very few services for these people, so they are going back to the hospitals again. (Canada, House of Commons, 1982, p. 15869)

While de-institutionalization undoubtedly improved the lives of those who were able to secure community-based treatments and supports, it also provided a political rationale for further erosion of public funding for mental health services at a time when provincial health systems were under increasing cost pressures.

The $C H A$, passed in 1984, further entrenched the legacies of exclusion and neglect of mental health services. In the wake of the 1980 Quebec referendum, the federal government was able to shift the federation toward a more centralized approach in the name of national unity (Ouimet, 2014). This centralization included imposing national 
health standards to put an end to extra billing through the $C H A$. However, this new appetite for federal standards did not extend to under-insured areas such as home care and pharmacare, and perhaps even more particularly it did not extend to mental health.

At the time of the CHA negotiations, the combined impact of the shift from costshared to block transfers, growing health care costs, and the shortfalls of deinstitutionalization left both levels of government with little appetite for expanding responsibility for mental health insurance coverage beyond services provided by physicians or in general hospitals. Federal Minister of Health Monique Bégin recalled federal/provincial discussion of the "gray areas of medicare" as follows:

Some ministers felt it put expansionist pressure on the health-care system ... Strategic as well as economic considerations prevented me from deviating one iota from the principle that the basic rules of health insurance remain unchanged ... Mental illness was a touchy question. Though in practice many of the treatments and services for mental illness were fully integrated into general health care, the provinces did not want to see anything in this category included in medicare. (Bégin, 1987, pp. 160-1)

By this time the issue was not so much coverage for mental hospitals; block transfers made the details of how federal health transfers were spent quite at the discretion of provincial governments. However, with new forms of psychotherapeutic and community-based treatment, coverage of non-medical providers (such as psychologists, social workers, and nurses) had become increasingly relevant. As argued by Bill Blaikie, a Member of Parliament from Winnipeg, the $C H A$ failed to:

...provide leadership and incentives for moving the health care model with which medicare currently co-exists away from the present physician-dominated, curative model, toward a more comprehensive, community-based preventive health care model such as groups like the Canadian Nurses' Association have suggested. (Canada, House of Commons, 1984, p. 454) 
Largely as a result of advocacy from the Canadian Nursing Association and over the objections of the Canadian Medical Association, a small toehold for non-medical providers was achieved in the comprehensiveness clause (clause 9) of the $\mathrm{CHA}$ :

In order to satisfy the criterion respecting comprehensiveness, the health care insurance plan of a province must insure all insured health services provided by hospitals, medical practitioners or dentists, and where the law of the province so permits, similar or additional services rendered by other health care practitioners. (CHA, 1985)

However, provincial governments have been very reluctant to use this clause to expand coverage of non-medical providers, which to date has been largely limited to public insurance coverage for midwifery services. When provincial governments have acted to expand access to non-medical services, they have sought to retain control by making targeted, direct investments in community agencies or hospital-based clinics, rather than opening the door to demand-driven insurance coverage. While these developments have been positive, these controlled investments have fallen far short of closing the gap in funding for mental health services.

\section{2-2014 Health Reform Transfers and National Mental Health Funding Proposals}

Mental health has steadily moved onto the national agenda over the past two decades of health reform transfers. However, none of the health reform transfers has resulted in significant mental health investment, as mental health has been largely crowded out by other priorities. The Standing Senate Committee on Social Affairs, Science and Technology report (Canada, 2006) on mental health, titled Out of the Shadows at Last, and the subsequent release of the 2012 Mental Health Commission of Canada report set out clear funding proposals, but to date the impact beyond raising the profile of mental health has been limited. 
The motivation for broader health reform stemmed as much from concerns about the sustainability of the healthcare system in the face of spiralling costs, as from new thinking about comprehensive, patient-centred, quality healthcare. In the context of these concerns about sustainability, it was once again difficult for real progress to be made in narrowing the gap in funding for mental health care. For a total cost of $\$ 150 \mathrm{M}$ between 1997 and 2001, the Health Transition Fund funded 141 pilot projects, of which 21 focused on mental health (Goldner, 2002). For a total cost of $\$ 800 \mathrm{M}$ from 2000 to 2006, the Primary Healthcare Transition Fund funded a variety of projects, including $\$ 3.8 \mathrm{M}$ for one national project on collaborative mental health care and a few provincial mental health projects (Canada, 2007; Health Canada, 2007). Even with the massive increases to federal health transfers with the 2003 and 2004 Health Accords, mental health only warranted being included as "short-term acute community mental health home care for two-week provision of case management and crisis response services," an awkward addon to one of three home care priorities (Canada, 2004).

It was only when the above mentioned Senate Standing Committee on Science and Technology followed up its 2002 report on health (Canada, 2002) with Out of the Shadows at Last, its 2006 report on mental health (Canada, 2006), that momentum started to build for mental health as a national priority. Building on the earlier transition funds, the 2006 report recommended a 10 year, $\$ 5.1 \mathrm{~B}$ Mental Health Transition Fund, with a focus on supporting the transition to community-based services and improving access to housing for people living with mental health problems and illnesses. The Harper Conservatives did not take up this recommendation, but did follow the Senate's recommendation to establish the Mental Health Commission of Canada (MHCC) in 2007 
with a budget of $\$ 140 \mathrm{M}$ over 10 years and a mandate that included the development of a national mental health strategy (Finance Canada, 2007). The development of the $M H S$ has spurred unprecedented mental health policy development at all levels of government and in many sectors (Mulvale et al., 2014; Lurie \& Goldloom, 2015). However, this policy development has not been matched by anything more than marginal new investments.

To put some real numbers around the shortfall, the goal set in the $M H S$ was to bring the proportion of public health spending on mental health up from 7 to 9 per cent (with equivalent increases in social spending as well as more efficient use of existing spending). Based on the $\$ 145 \mathrm{~B}$ in public spending on health in 2012 (Canadian Institute for Health Information, 2014), reaching 9 per cent would require increased spending on mental health by $\$ 3 \mathrm{~B}$ per year, from $\$ 10 \mathrm{~B}$ to $\$ 13 \mathrm{~B}$. The federal Canada Health Transfer (CHT) made up 21 per cent of provincial health expenditures in 2012 (Canadian Institute for Health Information, 2014; Finance Canada, 2015). If the federal government took on 21 per cent of this $\$ 3 \mathrm{~B}$ mental health funding gap, the cost would be $\$ 630 \mathrm{M}$ per year; if it went back to the original 50/50 cost-sharing formula for public health insurance, the cost would be $\$ 1.5 \mathrm{~B}$.

These kinds of numbers far exceed previous federal transfers on mental health, which seems to have peaked with the $\$ 7 \mathrm{M}$ per year spent on the mental health grant starting in 1948, the equivalent of $\$ 73 \mathrm{M}$ in 2015 after adjusting for inflation. Just as in 1957 and 1964 when mental hospitals were excluded from hospital insurance, in the 1970s when provinces closed mental hospitals without re-investing accordingly in community and general hospital services, and again in 1984 when the $C H A$ did not 
expand to include coverage of non-medical mental health services, provincial and territorial governments today are challenged to close the mental health funding gap without targeted federal support.

At the same time, this lack of progress in closing the mental health gap through the health reform years has been influenced by broader developments in fiscal federal politics. In exchange for commitments to consult and secure a set threshold of provincial support for major initiatives, the federal government pushed for greater constitutional recognition of federal spending power through the Meech and Charlottetown Accords. After these Accords failed, softer policy recognition was secured in 1999 with the Social Union Framework Agreement (SUFA), which was approved by all provinces and territories except for Quebec (Ouimet, 2014). However, this new recognition has not fundamentally changed the political nature of fiscal federalism. Post-SUFA, the federal government's choice of which national objectives to pursue through the use of federal spending power has been as much based on the political calculus of the day as ever.

For example, the 2011 announcement by the Harper Conservatives of a completely unconditional approach to the $C H T$ (Finance Canada, 2011) was consistent with the government's "open federalism" position, whereby the federal government sought to limit its involvement in areas of clear provincial and territorial jurisdiction. At the same time, this approach distanced the Conservative government from the perceived failures of the 2004 Health Accord. While provinces and territories gained certainty regarding federal health transfers, they were left to their own devices for the increasingly impossible task of health reform. By contrast, in 2014 the Conservatives strongly exerted 
federal spending power on job training (also clearly under provincial and territorial jurisdiction) through the Canada Jobs Grant, a far more politically-attractive policy area.

\section{A Concluding Political Analysis on the Near-Term Prospects for a Targeted Mental}

\section{Health Transfer}

The evidence from the review of Canada's historical record suggests that Canada's decentralized form of government has been at the heart of its inability to introduce the kinds of reforms being implemented in Australia and the UK. Other factors have clearly played a role: early investments by colonial and then provincial governments in asylums, stigma, sticker shock from the high prevalence of mental illness in the population, the lack of effective treatments until the mid- $20^{\text {th }}$ century, and interprofessional struggles over turf made it politically expedient for federal governments to evade and neglect mental health policy. However, the primary contribution of these other factors would appear to have been their influence over whether or not mental health has been enough of a national priority to warrant the use of federal spending power, with the threshold set by Canada's decentralized federal system.

What then are the near-term prospects for a targeted mental health transfer? Is the moral and economic case for closing the gap in funding for mental health services compelling enough to justify the use of federal spending power in an area of provincial and territorial jurisdiction? Has a real policy window opened?

On the down side of the ledger, as of October 2016 early signs suggest that mental health may be overshadowed by other pressing healthcare priorities, namely home care and pharmacare (Simpson, 2016). Mental health was not mentioned in the joint press release coming out of the first Federal/Provincial/Territorial Ministers of Health meeting 
early in 2016 (Canadian Intergovernmental Conference Secretariat, 2016). Meanwhile, federal fiscal politics are bound to be as intense, and health policy as intensely politically salient, as ever. Whatever interests provincial and territorial governments have in improving access to mental health care will be at least balanced by their interests in maintaining their autonomy, and Quebec will likely opt out of whatever deal can be reached. The \$3B that would be required to bring the mental health from 7 to 9 per cent of public spending on health would be difficult to achieve at the best of times, let alone during an economic downturn. Finally, while stigma may be lessening, the risks of exclusion and neglect by policy-makers are alive and well in a country where 46 per cent of people believe that mental illness is used as an excuse for poor behaviour (Canadian Medical Association, 2008).

On the plus side, the independent streams of problems, policies and politics in the Kingdon (1995) model of agenda setting are strongly aligned. The funding and equity gap between mental health and health care is increasingly recognized as a serious problem. To quote Prime Minister Trudeau, "this separation of mental health as being outside of health has to stop...we have to lean in" (quoted in Crespi, 2016). The MHS and related work lay out numerous policy solutions that are based on extensive civil society engagement (Mulvale et al., 2014), and have been welcomed by provincial governments. Lessons learned from the early Health Accords may also have increased the appetite for policy solutions that attach stronger conditions to federal transfers, by either targeting to specific issues such as mental health or setting specific targets. The political stream is also favourable, with public support for a targeted transfer at 90 per cent and a commitment from the Trudeau Liberals to improve access to mental health on the books. 
The remaining ingredient may be the policy entrepreneur who will invest the time and energy to advance this topic firmly on the decision agenda by coupling the three streams.

This political analysis suggests that the prospects for a targeted mental health transfer are good, maybe even strong, but not a sure thing. There are a variety of forms that such a transfer could take. It seems highly unlikely that there would be support from the provincial and territorial governments, let alone the federal government, to expand demand-driven public health insurance coverage under the $C H A$. The same can be said for approaches that tie federal transfers to employment-based or private insurance; thus far, such proposals have invoked politically unpalatable moves away from first-dollar coverage, even though they might actually be an improvement over the status quo for non-medical mental health services.

Far more likely is a variant of the earlier Health Accords. A targeted mental health transfer could be tied to fairly specific actions such as expanding access to psychotherapy (Anderssen, 2015, p. F1), or to the Out of the Shadows report proposal for transitional funding to strengthen community-based services. Alternatively, a targeted transfer could be more loosely tied to the implementation of the $M H S$, with a specific target to reach the 9 per cent targeted share of public health spending. As argued by Maslove (2016), the bilateral gas tax transfer agreement model might be more effective than multilateral agreements such as the earlier Health Accords. The gas tax transfer set national objectives but was implemented through bilateral agreements that responded to different provincial and territorial needs. Such a bilateral approach could potentially leverage federal spending power to spur innovation across the country, in a manner 
consistent with of the spread of Saskatchewan-based innovations in health insurance in the mid- $20^{\text {th }}$ century.

In the absence of successful negotiation of a targeted transfer, incremental progress can still be made to close the mental health gap, or to at least slow the rate at which the gap widens. With their recent mental health strategies and plans, some provincial and territorial governments have been able to make targeted investments in mental health, even in the face of escalating health costs and projected declines in federal transfers (although in the case of Ontario targeted investments in mental health have been outstripped by spending on physical health). The federal government could make smallerscale transfers to provincial and territorial governments and organizations through departmental budgets as it has done for addictions funding through the National AntiDrug Strategy (Canada, 2015), or as it has done for cancer and mental health through federally-funded organizations such as the Canadian Partnership Against Cancer (2015) and the MHCC.

While the focus of this chapter has been on prospects for a targeted mental health transfer under a new Health Accord, social spending plays a critical role in mental health policy as well, in sectors such as housing, education, justice and child welfare. Moreover, the federal government has important jurisdictional responsibilities to improve the quality and availability of mental health services for specific population groups such as indigenous peoples, federal inmates, and the military. The opportunity also exists to advance mental health funding through other health reforms, for example through home care or pharmaceutical insurance. This strategic approach has long been used as a way to 
advance mental health reform, which has traditionally been below the radar screen of policy-makers (Rochefort, 1999).

Incremental progress on health spending is of course progress, as is increased social spending, increased investment in direct federal services, or investments that are piggy-backed on other health reforms. However, with mental health at such a high priority level there does seem to be a window of opportunity to introduce a targeted mental health transfer. A national mental health strategy is in place, the federal government is committed, public interest and support are at an all-time high, and Health Accord negotiations are underway. With its decision in 1957 to not take on the high cost of insuring services for the 40 per cent of hospital patients in mental hospitals, the federal government entrenched a gap between mental health and physical health care that has never been closed. Without significant federal support, history tells us that provincial and territorial governments will continue to be challenged in their efforts to address this fundamental disparity affecting the lives of millions of Canadians. 


\section{References}

Anderssen, E. (2015, May 22). We have the evidence...Why aren't we providing evidence-based care? The Globe and Mail, p. F1.

Australia. (2015). Better Access to Psychiatrists, Psychologists and General Practitioners through the MBS initiative [website]. Canberra: Author. Retrieved from http://www.health.gov.au/mentalhealth-betteraccess

Banting, K. G., \& Corbett, S. M. (2002). Health policy and federalism: An introduction. In K. G. Banting \& S. M. Corbett (Eds.), Health policy and federalism: A comparative perspective on multi-level governance (pp. 1-38). Kingston, ON: Institute of Intergovernmental Relations, Queen’s University.

Bégin, M. (1988). Medicare: Canada's right to health. Montreal: Optimum Publishers, International.

Boadway, R. (2001). Inter-governmental fiscal relations: The facilitator of fiscal decentralization. Constitutional Political Economy, 12, 93-121.

Boadway, R. \& Watts, R. L. (2004). Fiscal federalism in Canada, the USA, and Germany. Working Paper, no. 6. Kingston, ON: Queen's University.

Brown, T. E. (1984). The origins of the asylum in Upper Canada, 1830-1839: Towards an interpretation. Canadian Bulletin of Medical History, 1, 27-58.

Canada. (2004). First Ministers' meeting on the future of health care. Retrieved from http://healthycanadians.gc.ca/health-system-systeme-sante/cardscartes/collaboration/2004-meeting-racontre-eng.php 
Canada. (2007). Primary Health Care Transition Fund. Retrieved from http:/healthycanadians.gc.ca/health-system-systeme-sante/services/primaryprimaires/transition-adaptation-eng.php

Canada. (2012). A consolidation of the Constitution Acts, 1867 to 1982. Ottawa: Justice Canada.

Canada. (2015). Anti-Drug Strategy Initiative funded projects. Retrieved from http://www.healthycanadians.gc.ca/anti-drug-antidrogue/fundingfinancement/projects-projets-eng.php

Canada Health Act 1985. Retrieved from http://laws-lois.justice.gc.ca/eng/acts/c-6/

Canada, House of Commons. (1948). Debates, Vol. 4.

Canada, House of Commons. (1948). Debates, Vol. 6.

Canada, House of Commons. (1957). Debates, Vol. 3.

Canada, House of Commons. (1964). Debates, Vol. 6.

Canada, House of Commons. (1967). Debates, Vol. 2.

Canada, House of Commons. (1968). Debates, Vol. 4.

Canada, House of Commons. (1982). Debates, Vol. 14.

Canada, House of Commons. (1984). Debates, Vol. 1.

Canada, Royal Commission on Health Services. (1964). Report. Volume 1. Ottawa: Author.

Canada, Standing Senate Committee on Social Affairs, Science and Technology. (2002). The health of Canadians: The federal role. Ottawa: Government of Canada. 
Canada, Standing Senate Committee on Social Affairs, Science and Technology. (2006). Out of the shadows at last: Transforming mental health, mental illness and addictions services in Canada. Ottawa: Government of Canada.

Canadian Institute for Health Information. (2014). National health expenditure trends 1975-2014. Ottawa: Author.

Canadian Intergovernmental Conference Secretariat. (2016). Statement of the federalprovincial-territorial Ministers of Health. Retrieved from http://www.scics.gc.ca/english/conferences.asp?a=viewdocument\&id=2341

Canadian Medical Association. (2008). 8th annual national report card on health care. Ottawa: Author.

Canadian Mental Health Association. (1964). More for the mind. Toronto: Author. Canadian Mental Health Association. (2015). CMHA announces results of Nanos research survey on mental health funding. Retrieved from http://www.cmha.ca/news/cmha-announces-results-of-nanos-research-survey-onmental-health-funding/\#.Vr31X-azk7I

Canadian Partnership Against Cancer. (2015). Progress in action: 2014/15 annual report. Toronto: Author.

Crespi, M. (2016, January 27). The Social [television broadcast]. Toronto: CTV. Finance Canada. (2007). Aspire to a better, safer, stronger Canada. Ottawa: Author. Finance Canada. (2011). Harper government announces major new investment in health care. Retrieved from http://www.fin.gc.ca/n11/11-141-eng.asp

Finance Canada. (2015). Federal support to provinces and territories. Retrieved from http://www.fin.gc.ca/fedprov/mtp-eng.asp 
Finance Canada. (2016). Growing the middle class. Retrieved from http://www.budget.gc.ca/2016/docs/plan/budget2016-en.pdf

Francis, D. (1977). The development of the lunatic asylum in the Maritime provinces. Acadiensis, 6(2), 23-38.

Goldner, E. M. (2002). Sharing the learning: The Health Transition Fund synthesis series - mental health. Ottawa: Canada.

Health Canada. (2007). Primary Health Transition Fund: Summary of initiatives. Retrieved from http://www.hc-sc.gc.ca/hcs-sss/pubs/prim/2007-initiatives/indexeng.php\#p3a3

Health Council of Canada. (2014). Better health, better care, better value for all: Refocusing health care reform in Canada. Toronto: Author.

Jacobs, P., Dewa, C., Lesage, A., Vasiliadis, H.-M., Escober, C., Mulvale, G., \& Yim, R. (2010). The cost of mental health and substance abuse services in Canada. Edmonton: Institute of Health Economics.

Kingdon, J. W. (1995). Agendas, alternatives and public policies (2 ${ }^{\text {nd }}$ ed.). New York: Longman.

Lim, K.-L., Jacobs, P., Ohinmaa, A, Schopflocher, D., \& Dewa, C. (2008). A new population-based measure of the economic burden of mental illness in Canada. Chronic Diseases in Canada, 28(3), 92-98.

Lurie, S., \& Goldbloom, D. S. (2015). More for the mind and its legacy. Canadian Journal of Community Mental Health, 34(4), 7-30. 
Maioni, A. (2002). Federalism and health care in Canada. In K. G. Banting \& S. M. Corbett (Eds.), Health policy and federalism: A comparative perspective on multilevel governance (pp. 52-67). Kingston, ON: Institute of Intergovernmental Relations, Queen's University.

Maslove, A. (2016, January 8). Health care problems structural, not financial. Hill Times. Mental Health Commission of Canada. (2012). Changing directions, changing lives: The mental health strategy for Canada. Calgary: Author.

Mulvale, G., Abelson, J., \& Goering, P. (2007). Mental health service delivery in Ontario, Canada: How do policy legacies shape prospects for reform? Health Economics, Policy and Law, 2(4), 363-389.

Mulvale, G., Chodos, H., Bartram, M., MacKinnon, M. P., \& Abud, M. (2014). Engaging civil society through deliberative dialogue to create the first mental health strategy for Canada: Changing directions, changing lives. Social Science and Medicine, $123,262-268$.

National Health and Welfare Canada. (1972). Annual report. Ottawa, Author.

New Brunswick. (2011). The action plan for mental health in New Brunswick 2011-2018. Fredericton, NB: Author.

NHS England. (n.d.). Adult Improving Access to Psychological Therapies programme [website]. London: Author. Retrieved from https://www.england.nhs.uk/mentalhealth/adults/iapt/

Ontario Shores Centre for Mental Health Sciences. (n.d.), A brief history. Retrieved from http://www.ontarioshores.ca/UserFiles/Servers/Server6/File/PDFs/Detailed_Hist ory.pdf 
Ouimet, H. R. (2014). Quebec and Canadian fiscal federalism: From Tremblay to Séguin and beyond. Canadian Journal of Political Science, 47, 47-69.

Prime Minister of Canada. (2015). Minister of Health mandate letter. Retrieved from http://pm.gc.ca/eng/minister-health-mandate-letter

Rochefort, D. (1999). Beneath the radar screen: The politics of mental health policy reform. Paper presented at the 1999-2000 Beverley Lecture, Toronto.

Rothman, D. J. (1990). The discovery of the asylum: Social order and disorder in the New Republic. New York: Aldine de Gruyter.

Smetanin, P., Stiff, D., Briante, C., Adair, C. E., Ahmad, S. \& Khan, M. (2011). The life and economic impact of major mental illnesses in Canada: 2011 to 2041. Risk Analytica, on behalf of the Mental Health Commission of Canada.

Statistics Canada. (2013). Canadian Community Health Survey, 2012: Annual component. Ottawa: Author. 


\section{Paper \#2: Income-Based Inequities in Access to Psychotherapy and other Mental Health Services in Canada}

\section{Introduction}

The first paper in this dissertation used qualitative methods to trace the role of government structure in shaping mental health policy in Canada, with Canada's decentralized structure constraining public funding for psychotherapy and other mental health services. This second paper uses quantitative methods to examine the extent to which, under these constrained policies, access to psychotherapy and other mental health services varies by income. The results of this study will contribute to baseline information for assessing the equity impacts of significant new investments in mental health. These investments will see $\$ 5$ billion in targeted funding transferred from the federal to provincial and territorial governments over ten years (starting in 2017-18; Finance Canada, 2017).

Concentration indices (CIs) measure the extent to which a particular health or social outcome is distributed along the income distribution. This study makes a significant contribution to the literature by using CIs to measure income-based inequities in access to mental health services (including psychotherapy), after standardizing for the fact that mental health needs are themselves more concentrated at lower income levels. It is a large-N study using data from the Canadian Community Health Survey (CCHS). Equity in access is assessed in two ways. First, to what extent is utilization of professional services for mental health problems (a positive indicator of access) concentrated among wealthier people (a pro-rich distribution)? Second, to what extent are 
unmet needs for mental health services (as a negative indicator of access) concentrated amongst lower-income Canadians (a pro-poor distribution)?

This paper first provides an overview of Canada's two-tier mental health system and predicts that income-based inequities will be found in the distribution of the utilization of non-physician providers, as well as in the distribution of unmet needs for mental health services. Next, this study is situated in the literature on access to healthcare and health inequities, followed by an explanation of need-standardized CIs as a method for assessing inequity in access to health care, and descriptions of the variables selected for the analysis. The results suggest that income-based inequities in access to psychotherapy and other mental health services are an issue in Canada, although largely in relation to general practitioner (GP) and psychologist services rather than the full range of insured and uninsured providers. Finally, possible explanations and policy implications for these findings are discussed.

\section{Overview of Two-Tier System and Predicted Implications for Concentration Indices}

Psychotherapy in Canada is currently provided through a two-tier system. Firstdollar public financing under the Canada Health Act covers a narrow range of services that are either provided by physicians in general practice, in hospitals, or in publiclyfunded clinics. Private financing (either through out-of-pocket payments or through employment-based insurance such as Employee Assistance Programs) covers the broader range of services that are provided by psychologists, social workers, and other mental health professionals (non-physician providers). Accordingly, the price at time-of-service (marginal cost for service users) for psychotherapy services provided by GPs and psychiatrists is the same regardless of the service user's income level. For the broader 
range of mental health services, the price at time-of-service will vary by income. The estimated twelve million Canadians who do not have employment-based benefits (largely lower-income Canadians) face a higher price for psychotherapy services that are not covered by their provincial or territorial insurance plans than those who do have such benefits (largely middle and higher-income Canadians; Canadian Life and Health Insurance Industry, 2016). Further, higher-income Canadians are most able to afford to pay out-of-pocket (i.e. directly) for non-physician psychotherapy. These differences in financial barriers are likely most pronounced for psychologists, who tend to be more concentrated in private practice (Hunsley, Ronson \& Cohen, 2013).

The two tiers are less distinct for the provision of another core mental health treatment: prescription medication. In Canada, every province and territory provides some kind of prescription coverage for people with very low incomes (Esmail \& Barua, 2015). As with non-physician psychotherapy, higher and middle-income Canadians tend to have access to drug coverage through employment-based insurance. However, lowerincome and self-employed Canadians and the working poor are likely to have no coverage at all, and to pay out-of-pocket (Gagnon \& Hebert, 2010). As a result, lower and middle-income Canadians can either face a lower price for medications than higherincome Canadians (if they qualify for means-tested public coverage), the same price (if they have similar employment-based benefits), or a higher price (if they have no coverage and have to pay out-of-pocket).

In keeping with these differences in financial barriers, the hypotheses for this study are as follows: after standardizing for need, lower-income Canadians are less likely to utilize non-physician mental health services than higher-income Canadians, 
particularly for psychologists (H1). Further, utilization of physician mental health services will be equitably distributed across the income gradient $(\mathrm{H} 2)$. As a result of inequities in access to non-physician providers, lower-income Canadians are more likely to have unmet needs for mental health services, and this inequity will be less pronounced for medication than for counselling (H3). Lastly, lower-income Canadians are more likely to have unmet needs for mental health services than for physical health services (H4), as the Canada Health Act ensures that Canadians face the same price for any physician service regardless of income.

H1: Utilization of non-physician mental health services pro-rich, particularly for psychologists.

H2: Utilization of physician mental health services equitable.

H3: Unmet need for mental health services pro-poor, and more pro-poor for counselling than for medication.

H4: Unmet need for healthcare for mental health problems more pro-poor than for physical health problems.

\section{Literature Review}

This study builds on the considerable literature on access to healthcare and the more recent literature on health inequities. The literature on access to healthcare provided an evidence-base for which factors to include in this study, including both the dimensions of access itself and the factors that contribute to variations in access. The literature on health and mental health inequities frames access to care not just as a health care issue but as an equity issue, with a particular focus on the distribution of access by income and other socio-economic markers. 


\section{Access to Health and Mental Health Care}

There is considerable confusion regarding access as a term, arising from its two closely-related meanings in common usage (Riegle and Stewart, 2013). "[A]ccess can ... be an action word (verb) meaning the act of accessing" (p. 5), or 'realized access.' Access is also used to mean that one could obtain medical services if required or desired, or 'potential access.' Even in health system publications, the terms 'access' and 'utilization' are often used interchangeably. Even more common is the use of utilization as a proxy for potential access, which is harder to measure. The relationship between realized access and potential access can be complicated by personal preferences (such as the preference to self-manage a mental illness or fear or stigma associated with seeking care) that can only be partially observed by survey data (Goddard and Smith, 2001). This study includes two measures of access: utilization, which is a clearly a measure of realized access, and unmet need. Unmet need is both a direct indicator of unrealized access, but also an indirect indicator of barriers to potential access. For example, consider a person with a mental health problem who reports having an unmet need for counselling even though he or she could, in theory, access psychotherapy services. That person may nevertheless not seek services because of any number of barriers, such as being afraid of what people might think or lacking confidence in the mental health system.

The factors studied in the literature on access to mental health care are largely consistent with Anderson's (1995) behavioural healthcare access model, which has been the cornerstone of research on access to health care since it was first developed in the 1960s. Anderson broke down factors contributing to health care access into three categories: (1) predisposing factors, related to tendency to use healthcare services, (2) 
enabling factors, such as income and availability within a geographic area, and (3) need for health care. In the most recent iteration of this model, Anderson (1995) explicitly recognized the bi-directional relationships between factors, such as how health status can effect income and education and vice versa. These bi-directional relationships also contribute to access to mental health services, and point to the need to control for possible endogeneity. As will be discussed in more detail in the methodology section below, this study includes income and other socio-demographic variables as control variables in order to minimize the risk of endogeneity and bias.

Despite a shared interest in the type of factors identified in Anderson's model, there is little consensus in the Canadian literature on which factor contributes the most to access to mental health services, or on the related implications for Canadian policy. In their analysis of characteristics of people using psychological services, Hunsley, Lee, and Aubry (1999) found that enabling factors played a stronger role than need, since "those with higher education and higher income were more likely to receive psychological services" (p. 232), and as most people with identified mental health needs were not accessing services. Results were mixed in Kurdyak et al.'s (2014) study of the utilization of psychiatric services in Ontario, which are publicly insured. As would be expected given higher rates of mental health problems at lower income levels, utilization rates generally increased as income decreased; however, utilization rates in Toronto were highest in the richest income quintile. Other researchers used regression analysis to identify need as the key factor in determining utilization of mental health services, suggesting that pubic health insurance is reducing financial barriers to access as intended 
by policy-makers (Lewis, 2013; Vasiliadis, Lesage, Adair, \& Boyer, 2005; Vasiliadis, Tempier, Lesage \& Kates, 2009).

By contrast, Steele, Dewa and Lee (2007) found (also through regression analysis) that "most of the unmet need for mental health services is driven by acceptability issues that are unrelated to the cost or availability of services" (p. 201). Examples of acceptability barriers include health beliefs and stigma (in keeping with Andersen's predisposing factors), and point to the need for improved mental health literacy programs. Similarly, Sunderland and Findlay's descriptive analysis (2013) found that acceptability factors played a key role: more than a third of Canadians who reported having unmet needs for mental health care preferred (somewhat paradoxically, given that they also reported having unmet need) to manage their mental health problems on their own. While this preference could be related to stigma, there may be something about the nature of some mental health problems that lends itself to self-management and informal care. The mental health system and policy-makers have started to encourage these kinds of approaches through peer support and online programs.

Notwithstanding the different findings, these studies point strongly to there being at least three factors with strong relevance for research on access to mental health care: income, need and acceptability. The role of socio-demographic variables (other than income) in determining access to mental health services has also been explored in the Canadian literature. There would appear to be greater challenges in access to health services in Atlantic Canada and in rural and remote areas regions where providers are less available (Starkes, Poulin \& Kisely, 2005; Vasiliadis et al., 2005), and higher rates of utilization of psychotherapy services in Quebec where the broadest range of providers is 
regulated (Lesage \& the Canadian Collaborative Mental Health Initiative, 2006). Rates of mental health service use have also been found to be higher for women, and lower for immigrants and for those with lower levels of education and income (Vasiliadis et al., 2005; Vasiliadis et al., 2009).

\section{Health and Mental Health Inequities}

The literature on social determinants and health inequities points to the importance of 1) keeping the limited role of health services in determining health status in perspective, and 2) making sure that reducing inequities in access is accorded as much priority as improving access across the population as a whole.

The literature on social determinants of health suggests that access to health services is just one (and a weaker one at that) of many determinants of the health of populations (McGinnis, Williams-Russo \& Knickman, 2002). Access to mental health services is similarly understood to be just one of the determinants of mental health status alongside of others such as poverty, housing, education and employment, as well as freedom from stigma and discrimination (Canada, Public Health Agency of Canada, 2006). Moreover, research on socio-economic inequity is finding that these socioeconomic inequities are also determinants in and of themselves.

Socio-economic inequity has become a high-profile social issue in the 21 st century, through the 2011 Occupy Movement and the writings of Marmot, Wilkinson, Pickett, and Piketty (Marmot \& Wilkinson, 1999/2005; Piketty, 2013; Wilkinson \& Pickett, 2010). Over and above poverty, socio-economic inequity has itself been found to have a negative effect on health and social outcomes (Marmot et al., 1991). In Marmot's landmark 1991 study, illnesses, whether physical or mental, were found to have the 
highest prevalence rates among British civil servants with the lowest status occupations, and to follow a gradient to the lowest prevalence rates among those in the highest status occupations.

This focus on inequities has spurred the development of a new literature on health inequities (both outcomes and access), typically using CI methods (Hosseinpoor, Itani \& Petersen, 2012; Jiménez-Rubio, Smith \& van Doorslaer, 2008; van Doorslaer, Masseria \& the OECD Health Equity Research Group Members, 2004; Zhang et al., 2015).

Research into mental health inequities is particularly needed given the strong association between poverty and mental illness and the prevalence of financial barriers to accessing mental health care. Higher concentrations of mental health problems (measured by CIs) have been found at lower income levels in former Soviet Union countries and the United Kingdom (Goryakin, Suhrcke, Roberts \& McKee, 2015; Mangalore, Knapp \& Jenkins, 2007). Research has also emerged using CIs to measure inequities in access in the United Kingdom and Australia (Jokela, Batty, Vahtera, Elovainio \& Kivimaki, 2013; Meadows et al., 2015; Meadows \& Tylee, 2013). However, this research has not yet standardized for need. As such, it has thus far missed how much greater these inequities would be if the higher concentration of mental health problems at lower income levels were first taken into account.

Canadian research has not yet applied CI methods to study either inequities in mental health outcomes or access to mental health services. As described above, studies on access to mental health services in Canada more typically include social determinants such as income and education as explanatory variables in regression models (Sunderland \& Findlay, 2013; Lewis, 2013), and occasionally break out access by income percentiles 
(Kurdyak et al., 2016; Vasiliadis et al., 2009). By measuring CIs of access to psychotherapy and other mental health services in Canada, standardized for need, this study will address gaps in both the Canadian and international literature.

Another relevant variation on the growing interest in equity is mental health parity with physical health. For example, mental health parity legislation in the United States requires the insurance industry to provide the same level of coverage for mental and physical health problems. The Mental Health Strategy for Canada opens with a call for people who are confronting a mental illness "to count on the same support, treatment and services as anyone who is facing a physical health challenge" (Mental Health Commission of Canada, 2012, p. 3). This focus on parity opens up another avenue for research on mental health equity. By comparing need-standardized CIs for unmet need for healthcare for physical illness with those for unmet need for healthcare for mental illness, this study assesses the extent to which there is parity.

\section{Methodology}

In addition to helping to conceptualize inequities in access to mental health services, the literature on health and mental health inequities is also important for developing appropriate methodologies. Just as Gini-coefficients measure income inequity by calculating how much of the share of income is taken up by the bottom ten percent of population, the top one percent and so on, CIs were developed to measure how the share of various health and social outcomes is distributed along an income distribution. CIs are related to the diagrammatic approach of concentration curves, which plot the share of a variable (such as a health outcome) accounted for by cumulative proportions of individuals in the population ranked from poorest to richest. When the cumulative 
proportion matches the share of the variable, the curve is a straight line at a 45 degree angle called the line of equality. As can be seen in the illustrative example in Figure 1, when the outcome is concentrated at lower income levels, the line bows above this line (a pro-poor distribution), and when it is concentrated at higher income levels, the line bows below (a pro-rich distribution). A standard CI is calculated as twice the area between the concentration curve and the line of equality, with negative values representing a pro-poor distribution, positive values representing a pro-rich distribution, and zero values representing an equitable distribution. In this study, standard CIs are referred to as basic CIs, to avoid confusion with need-standardized CIs.

Following the guidelines set out by O'Donnell and the World Bank (2008), this study uses CIs to measure inequity in access to mental health services, after standardizing for need and controlling for non-need variables. Methodologists have developed many different kinds of CIs that vary according to how sensitive they are to poverty as opposed to wealth, or to horizontal as opposed to vertical inequity, and that are suitable for different kinds of variables (O’Donnell, O'Neill, Van Ourti \& Walsh, 2016). This study uses basic CIs that are suitable for the measurement of inequity in binomial variables and have not been calculated for access to mental health services in Canada.

In order to account for the income gradient in the distribution of mental health problems when measuring equity in access to mental health services, it is important to standardize for need. This kind of equity is called horizontal equity, which is defined as equal treatment for equal need irrespective of other characteristics such as income, race, place of residence, etc., in contrast with vertical equity, which is defined as appropriate unequal treatment for unequal need (O'Donnell \& the World Bank, 2008). To achieve 
horizontal equity, access to mental health services should follow the same gradient as the need for these services. If one does not standardize for need, higher concentrations of access to mental health services at lower income levels can make it seem as if lowerincome people have better access to services, when the opposite may be true if the higher concentration of access does not match the higher concentration of needs.

Accordingly, O'Donnell and the World Bank's (2008) method for calculating need-standardized income-based inequities in access to health services has three steps (see Appendix A for a more detailed overview). First, access that could be expected based on need is predicted using a probit function. Second, need-standardized access is calculated. Third, CIs are calculated from this need-standardized access calculation. An illustrative example can be found in Table B9 regarding utilization of GP mental health services. The actual (basic) CI is -.0689 , which suggests a concentration of access at lower income levels. However, the predicted CI is -.0451 . This predicted value represents the distribution of access one would expect based on the distribution of poor mental health, age and sex across the income gradient, after controlling for non-need variables. After standardizing for need, the CI drops to the less pro-poor value of -.0247.

Before testing the hypotheses set out above, this study first assesses the degree of income-based inequity in the distribution of mental health need. This preliminary analysis establishes the importance of standardizing for need by first confirming the income gradient in mental health problems, and includes an analysis of potential mental health need variables. Next, $\mathrm{H} 1$ and $\mathrm{H} 2$ are tested by comparing CIs for the utilization of various kinds of service providers. The results of a sensitivity analysis standardizing for different mental health need variables is presented, with a particular focus on substance 
abuse. $\mathrm{H} 3$ is then tested by comparing the CIs for having an unmet need for counselling, medication, or any mental health services. Lastly, $\mathrm{H} 4$ is tested by comparing the CIs for having an unmet need for healthcare for physical health problems and mental health problems. All CIs are standardized for need and controlled for non-need sociodemographic variables.

As a descriptive study, the results presented here describe the nature of the association between income, access, and the socio-demographic control variables that are included in the analysis. The strengths of this approach are that predictions and measurements can be made based on descriptive statistics such as regression analysis and inequality indices. However, as a descriptive study there is no claim of any causal relationships between variables. Questions about causation, such as whether higher income causes higher rates of utilization of psychotherapy, or whether unmet need for psychotherapy causes lower income, are beyond the scope of this study.

\section{Data}

Data are drawn from three versions of the CCHS: the CCHS Annual 2011-12, the CCHS Annual 2013-14, and the CCHS Mental Health (CCHS MH) 2012. The CCHS Annual is a cross-sectional survey on health status, health care utilization and health determinants for the Canadian population (Statistics Canada, 2015a). It is a self-report survey with large sample (age 12+, N 65,000 annually) designed to provide reliable estimates at the health region level in all provinces and territories. Both single year and two-year versions (which roll up two years together) are released by Statistics Canada. Three sample frames are used to select households, with approximately half of the sample based on the multistage stratified cluster design used in the Canadian Labour Force 
Survey, half based on a list frame of telephone numbers, and 1\% on Random Digit Dialing. While the survey excludes several population groups, some of these exclusions are helpful for the purposes of this study. For example, the CCHS Annual excludes groups who are eligible for federally-funded mental health services that fall outside of Medicare (such as members of the Canadian Forces and people living on reserves or in prisons). On the other hand, the CCHS Annual also excludes people who live in institutional settings such as long-term care and hospitals, thus reducing the relevance of this study for these subgroups who are covered by public health insurance.

The CCHS MH 2012 (age 15+, N=25,113 from all ten provinces but none of the territories) is an in-depth survey regarding mental health issues, attitudes and service utilization (Statistics Canada, 2013). The CCHS MH 2012 excludes the same populations as the CCHS Annual.

Four kinds of variables are needed to apply O'Donnell and the World Bank's (2008) method for calculating need-standardized income-based inequities in access to mental health services: outcome, need, non-need (control), and ranking variables. Descriptive statistics are presented below, including descriptions of how the variables are coded and how missing variables are addressed.

Outcome variables. This study uses two kinds of outcome variables: utilization of professional services for mental health problems, and unmet need for mental health care. The utilization variables are distinguished by the provider of care: GP, psychiatrist, psychologist, nurse, and social worker (see Table 1 for frequencies). A not-psychologist variable was also created, to differentiate between psychologists and any other mental health service provider. This variable was added because of the specific hypothesis that 
income-based inequities in access will be most pronounced for psychologists, with their higher concentration in the private sector. The CCHS MH 2012 and the CCHS Annual 2011-12 asked these utilization questions of all respondents, but this component in the CCHS Annual 2013-14 only included respondents from Newfoundland and Labrador, Quebec, Ontario, Manitoba, British Columbia, the Northwest Territories and Nunavut. While all three $C C H S$ included in this study collected data regarding these utilization variables, the CCHS MH 2012 changed the way the question was worded to include substance abuse. Whereas the CCHS Annual 2011-12 and 2013-14 asked whether respondents have seen or talked to a professional in the past 12 months about their “emotional or mental health," (Statistics Canada, 2012a; Statistics Canada, 2014), CCHS MH 2012 changed this question to "emotions, mental health, or use of alcohol or drugs" (Statistics Canada, 2012b). As will be seen below, this change has important consequences for the measurement of income-based inequities in access.

Unmet need is measured in two ways (see Table 2 for frequencies). First, $C C H S$ MH 2012 collected data from all provinces on unmet need (in the past 12 months) for all mental health services including counselling, medication, information and other (here broken out by need for all mental health services, counselling or medication). Dichotomous variables were created that coded unmet need or partially met need as 1 , and met need or no need as 0 . Unmet need includes both respondents who accessed mental health services but did not receive enough, and respondents who needed mental health services but did not access them. Second, CCHS Annual collected data on unmet need for healthcare in the past 12 months, broken out by physical and mental health problems. As this component was optional, CCHS Annual 2011-12 only collected this 
data for Nova Scotia, Ontario, British Columbia, the Northwest Territories, and Nunavut, and CCHS Annual 2013-14 collected this data for Newfoundland and Labrador, Ontario, Alberta and the Northwest Territories. Both are included here to assess the validity of the findings as representative of the Canadian population as a whole, to the extent that the findings for the different regions are similar.

Need variables. In addition to sex and age, this analysis evaluates several mental health need variables from $C C H S$ for potential use in predicting need-standardized access outcomes. These mental health need variables include: self-reported mental health (with poor or fair indicating need, and good, very good and excellent indicating no need), meeting the World Health Organization's (WHO) diagnostic screening criteria for disorders (mood, anxiety and substance use), and moderate distress on the Kessler distress scale (K6). The Kessler scale is generally used to identify people who meet diagnostic criteria for mental disorders who score higher than 13 (out of a possible 24); however, in order to identify those in distress who might benefit from psychotherapy, this study uses the lower threshold of $>4$ developed by Sunderland and Findlay (2013). As can be seen in Table 3, the percentage of the population with this lower-threshold level of distress is high (22.8\% for distress vs $7.8 \%$ for poor/fair mental health and $5.3 \%$ for any mood disorder). However, with estimates of the prevalence of mental health problems and illnesses as high as one in five in any given year (Mental Health Commission of Canada, 2013), the higher percentage for low-threshold distress seems reasonable. In the end, self-reported mental health is used to standardize for need for all of the CI calculations, for the following reasons. First, self-reported mental health is most consistently available across the various $C C H S$; the Kessler distress scale, for example, is 
only collected for Saskatchewan and Ontario in the CCHS Annual 2011-12 and only for Quebec in the CCHS Annual 2013-14, and the WHO screening variables are not included in the CCHS Annual. Second, both self-reported mental health and self-reported physical health are collected by the CCHS Annual (with the same options of poor, fair, good, very good and excellent), thus allowing for a comparison of need-standardized unmet need for health care for physical and mental health problems. Third, self-reported mental health is collected in many countries around the world, making it possible to compare results as is done in the third paper of this disseration. Fourth, poor and fair self-reported mental health captures a broader range of mental health need than diagnostic screening variables. A broader range is more theoretically relevant as access to mental health services has an important role in preventing the developing of disorder as well as in treating illness once a diagnosable level of symptoms has manifested. Lastly, as will be seen below, CIs standardized for distress have similar values to those standardized for both self-reported mental health and any mood disorder. Nevertheless, all of the potential mental health need variables from CCHS MH 2012 are used in the study for the purposes of a sensitivity analysis. Frequencies are reported in Table 3 below, with different values noted for the different sub-samples opting in to the different mental health outcome variables.

Non-need variables. Four socio-demographic non-need variables are included: education, immigration, residence in non-urban areas, and household income (see Table 4 and Table 5 for frequencies). These four variables were identified earlier as having a role in determining both mental health need and access to mental health care, and could, if not controlled for, potentially introduce endogeneity into the results of the probit. For 
example, if income were not included as a non-need variable, the coefficients on selfreported mental health (the key need variable) would not only measure the relationship between need and access to mental health services (the outcome variables), but would also include the effect of income on both self-reported mental health and access. Regional variations were also identified in the literature (such as higher rates of utilization in Quebec and lower rates in the Atlantic provinces). However, in light of the varying mixes of provinces and territories opting into the access variables as discussed above, regions were not included as a non-need variable.

The first three non-need variables were coded as follows. Education was divided into four dummy variables according to the highest level of educational attainment in the household: less than secondary school, secondary school, some post-secondary, and postsecondary graduate. Immigration was coded as a dichotomous variable, coded as one for people born outside of Canada. Similarly, residence in non-urban areas (other than urban core and secondary core) was coded as one in a dichotomous variable, with the assumption being that access to mental health services declines outside of urban areas (Statistics Canada, 2015b). The fourth non-need variable, household income, is also the ranking variable and is described below.

Ranking variable. Household income is used both as a non-need variable (that is controlled for in the calculation of predicted access), and as a ranking variable for the calculation of CIs (see Table 5 for mean, Gini coefficient, and income distribution statistics). The reason for choosing household over personal income is that to the extent that households are made up of people with familial or otherwise-close ties, financial barriers to mental health services are more likely faced by households as opposed to 
individuals. $C C H S$ income variables are self-reported and contain no missing values, as CCHS uses an imputation process to generate a full set of income values (Statistics Canada, n.d.). This study transforms the $C C H S$ household income variable in two ways. First, household income has been equivalized (divided by the square root of household size) to account for differences in the purchasing power of different-sized households (OECD, n.d.). Second, for use as a ranking variable, a random unique amount (the observation number divided by 10000 , with values ranging from .000001 to 12) has been added to the equivalized household income. This transformation breaks ties between identical income values, thus ensuring that each income value is unique and allowing for the effective use of household income as ranking variable.

Missing values. Observations with missing values from need and non-need variables were dropped from the study, ranging from a handful to larger numbers such as 2,603 missing values for self-reported mental health, 11,000 missing values for education and 4,256 missing values for immigration dropped from CCHS Annual 2011-12, which has a total sample size of 65,000 annually. Details for each variable can be found in Tables 1-4. Dropping these observation is most likely to have led to an underestimation of income-based inequity in access, as the missing values are generally concentrated at lower income levels. Missing values may lead to an underestimation of income-based inequity in access, as the inclusion of more lower-income respondents in the analysis would likely have strengthened the findings in the direction of greater inequity.

\section{Results}

This study confirms that there is an income gradient in the distribution of mental health need, with higher percentages of people with mental health need concentrated at 
lower income deciles, and with correspondingly significant negative (pro-poor) basic CI values (see Table 6). This result underscores the importance of first standardizing for need before measuring income-based inequity in access to mental health services. For example, an equitable distribution of service utilization should match the concentration of need at lower income levels; an inequitable distribution would be less concentrated at lower income levels than need.

The distribution of mental health need across income deciles is similar across all three $C C H S$ when measured by self-reported poor/fair mental health, and when measured from CCHS MH 2012 by distress or by meeting screening criteria for mood disorders (the $n$ for anxiety was too small to support a CI calculation). The gradient for distress, which is coded at a low threshold, is less pronounced than for self-reported mental health or any mood disorder: the basic CI for distress is -.138 vs -.234 for self-reported mental health and -.219 for any mood disorder. Nevertheless, the gradient all three for of these CIs is statistically significant $(\mathrm{p}<.000)$. Moreover, as will be seen below, distress functions similarly to self-reported mental health as a need variable when calculating CIs for mental health outcomes. There is, however, a striking difference in the gradient for substance use disorders. The distribution of substance use disorders is more variable across income deciles, with a CI of -.002 that is not statistically significant $(\mathrm{p}<.917)$. This finding will have important consequences for the suitability of CCHS MH 2012, which included substance use in its question about consultations with health professionals, in calculating CIs.

The next set of results compares the degree of income-based inequity in the utilization of services provided by various types of mental health professionals, after 
standardizing for need and controlling for non-need demographic variables (see Table 7 for need-standardized CIs, and Tables B1-B17 for more detailed findings). As predicted in $\mathrm{H} 1$ and $\mathrm{H} 2$, the need-standardized CI for psychologists is pro-rich at +.086 , and is more equitable for GPs at -.025 (using just the results from CCHS Annual 2011-12; $p<.000$ for both CIs). As is suggested by the corresponding concentration curves in Figure 2, after standardizing for need the lower-income half of the population takes up roughly half of the share of people who report using GPs for a mental health problem, but only about $40 \%$ of the share for psychologist services.

Interestingly, the CIs for both psychiatrists $(-.046, \mathrm{p}<.000)$ and social workers $(-.033, \mathrm{p}<.014)$ are also significantly pro-poor. This result suggests that psychiatrists provide even more services to lower-income Canadians than the higher rates of mental health need at lower income levels would warrant. This finding may speak to a higher concentration of more severe mental health problems at lower income levels, or some other dimension of mental health that is not fully captured in this study's methodology. The results for social workers suggest that, even though social workers are not covered by public health insurance, they are more likely to practice in settings (whether public or private) that provide psychotherapy and other mental health services to people who are at the lower end of the income distribution.

While the CIs from the analysis of CCHS Annual 2011-12 and CCHS Annual 2013-14 are fairly similar, the CIs from CCHS MH 2012 tend to be more pro-poor (or less pro-rich in the case of psychologists). As noted above, CCHS MH 2012 added substance use as a reason for consulting professionals. With the more even income 
distribution of substance disorders, this addition may well have muddied the waters with regard to income-based inequity in the utilization of professionals.

This effect was explored further in a sensitivity analysis of various potential mental health need variables from CCHS MH 2012. This sensitivity analysis was conducted using CIs for use of GPs and psychologists as an illustrative example (see Table 8 for standardized CIs, and more detailed results in Tables B12 and B14). The results show that need-standardized CIs are very similar when self-reported poor or fair mental health, any mood disorder, or low-threshold distress $(>4)$ are used as the mental health need variable. However, in keeping with the findings for mental health service utilization with CCHS MH 2012 (which included substance abuse in the utilization question), the CIs that use the substance abuse variable to standardize for need are more concentrated at lower income levels than the other mental health need variables (-.17). This finding reflects the more equitable distribution of substance abuse disorders across the income gradient: when the mental health need variable is equitable, standardizing for need requires little adjustment and results in a standardized CI that is as pro-poor as the actual utilization of mental health services. Further, the psychologist CIs that were standardized for any substance abuse disorder are not statistically significant $(\mathfrak{p}<.48)$; less variation across the income gradient makes it more difficult to have either statistically significant pro-poor or pro-rich concentrations of utilization. While the CIs standardizing for anxiety are also similarly more pro-poor and less statistically significant, these differences may have more to do with the smaller number of respondents with anxiety disorders in the CCHS MH 2012 sample (640 out of 25,113 with anxiety compared with 1,075 with any substance disorder and 1,347 with any mood disorder). 
Where the previous set of results analyzed the income distribution of utilization of mental health services, the next two sets of results focus on unmet need. Given the higher concentration of people with mental health needs at lower income levels, if there is equitable access the amount of unmet need should follow the same gradient (but not be even more concentrated at lower income levels). The first of these sets of results compares the degree of income-based inequity in unmet need for mental health services (broken out by all mental health services, counselling and medication). Data is only drawn from CCHS MH 2012, as this specific breakdown of mental health need is not available in the CCHS Annual. The results for $\mathrm{H} 3$ are mixed (see Table 9 for summary results, and Tables B18-B20 for more detailed results). As predicted, the needstandardized CIs for the unmet need for mental health services variables are pro-poor. However, the need-standardized CI for medication $(-.135, \mathrm{p}<.000)$ is more rather than less pro-poor than the need-standardized CI for counselling (-.38, p<.094). At the same time, consistent with Sunderland and Findlay's (2013) findings that unmet need for counselling outstrips unmet need for other mental health services, the results of this analysis show more unmet need for counselling ( $4.5 \%$ of the population) than for medication $(.09 \%$ of the population).

The next set of results compares unmet needs for healthcare for physical health problems with unmet needs for healthcare for mental health problems, using data from CCHS Annual 2013-14 (collected only for NL ON, AB and NT) and CCHS Annual 201112 (collected only for NS, ON, BC, NT, and NU). As predicted in $\mathrm{H} 4$, the results suggest that there is a lack of parity across the income gradient (see Table 10 for summary results, and Tables B21-B24 for more detailed results). Looking just at CCHS Annual 
2011-12, unmet need for healthcare for mental health problems has a more pro-poor distribution, with a CI of -..127 ( $p<.000$; standardized for age, sex and self-reported mental health), than unmet need for healthcare for physical health problems, with a CI of -.035 ( $<<.000$; standardized for age, sex and self-reported physical health). This difference is clearly illustrated in the concentration curves in Figure 3, with the lowerincome half of the population having approximately $60 \%$ of the unmet need for healthcare for mental health problems but only a bit more than half of the unmet need for healthcare for physical health problems. At the same time, it is important to note that the average level of unmet need was higher for healthcare for physical health problems than for mental health problems in both time periods (7.1\% vs $1.2 \%$ in $2011-12)$, suggesting that both dimensions of equity should also be considered here.

\section{Discussion}

By standardizing for the pro-poor distribution of mental health need, this study demonstrates that income-based inequity in the distribution of access to mental health services is an issue in Canada, although not always exactly as predicted. The first two hypotheses predicting pro-rich utilization of non-physician services (H1) and equitable utilization of physician services (H2) were largely confirmed, but only for psychologists and GPs. Unmet need for mental health services was found to be more pro-poor as predicted (H3), but more so for medication rather than for counselling. Unmet need for healthcare for mental health problems was found to be more pro-poor than unmet need for physical health problems, as predicted (H4).

The findings regarding utilization suggest that Canada's two-tier system has equity impacts, but largely with regard to GPs and psychologists. The first tier ensures 
equitable access to mental health services provided by GPs, which are fully covered by public health insurance. On the first tier, all service users face the same price regardless of income. The second tier is characterized by income-based inequities in access to psychologists in private practice, whose services are not publicly insured but are either covered by employment-based insurance or paid for out-of-pocket. On the second tier, lower-income service users typically face a higher price than middle and higher-income service users.

By contrast, both social workers (non-physician providers) and psychiatrists (physician providers) seem to work more intensively with lower-income people than would be predicted by mental health need. Social workers, in keeping with their orientation, may be more likely than psychologists to work with marginalized populations and in publicly-funded settings such as hospitals and community mental health centres. Psychiatrists may work more with lower-income people because of higher incidence of more serious mental illnesses at lower income levels. This study uses the broad binomial categories of poor/fair vs good/very good/excellent mental health as the mental health need variable; if the study had standardized for a more graduated indicator of mental health need, the pro-poor results for psychiatrists may have been less pronounced. Moreover, as psychiatrists are covered by public health insurance and psychologists are not, lower-income people may be more likely to either be referred to or seek out psychiatric services.

Income-based inequities in utilization seem to be correlated with income-based inequities in unmet need for counselling (here equated with psychotherapy). Moreover, with $4.5 \%$ of the population reporting unmet need for counselling, unmet need is high 
overall. Unmet need for counselling is not more pro-poor than unmet need for medication despite public insurance coverage for low-income Canadians in most provinces and territories. However, only .09\% of the population report having an unmet need for medication.

Taken together, these findings underscore the importance of studying both dimensions of unmet need: income-based inequity and average levels in the population. Looking at inequity alone shows that there is a higher concentration of unmet need across the board at lower income levels, but does not catch the far greater frequency (on average across the population) of having an unmet need for counselling than for medication. A strong pro-poor distribution may be less of an issue when the overall prevalence of unmet need is small, as is the case for medication. Conversely, a less strong pro-poor distribution can have a significant impact on a population when the overall prevalence of unmet need is large, as is the case for counselling.

The comparison between unmet need for health care for health care for physical and mental health problems in Canada provides another perspective on income-based inequities in access. The concentration of unmet care needs for mental health was four times more pro-poor than the concentration for physical health in 2011-12, and two times more pro-poor in 2013-14. This suggests either that the gap is narrowing, or that inequity is worse in the provinces and territories that opted-in in 2011-12 (NS, ON, BC, NT, and $\mathrm{NU})$ than in the provinces and territories that opted in in 2013-14 ( NL, ON, AB and NT), something that could be tested with future cycles of $C C H S$. However, just as for unmet need for counselling and medication, this inequity needs to be considered in the context of higher average levels of unmet need for physical healthcare. It could be that 
standardizing for self-reported fair/poor physical health (as a need variable) is not fully equivalent to standardizing for self-reported fair/poor mental health.

In addition to these main findings, this study also identifies important differences in the relationship between substance abuse, mental health problems, income and access. As substance abuse disorders are more evenly distributed across the income gradient than mood and anxiety disorders, adding substance abuse to the survey questions regarding utilization of professional services would appear to have complicated the analysis of income-based inequity. Future survey designs may be able to differentiate between the two kinds of disorders, while still promoting the recognition of the close relationship between mental health problems and substance abuse.

The key limitation of the study is its inability to measure income-based inequities in acceptability barriers such as stigma, language of service provision or a preference to self-manage a mental health problem. While theories about access to healthcare service suggest that these variables could play an important role, these variables were only collected from the sub-sample of respondents with unmet needs. Even with large samples such as the two-year cycles of the CCHS Annual, the number of respondents answering questions regarding acceptability barriers was not large enough to support the calculation of meaningful CIs. Regional comparisons in income-based inequities were also excluded in light of provinces and territories opting in and out of different components of the CCHS. This study is also limited by its use of self-reported survey data, which relies on people's ability to accurately report their mental health status, use of services, income and so forth. Although administrative data is generally limited to physician and hospitalbased services, it would nevertheless be interesting to use this data to calculate CIs. For 
example, how pro-poor or pro-rich is the CI for re-hospitalizations for mental illness within 30 days?

The policy implications of this study are clear. Without making income-based equity a clear objective, there is a strong risk that efforts to improve access across the population will not reduce inequities (and may even widen the gap). A dual-focus is needed, to both lift the average levels of access across the population and reduce disparities between income groups. Efforts to reduce disparities should focus on increasing the utilization of psychological services among lower-income Canadians, and ensuring that lower-income Canadians with mental health problems are no more likely to have an unmet need for care than lower-income Canadians with physical health problems.

To support these objectives, Statistics Canada will need to have robust data on access to mental health services, both utilization and unmet need, for all provinces and territories rather than just those who opt-in to one component or another. Further, tracking changes in stigma will be critical for contextualizing changes in access; to the extent that stigma is decreasing, more and more people will seek care, thus potentially driving up both utilization rates and unmet need. Accordingly, the CCHS MH 2012 module on stigma and discrimination should be replicated at regular intervals. Gaps in both public and private administrative data also need to be addressed, particularly at the community level.

With the new $\$ 5$ billion targeted federal mental health transfer set to roll out over the next ten years, there is a critical window of opportunity to set a baseline and track results. When standardized for need, CIs are a strong, high-level indicator of income- 
based inequity that could be used to track changes in income-based inequities in access to mental health services. After all, Canadians have been raising concerns about our two-tier system of access to mental health services for decades, with the main impact on those who either lack employment-based insurance or cannot afford to pay out-of-pocket. If we do not actually measure income-based inequities, how will we know whether policy reforms are reaching those most affected by current policy gaps? 


\section{References}

Anderson, R. M. (1995). Revisiting the behavioral model and access to medical care: Does it matter? Journal of Health and Social Behavior, 36, 1-10.

Canada, Public Health Agency of Canada. (2006). The human face of mental health and mental illness in Canada. Ottawa: Public Health Agency of Canada.

Canadian Life and Health Insurance Industry. (2016). Canadian life and health insurance facts [website]. Toronto: Author. Retrieved from https://www.clhia.ca/domino/html/clhia/CLHIA_LP4W_LND_Webstation.nsf/res ources/Factbook_2/\$file/2016+CLHIA+Factbook+ENG.pdf

Esmail, N., \& Bacchus, B. (2015). Drug coverage for low income families: The Canadian reality and lessons from Switzerland and the Netherlands. Fraser Institute.

Finance Canada. (2017). Building a strong middle class. Ottawa, ON: Author.

Gagnon, M.-A., Hébert, G. (2010). The economic case for universal pharmacare: Costs and benefits of publicly funded drug coverage for all Canadians. Ottawa; Montréal: Canadian Centre for Policy Alternatives ; Institut de recherche et d'information socio-économiques.

Goddard, M., \& Smith, P. (2001). Equity of access to health care services: Theory and evidence from the UK. Social Science \& Medicine, 53, 1149-1162.

Goryakin, Y., Suhrcke, M., Roberts, B., \& McKee, M. (2015). Mental health inequalities in 9 former Soviet Union countries: Evidence from the previous decade. Social Science \& Medicine, 124, 142-151. 
Hosseinpoor, A. R., Itani, L., \& Petersen, P. E. (2012). Socio-economic Inequality in Oral Healthcare Coverage: Results from the World Health Survey. Journal of Dental Research, 91(3), 275-281.

Hunsley, J., Lee, C. M., \& Aubry, T. (1999). Who uses psychological services in Canada? Canadian Psychology/Psychologie Canadienne, 40(3), 232-240.

Hunsley, J., Ronson, A., \& Cohen, K. R. (2013). Professional psychology in Canada: A survey of demographic and practice characteristics. Professional Psychology: Research and Practice, 44(2), 118-126.

Jiménez-Rubio, D., Smith, P. C., \& Van Doorslaer, E. (2008). Equity in health and health care in a decentralised context: Evidence from Canada. Health Economics, 17(3), $377-392$.

Jokela, M., Batty, G. D., Vahtera, J., Elovainio, M., \& Kivimaki, M. (2013).

Socioeconomic inequalities in common mental disorders and psychotherapy treatment in the UK between 1991 and 2009. The British Journal of Psychiatry, 202(2), 115-120.

Kurdyak, P., Stukel, T. A., Goldbloom, D., Kopp, A., Zagorski, B. M., \& Mulsant, B. H. (2014). Universal coverage without universal access: a study of psychiatrist supply and practice patterns in Ontario. Open Medicine: A Peer-Reviewed, Independent, Open-Access Journal, 8(3), e87-99.

Lesage, A., \& Canadian Collaborative Mental Health Initiative. (2006). Prevalence of mental illness and related service utilization in Canada an analysis of the Canadian Community Health Survey. Mississauga, ON: Canadian Collaborative Mental Health Initiative. Retrieved from http://site.ebrary.com/id/10127110 
Lewis, J. D. (2013). Mental health services in Canada: Building a model of mental health care utilization (Unpublished doctoral dissertation). University of Regina, Regina. Retrieved from http://ourspace.uregina.ca/bitstream/handle/10294/3842/Lewis_John_Dufton_20 $\underline{0230739 \mathrm{PhD} \text { ClinPsyc Fall2013.pdf?sequence }=1}$

Mangalore, R., Knapp, M., \& Jenkins, R. (2007). Income-related inequality in mental health in Britain: The CI approach. Psychological Medicine, 37(7), 1037.

Marmot, M. G., Stansfeld, S., Patel, C., North, F., Head, J., White, I., ... Davey Smith, G. (1991). Health inequalities among British civil servants: The Whitehall II study. The Lancet, 337(8754), 1387-1393.

Marmot, M. G. \& Wilkinson, R. G. (1999/2005). Social determinants of health ( $2^{\text {nd }}$ edition). Oxford: Oxford University Press.

McGinnis, J. M., Williams-Russo, P., \& Knickman, J. R. (2002). The case for more active policy attention to health promotion. Health Affairs, 21(2), 78-93.

Meadows, G. N., Enticott, J. C., Inder, B., Russell, G. M., \& Gurr, R. (2015). Better access to mental health care and the failure of the Medicare principle of universality. The Medical Journal of Australia, 202(4), 190-194.

Meadows, G. N., \& Tylee, A. T. (2013). Socioeconomic disadvantage and psychotherapy. The British Journal of Psychiatry, 202(2), 86-88.

Mental Health Commission of Canada. (2012). Changing directions, changing lives: The mental health strategy for Canada. Calgary, AB: Author. 
Mental Health Commission of Canada. (2013). Why investing in mental health will contribute to Canada's economic prosperity and to the sustainability of our health care system. Calgary, AB: Author.

O’Donnell, O., O’Neill, S., Van Ourti, T., \& Walsh, B. (2016). conindex: Estimation of CIs. Stata Journal, 16(1), 112-138.

O’Donnell, O. \& World Bank (Eds.). (2008). Analyzing health equity using household survey data: a guide to techniques and their implementation. Washington, D.C: World Bank.

OECD. (n.d.). What are equivalence scales? Project on Income Distribution and Poverty. Paris: Author. Retrieved from http://www.oecd.org/eco/growth/OECD-NoteEquivalenceScales.pdf

Piketty, T. (2013). Capital in the twenty-first century. Cambridge Massachusetts: The Belknap Press of Harvard University Press.

Riegle, A. L., \& Steward, S. D. (2013). Health care access and utilization among the poor. In M. K. Fitzpatrick (Ed.), Poverty and health: a crisis among America's most vulnerable (pp. 183-208). Santa Barbara, California: Praeger.

Starkes, J. M., Poulin, C. C., \& Kisely, S. R. (2005). Unmet need for the treatment of depression in Atlantic Canada. Canadian Journal of Psychiatry. Revue Canadienne De Psychiatrie, 50(10), 580-590.

Statistics Canada. (n.d.). Income imputation for the CCHS. Ottawa: Author. Statistics Canada. (2012a). Canadian Community Health Survey - Annual Component: 2012 Questionnaire. Ottawa, Author. 
Statistics Canada. (2012b). Canadian Community Health Survey - Mental Health: 2012 Questionnaire. Ottawa, Author.

Statistics Canada. (2013). Canadian Community Health Survey - Mental Health:

Detailed information for 2012 [website]. Retrieved from http://www23.statcan.gc.ca/imdb/p2SV.pl?Function=getSurvey\&SDDS=5015

Statistics Canada. (2014). Canadian Community Health Survey - Annual Component: 2014 Questionnaire. Ottawa, Author.

Statistics Canada. (2015a). Canadian Community Health Survey - Annual Component: Detailed information for 2015 [website]. Retrieved from http://www23.statcan.gc.ca/imdb/p2SV.pl?Function=getSurvey\&Id=164081

Statistics Canada. (2015b). Core, fringe and rural area: Detailed definition [website]. Retrieved from http://www.statcan.gc.ca/pub/92-195-x/2011001/geo/rur/rureng.htm

Steele, L., Dewa, C., \& Lee, K. (2007). Socioeconomic status and self-reported barriers to mental health service use. Canadian Journal of Psychiatry. Revue Canadienne De Psychiatrie, 52(3), 201-206.

Sunderland, A. \& Findlay, L. C. (2013). Perceived need for mental health care in Canada: Results from the 2012 Canadian Community Health Survey-Mental Health. Statistics Canada Health Reports, 24(9), 3-9.

Van Doorslaer, E., Masseria, C. \& the OECD Health Equity Research Group Members. (2004). Income-related inequality in the use of medical care in 21 OECD countries. OECD Health Working Paper \#14. Paris: OECD. 
Vasiliadis, H.-M., Tempier, R., Lesage, A., \& Kates, N. (2009). General practice and mental health care: determinants of outpatient service use. Canadian Journal of Psychiatry. Revue Canadienne De Psychiatrie, 54(7), 468-476.

Vasiliadis, H.-M., Lesage, A., Adair, C., \& Boyer, R. (2005). Service use for mental health reasons: Cross-provincial differences in rates, determinants, and equity of access. Canadian Journal of Psychiatry. Revue Canadienne De Psychiatrie, $50(10), 614-619$.

Wilkinson, R. G., \& Pickett, K. (2010). The spirit level: Why greater equality makes societies stronger. New York: Bloomsbury Press.

Zhang, X., Wu, Q., Shao, Y., Fu, W., Liu, G., \& Coyte, P. C. (2015). Socioeconomic inequities in health care utilization in China. Asia-Pacific Journal of Public Health, 27(4), 429-438. 
Table 1 Outcome Variable Frequencies: Utilization

Professional Mental Health Service Utilization (12 mos)*\#

\begin{tabular}{|c|c|c|c|}
\hline \multirow[b]{3}{*}{ Utilization } & \multicolumn{3}{|c|}{ CCHS Annual } \\
\hline & CCHS Annual 2013-14 & $2011-12$ & CCHS MH 2012 \\
\hline & $\%$ of weighted sample & $\begin{array}{c}\% \text { of weighted } \\
\text { sample }\end{array}$ & $\begin{array}{c}\% \text { of weighted } \\
\text { sample }\end{array}$ \\
\hline GP & 6.4 & 7.1 & 6.9 \\
\hline Psychiatrist & 2.3 & 2.3 & 2.2 \\
\hline Psychologist & 2.9 & 2.8 & 2.4 \\
\hline Nurse & 0.6 & 0.5 & 1.0 \\
\hline $\begin{array}{l}\text { Social } \\
\text { Worker }\end{array}$ & 2.8 & 2.7 & 3.1 \\
\hline $\begin{array}{l}\text { Not- } \\
\text { Psychologist }\end{array}$ & 9.9 & 10.5 & 9.5 \\
\hline
\end{tabular}

*CCHS Annual - for "emotional or mental health;" CCHS MH 2012 - for "emotions, mental health, or use of alcohol or drugs"

\# Observations with missing values were dropped from the analysis for all of the provider utilization outcome variables (4,389 from CCHS 2013-14, 5,573 from CCHS 2011-12, and 25 from CCHS MH 2012)

${ }^{+}$Utilization data only collected for NL, QC, ON, MB, BC, NT and NU 
Table 2 Outcome Variable Frequencies: Unmet Need

Unmet Need for Care $(12 \mathrm{mos})^{*}$

\begin{tabular}{|c|c|c|c|}
\hline \multirow[b]{3}{*}{ Unmet need } & \multicolumn{3}{|c|}{ CCHS Annual } \\
\hline & CCHS Annual 2013-14" & $\underline{2011-12^{+}}$ & CCHS MH 2012 \\
\hline & $\%$ of weighted sample & $\begin{array}{c}\% \text { of weighted } \\
\text { sample }\end{array}$ & $\begin{array}{c}\% \text { of weighted } \\
\text { sample }\end{array}$ \\
\hline $\begin{array}{l}\text { Healthcare: } \\
\text { physical }\end{array}$ & 6.7 & 7.1 & NA \\
\hline $\begin{array}{l}\text { Healthcare: } \\
\text { mental }\end{array}$ & 1.1 & 1.2 & NA \\
\hline $\begin{array}{l}\text { All mental } \\
\text { health } \\
\text { services }\end{array}$ & NA & NA & 5.8 \\
\hline Counselling & NA & NA & 4.4 \\
\hline Medication & NA & NA & 0.9 \\
\hline
\end{tabular}

*Observations with missing values were dropped from the analysis for all of the unmet need outcome variables (103 and 90 for unmet need for healthcare from CCHS 2013-14 and CCHS 2011-12 respectively, and 90, 103, 119 from CCHS MH 2012 for unmet need for counselling, medication and all mental health services respectively).

${ }^{\#}$ Unmet need for healthcare collected only for NL ON, AB and NT

${ }^{+}$Unmet need for healthcare collected only for NS, ON, BC, NT, and NU 
Table 3 Need Variable Frequencies

Age, Sex, and Health/Mental Health Need*

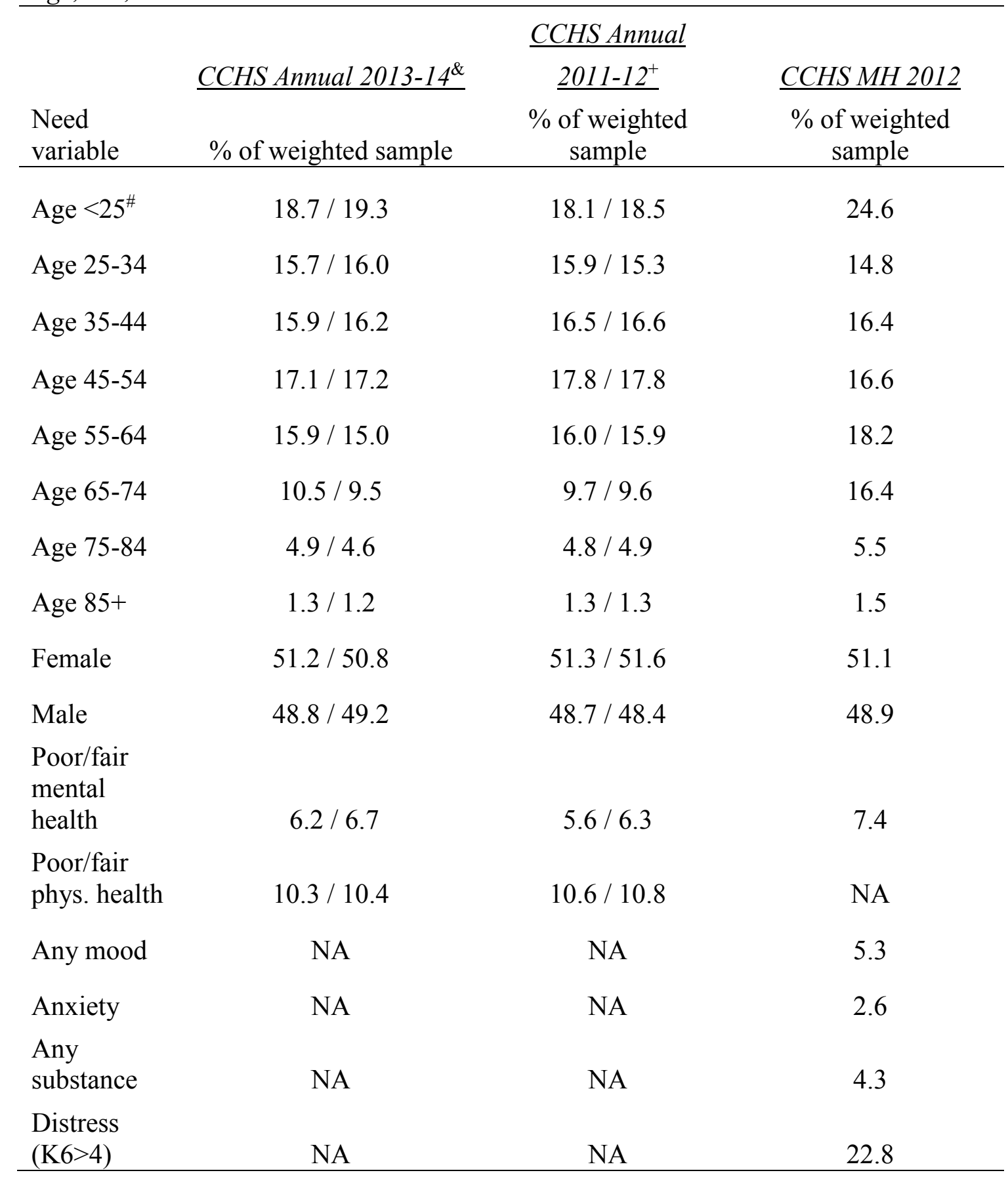

*Observations with missing values for self-reported mental health $(2,157)$ and selfreported physical health (96) were dropped from CCHS Annual 2013-14, with 2,603 and 177 dropped for the same variables from CCHS Annual 2011-12; observations with missing values for self-reported mental health (19), any mood disorder (203), anxiety disorder (204), any substance disorder (597), and distress (164) were dropped from 
CCHS MH 2012. With CCHS Annual 2013-14 and 2011-12, smaller numbers of observations were dropped from the smaller sub-samples for unmet healthcare needs. ${ }^{\&}$ CCHS Annual 2013-14 values for P/Ts opting into utilization (NL, QC, ON, MB, BC, NT and NU) are separated by a " " " from values for P/Ts opting into unmet healthcare need ( NL, ON, AB and NT)

${ }^{+}$CCHS Annual 2011-12 values for P/Ts opting into utilization (all P/Ts) are separated by a "" from values for P/Ts opting into unmet healthcare need (NS, ON, BC, NT, and NU)

${ }^{\#}$ CCHS Annual 2011-12 and 2013-14 are 12+, CCHS MH 2012 is 15+ 
Table 4 Non-Need (Control) Variable Frequencies

Education, Immigration, Non-Urban*

\begin{tabular}{|c|c|c|c|}
\hline & $\frac{\text { CCHS Annual }}{\underline{2013-14^{\#}}}$ & $\frac{\text { CCHS Annual }}{\underline{2011-12+}}$ & $\underline{\text { CCHS MH } 2012}$ \\
\hline $\begin{array}{l}\text { Non-need } \\
\text { variable }\end{array}$ & $\%$ of weighted sample & $\begin{array}{c}\% \text { of weighted } \\
\text { sample }\end{array}$ & $\%$ of weighted sample \\
\hline $\begin{array}{l}\text { Educ: Less } \\
\text { than } \\
\text { secondary }\end{array}$ & $6.4 / 5.7$ & $6.4 / 5.3$ & 7.25 \\
\hline $\begin{array}{l}\text { Educ: } \\
\text { Secondary }\end{array}$ & $11.4 / 12.8$ & $10.8 / 11.2$ & 10.3 \\
\hline $\begin{array}{l}\text { Educ: Some } \\
\text { post- } \\
\text { secondary }\end{array}$ & $3.9 / 3.2$ & $4.1 / 3.7$ & 4.3 \\
\hline $\begin{array}{l}\text { Educ: Post- } \\
\text { secondary } \\
\text { grad }\end{array}$ & $78.3 / 78.3$ & $78.7 / 79.9$ & 78.2 \\
\hline Immigrant & $26.2 / 29.1$ & $22.9 / 29.8$ & 24.6 \\
\hline Non-Urban & $25.0 / 24.0$ & $28.8 / 25.0$ & 27.2 \\
\hline
\end{tabular}

* Observations with missing values for education $(3,777)$ and immigration $(3,761)$ were dropped from CCHS Annual 2013-14, with 11,500 and 4,256 dropped for the same variables from CCHS Annual 2011-12 and 1,930 and 177 from CCHS MH 2012. Smaller numbers of observations were dropped from the smaller sub-samples for unmet healthcare needs in CCHS Annual 2013-14 and 2011-12.

${ }^{\#}$ CCHS Annual 2013-14 values for P/Ts opting into utilization (NL, QC, ON, MB, BC, NT and NU) are separated by a "/" from values for P/Ts opting into unmet healthcare need ( NL, ON, AB and NT)

${ }^{+}$CCHS Annual 2011-12 values for $\mathrm{P} /$ Ts opting into utilization (all $\mathrm{P} / \mathrm{Ts}$ ) are separated by a "/" from values for P/Ts opting into unmet healthcare need (NS, ON, BC, NT, and NU) 
Table 5 Equivalized Household Income

Equivalized Household Income: Non-Need (Control) and Ranking Variable

\begin{tabular}{|c|c|c|c|}
\hline & \multicolumn{3}{|c|}{ CCHS Annual } \\
\hline & CCHS Annual 2013-14* & $2011-12^{+}$ & CCHS MH 2012 \\
\hline Mean & $52,236 / 58,273$ & $51,227 / 51,614$ & 50,651 \\
\hline Gini & $.399 / .416$ & $.390 / .391$ & .385 \\
\hline $\begin{array}{l}\text { Income } \\
\text { share: top } \\
10 \%\end{array}$ & $28.5 / 29.9$ & $27.6 / 28.9$ & 26.5 \\
\hline $\begin{array}{l}\text { Income } \\
\text { share: top } \\
1 \%\end{array}$ & $9.1 / 10.7$ & $9.0 / 9.7$ & 8.3 \\
\hline $\begin{array}{l}\text { Income } \\
\text { share: top } \\
.1 \%\end{array}$ & $4.1 / 5.8$ & $4.5 / 4.8$ & 3.3 \\
\hline
\end{tabular}

*CCHS Annual 2013-14 values for P/Ts opting into utilization (NL, QC, ON, MB, BC, NT and NU) are separated by a " " " from values for P/Ts opting into unmet healthcare need ( NL, ON, AB and NT) ${ }^{+}$CCHS Annual 2011-12 values for P/Ts opting into utilization (all P/Ts) are separated by a "/" from values for P/Ts opting into unmet healthcare need (NS, ON, BC, NT, and NU) 
Table 6 Distribution of Mental Health Need Across Income Deciles

Distribution of Mental Health Need (\%) Across Household Income Deciles, with CIs

\begin{tabular}{|c|c|c|c|c|c|c|c|c|c|c|c|}
\hline & Poorest & $2^{\text {nd }}$ & $3^{\text {rd }}$ & $4^{\text {th }}$ & $5^{\text {th }}$ & $6^{\text {th }}$ & $7^{\text {th }}$ & $8^{\text {th }}$ & $9^{\text {th }}$ & Richest & CI* \\
\hline \multicolumn{12}{|c|}{ CCHS Annual 2013-14 } \\
\hline $\begin{array}{l}\text { Self-reported } \\
\text { mental health }\end{array}$ & 22.1 & 16.0 & 11.6 & 9.7 & 9.1 & 8.1 & 7.6 & 7.7 & 5.4 & 4.7 & -.252 \\
\hline \multicolumn{12}{|c|}{ CCHS Annual 2011-12 } \\
\hline $\begin{array}{l}\text { Self-reported } \\
\text { mental health }\end{array}$ & 21.8 & 14.7 & 12.1 & 10.3 & 9.5 & 7.0 & 8.0 & 6.2 & 6.4 & 4.0 & -.258 \\
\hline \multicolumn{12}{|c|}{ CCHS MH 2012} \\
\hline $\begin{array}{l}\text { Self-reported } \\
\text { mental health }\end{array}$ & 19.4 & 15.0 & 12.5 & 10.8 & 9.0 & 7.1 & 7.8 & 8.3 & 5.3 & 4.8 & -.234 \\
\hline Distress & 14.7 & 12.0 & 12.5 & 10.6 & 11.2 & 8.6 & 9.0 & 8.6 & 7.1 & 5.9 & -.138 \\
\hline Any mood & 19.2 & 13.7 & 10.6 & 13.5 & 8.7 & 7.9 & 8.6 & 7.0 & 6.3 & 4.4 & -.219 \\
\hline $\begin{array}{l}\text { Any } \\
\text { substance use }\end{array}$ & 13.3 & 8.0 & 7.4 & 10.2 & 10.1 & 9.7 & 10.7 & 9.7 & 11.2 & 9.7 & -.002 \\
\hline Anxiety & 19.5 & 12.5 & 13.1 & 12.4 & 10.7 & 6.9 & 6.1 & 7.3 & 5.1 & 6.1 & --- \\
\hline
\end{tabular}

*p-value for any substance disorder CI is .917; p-value for all other mental health need variables' CI is .000; sub-sample with anxiety too small to calculate CI. 
Table 7 CIs for Utilization

Need-Standardized CIs for Utilizing Professional Services (12 mos)*+

\begin{tabular}{|c|c|c|c|c|c|c|}
\hline & \multicolumn{6}{|c|}{$\underline{\text { CCHS Annual }}$} \\
\hline & \multicolumn{2}{|c|}{ CCHS Annual 2013-14 } & \multicolumn{2}{|c|}{$\underline{2011-12}$} & \multicolumn{2}{|c|}{ CCHS MH 2012} \\
\hline & $\mathrm{CI}_{\mathrm{st}}$ & $\mathrm{p}$-value & $\mathrm{CI}_{\text {st }}$ & $\mathrm{p}$-value & $\mathrm{CI}_{\mathrm{st}}$ & $\mathrm{p}$-value \\
\hline GP & .010 & .1646 & -.025 & .0000 & -.043 & .0009 \\
\hline Psychiatrist & -.063 & .0000 & -.046 & .0000 & -.073 & .0023 \\
\hline Psychologist & .096 & .0000 & .086 & .0000 & .048 & .0387 \\
\hline Nurse & -.070 & .0052 & --- & --- & -.045 & .2385 \\
\hline $\begin{array}{l}\text { Social } \\
\text { worker }\end{array}$ & -.020 & .0004 & -.033 & .0014 & -.054 & .0083 \\
\hline $\begin{array}{l}\text { Not } \\
\text { psychologist }\end{array}$ & -.019 & .0007 & -.020 & .0000 & -.037 & .0005 \\
\hline
\end{tabular}

*CCHS Annual - for "emotional or mental health;" CCHS MH 2012 - for "emotions, mental health, or use of alcohol or drugs"

${ }^{+}$Need variables - age, sex, self-reported mental health; control variables - immigration, education, non-urban and household income 
Table 8 Sensitivity Analysis of Various Mental Health Need Variables

CCHS MH 2012: Sensitivity Analysis of CIs for Use of GPs and Psychologists, Standardized for Various Mental Health Need Variables*

\begin{tabular}{lcccc}
\hline & \multicolumn{2}{c}{$\underline{\mathrm{GP}}$} & \multicolumn{2}{c}{ Psychologist $^{2}$} \\
& $\mathrm{CI}_{\mathrm{st}}$ & $\mathrm{p}$-value & $\mathrm{CI}_{\mathrm{st}}$ & $\mathrm{p}$-value \\
\hline Self-reported mental & & & & \\
health & -.043 & .0009 & .048 & .0387 \\
Distress & -.045 & .0005 & .049 & .0383 \\
Any mood disorder & -.045 & .0005 & .053 & .0235 \\
Anxiety disorder & -.073 & .0000 & .019 & .4098 \\
Substance disorder & -.117 & .0000 & -.017 & .4800 \\
\hline
\end{tabular}

*Need variables - age, sex, mental health need as indicated; control variables immigration, education, non-urban and household income 
Table 9 CCHS MH 2012: CIs for Unmet Need for Mental Health Services

CCHS MH 2012: Need-Standardized CIs for Unmet Need for Mental Health Services $(12 \mathrm{mos})^{*}$

\begin{tabular}{lccc}
\hline & Mean & $\mathrm{CI}_{\mathrm{st}}$ & $\mathrm{p}$-value \\
\hline All mental health & & & \\
services & .0590 & -.038 & .0070 \\
Counselling & .0448 & -.028 & .0937 \\
Medication & .0094 & -.135 & .0004 \\
\hline
\end{tabular}

*Need variables - age, sex, self-reported mental health; control variables - immigration, education, non-urban and household income 
Table 10 CCHS Annual: CIs for Unmet Need for Healthcare

CCHS Annual: Need-Standardized CIs for Unmet Need for Healthcare $(12 \mathrm{mos})^{*+}$

\begin{tabular}{|c|c|c|c|c|c|c|}
\hline & \multicolumn{2}{|c|}{ Mean } & \multicolumn{2}{|c|}{ CIst } & \multicolumn{2}{|c|}{$\mathrm{p}$-value } \\
\hline & 2013-14 & 2011-12 & $\underline{2013-14}$ & 2011-12 & 2013-14 & 2011-12 \\
\hline $\begin{array}{l}\text { Physical health } \\
\text { problem }\end{array}$ & .067 & .071 & -.060 & -.035 & .0000 & .0000 \\
\hline Mental health problem & .011 & .012 & -.135 & -.127 & .0000 & .0000 \\
\hline
\end{tabular}

*Need variables - age, sex, self-reported physical or mental health; control variables immigration, education, non-urban and household income

${ }^{+}$CCHS Annual 2013-14 collected only for NL, ON, AB and NT; CCHS Annual 2011-12 collected only for NS, ON, BC, NT, and NU 
Figure 1 Illustrative Example of Concentration Curves and Indices

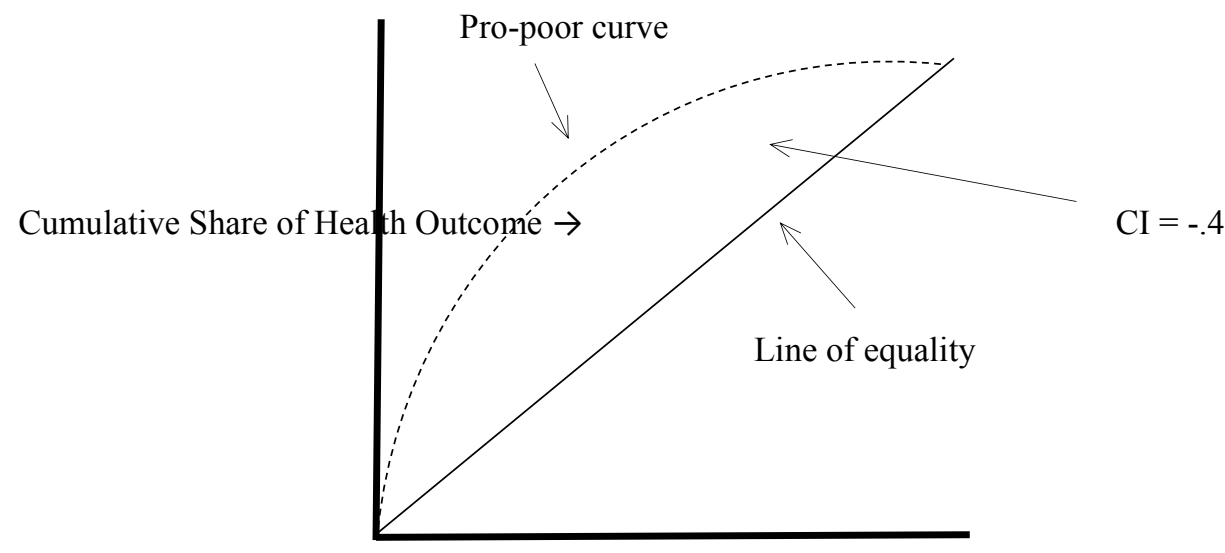

Income Decile $\rightarrow$

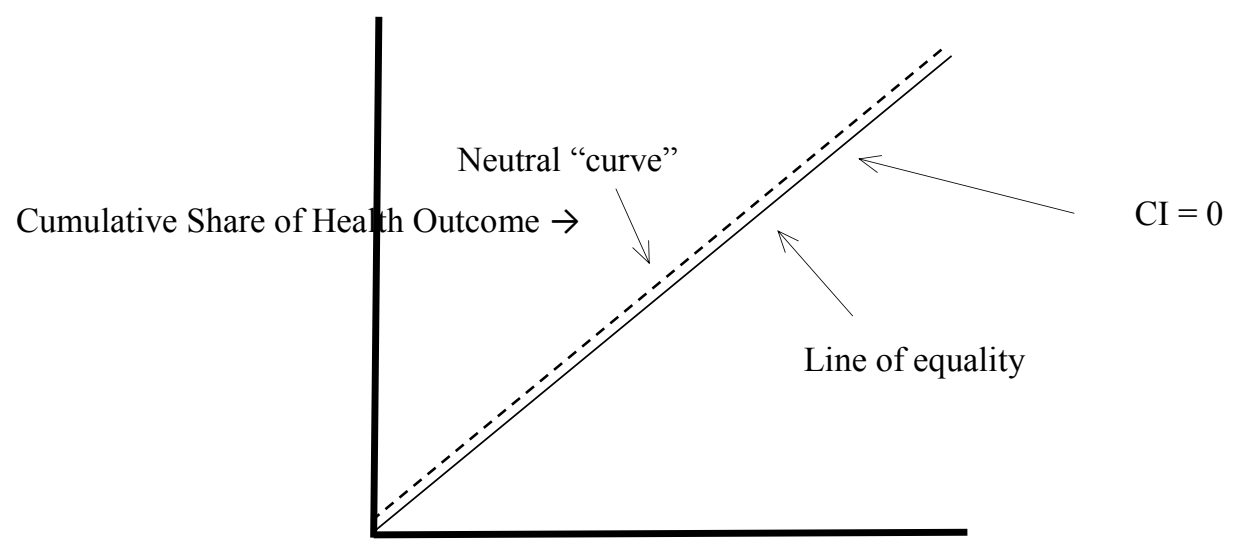

Income Decile $\rightarrow$

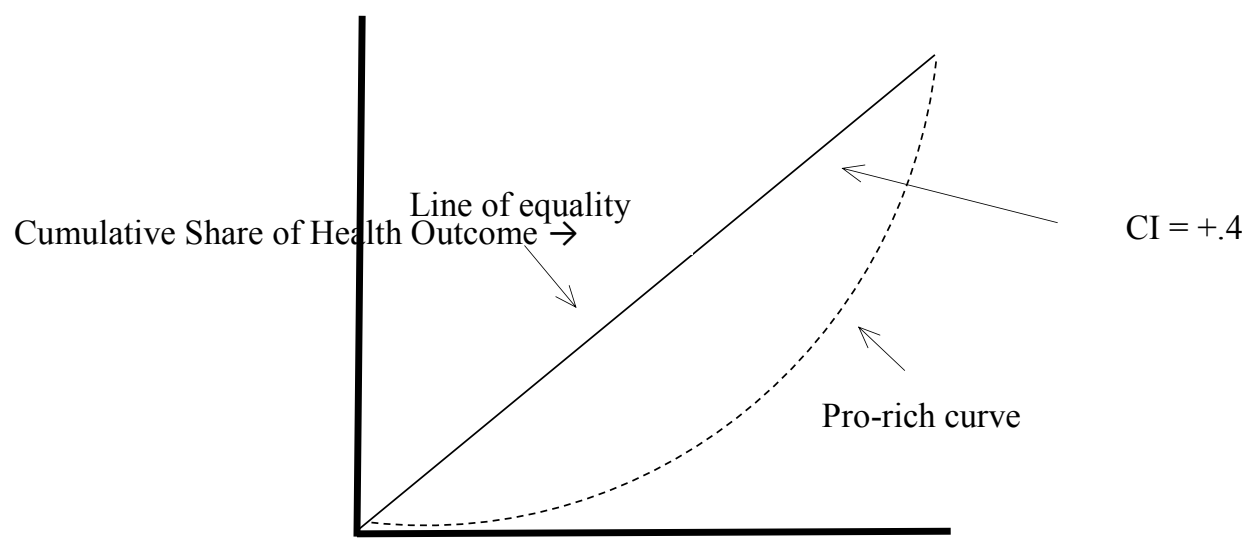

Income Decile $\rightarrow$ 
Figure 2 Need-Standardized Concentration Curves for Utilization of GPs vs Psychologists, 2011-12
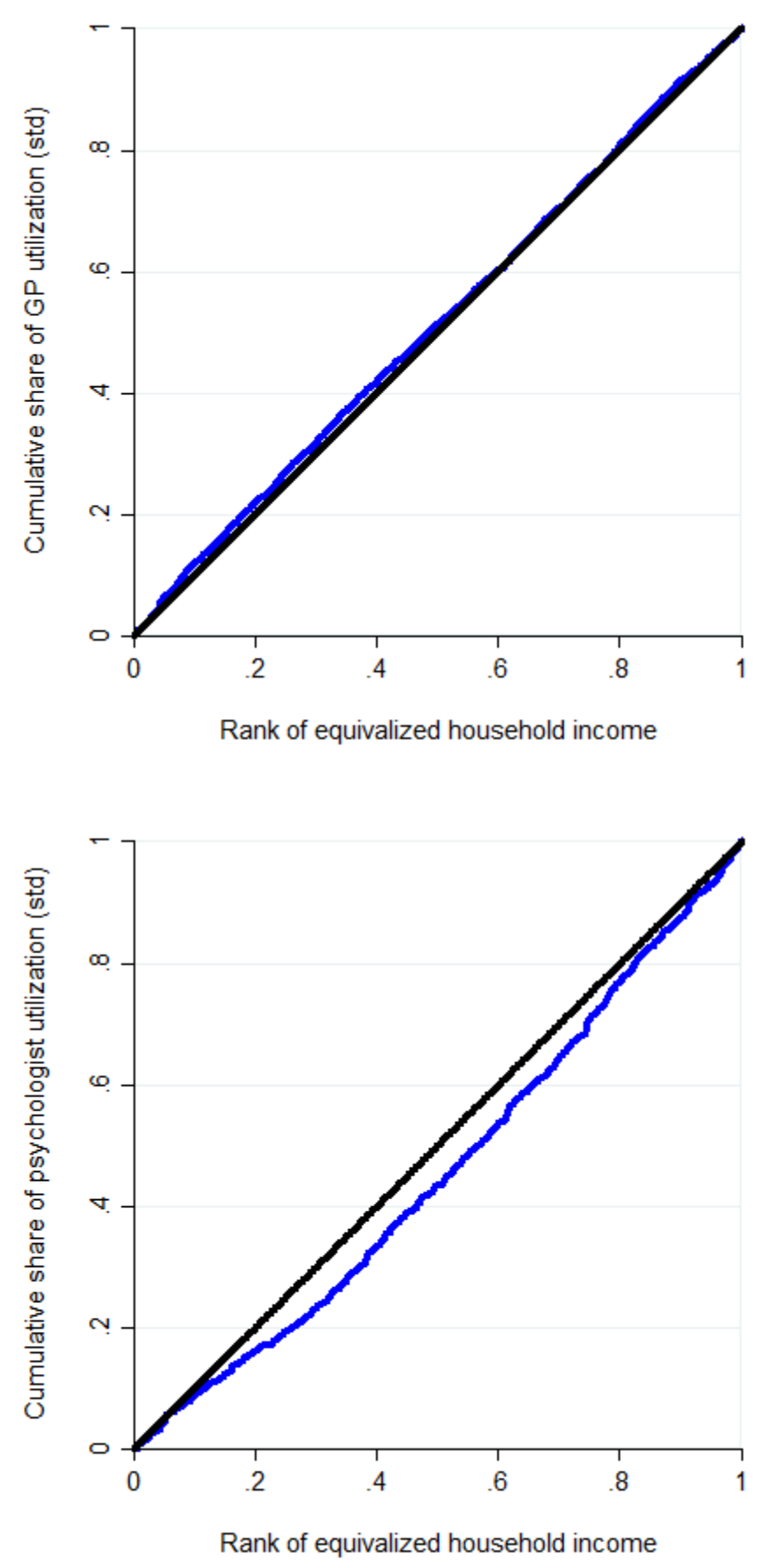
Figure 3 Need-Standardized Concentration Curves for Unmet Need for Healthcare (Physical vs Mental Health Problems), 2011-12
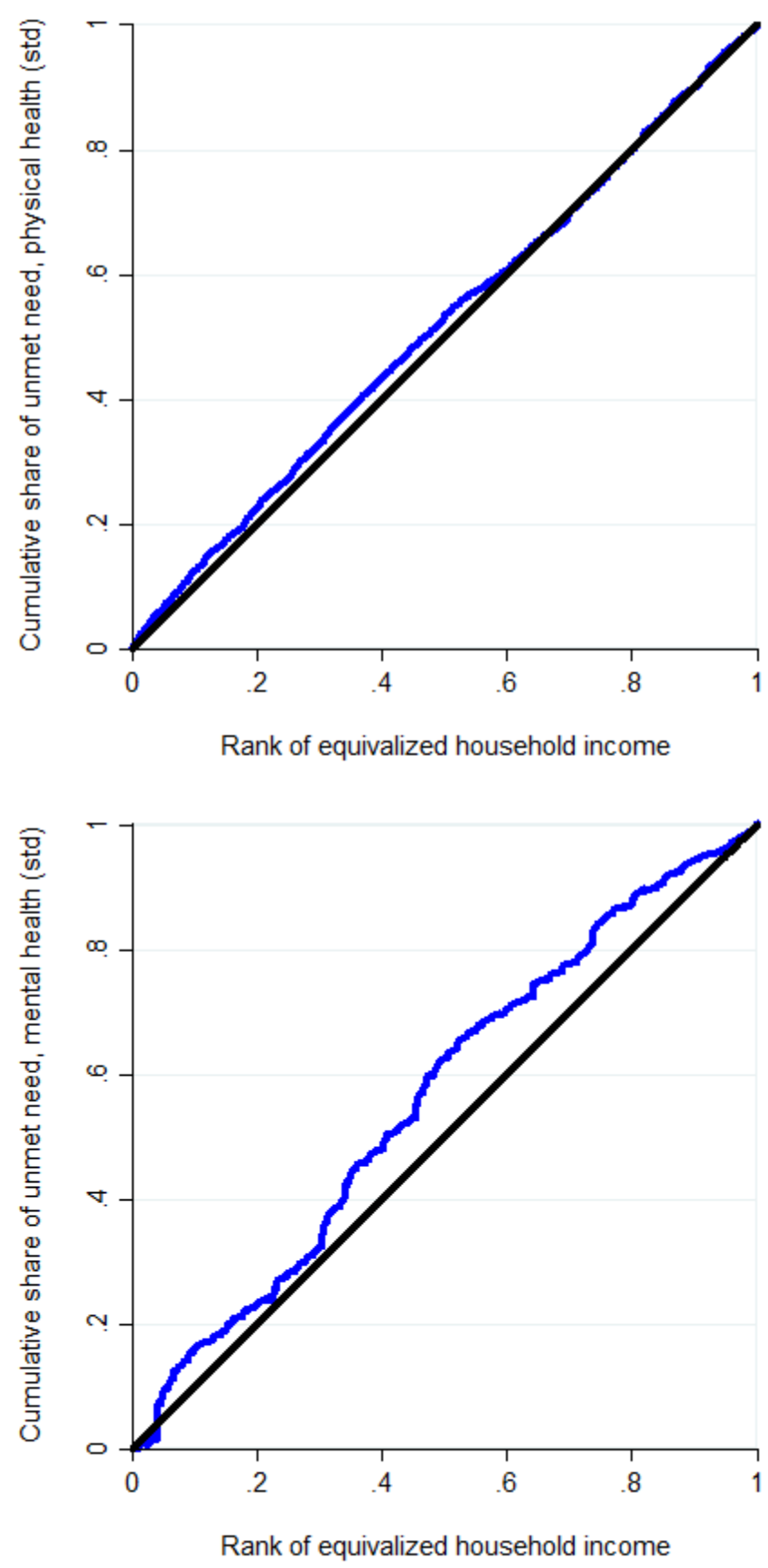


\section{Appendix A: Calculating Need-Standardized Income-Based Inequities in Access to Health Services}

O’Donnell and the World Bank's (2008) method for calculating needstandardized income-based inequities in access to health services has three steps. First, access that could be expected based on need is predicted using a probit function (see formula $1.1 ; A C$ is access).

$A C_{\text {predicted }}=$ probit $\left(A C_{\text {actual }}\right)(N E E D$ VAR $)(M E A N$ of NON-NEED VAR)

A probit is used because binomial variables do not have the linear properties required for the more common ordinary least squares approach to regression analysis. Two kinds of variables are included as predictor variables: need variables (including age, sex, and health status), and non-need (or control) variables set to their mean. O'Donnell and the World Bank (2008) define non-need variables as those variables "for which we do not wish to standardize but which would bias the coefficients on the need variables if omitted from the regression" (p. 178). Accordingly, the means of non-need variables such as education and income are included in the probit equation.

Second, need-standardized access $\left(A C_{s t}\right)$ is calculated by subtracting the predicted $A C$ from the actual $A C$, and adding back the mean of predicted $A C$ (see formula 1.2). Adding back the mean ensures that the mean of standardized access is the same as the actual mean.

$A C_{s t}=A C_{\text {actual }}-A C_{\text {predicted }}+\overline{A C}_{\text {predicted }}$

Step three measures income-based inequity of access to health services by calculating CIs for need-standardized access. Need-standardized CIs are generally a measure of the actual income-based inequity in access minus the predicted inequity in 
access. According to O'Donnell and the World Bank (2008), "after standardizing for need, any residual inequality in utilization, by income for example, is interpreted as horizontal inequity, which could be pro-rich or pro-poor" (p. 178). When CIs are calculated using ordinary least squares regression, the need-standardized index is equal to the actual index minus the predicted index. However, when using probit, the relationship is slightly less linear and the standardized index is best calculated directly from the needstandardized access variable (O’Donnell, personal communication, 2017).

An illustrative example can be found in Table B9 regarding access to GPs. The actual $\mathrm{CI}$ is.- .0689 , which suggests considerable concentration of access at lower income levels. However, the predicted CI is -.0451 . This predicted value represents the distribution of access one would expect based on the distribution of poor mental health, age and sex across the income gradient, after controlling for non-need variables. After standardizing for need, the CI drops to the more equitable value of -.0247. This needstandardized CI is slightly more negative than what one gets from simply subtracting the predicted CI from the basic (actual) CI (-.0238), in keeping with the slightly less linear relationship between CI values when probit is used for binomial variables. 


\section{Appendix B: Detailed Access Tables}

Notes for all:

All values are weighted.

Need variables - age, sex, self-reported mental health (unless otherwise specified); control variables - immigration, education, non-urban and household income.

--- $n$ for utilization variable too small to release results; in some cases, there are no results for utilization of nurses due to the small $n$. 
Table B 1 CCHS Annual 2013-14: GPs

CCHS Annual 2013-14: Need-Standardized Utilization of GPs for Mental Health Problems (12 mos), $n=86,764$ (NL, QC, ON, MB, BC, NT and NU only)

Probit with controls

\begin{tabular}{lccc} 
\%tile & Actual & Need-predicted & Need-standardized \\
\hline Poorest $2 \%$ & .0676 & .0725 & .0579 \\
Poorest $5 \%$ & .0892 & .0809 & .0712 \\
Poorest $10 \%$ & .0871 & .0822 & .0678 \\
Poorest $20 \%$ & .0748 & .0744 & .0634 \\
$2^{\text {nd }}$ poorest $20 \%$ & .0594 & .0615 & .0608 \\
Middle & .0608 & .0601 & .0637 \\
$2^{\text {nd }}$ richest $20 \%$ & .0662 & .0608 & .0682 \\
Richest 20\% & .0583 & .0571 & .0641 \\
Mean & .0640 & .0629 & .0640 \\
CI & -.0364 & -.0473 & .0101 \\
Standard error & .0075 & .0019 & .0072 \\
p-value & .0000 & .0000 & .1646 \\
\hline
\end{tabular}

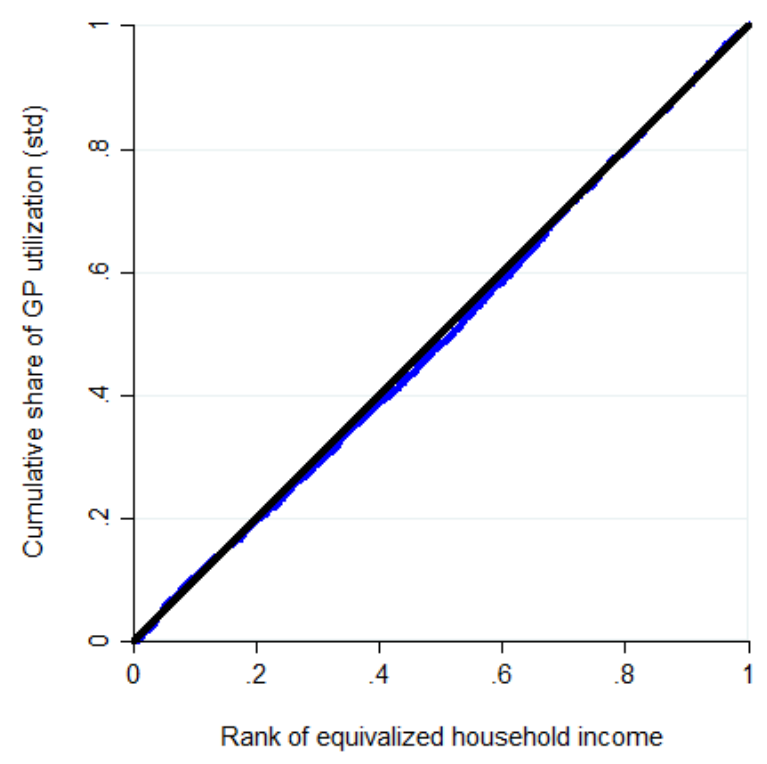


Table B 2 CCHS Annual 2013-14: Psychiatrists

CCHS Annual 2013-14: Need-Standardized Utilization of Psychiatrists for Mental Health Problems (12 mos), $n=86,764$ (NL, QC, ON, MB, BC, NT and NU only)

Probit with controls

\begin{tabular}{lccc}
$\%$ tile & Actual & Need-predicted & Need-standardized \\
\hline Poorest $2 \%$ & .0389 & .0281 & .0328 \\
Poorest $5 \%$ & .0472 & .0329 & .0363 \\
Poorest $10 \%$ & .0474 & .0335 & .0358 \\
Poorest $20 \%$ & .0367 & .0277 & .0297 \\
$2^{\text {nd }}$ poorest $20 \%$ & .0195 & .0216 & .0199 \\
Middle & .0208 & .0202 & .0226 \\
$2^{\text {nd }}$ richest $20 \%$ & .0209 & .0204 & .0226 \\
Richest 20\% & .0169 & .0186 & .0203 \\
Mean & .0220 & .0220 & .0230 \\
CI & -.1452 & -.0862 & -.0628 \\
Standard error & .0128 & .0031 & .0124 \\
p-value & .0000 & .0000 & .0000 \\
\hline
\end{tabular}

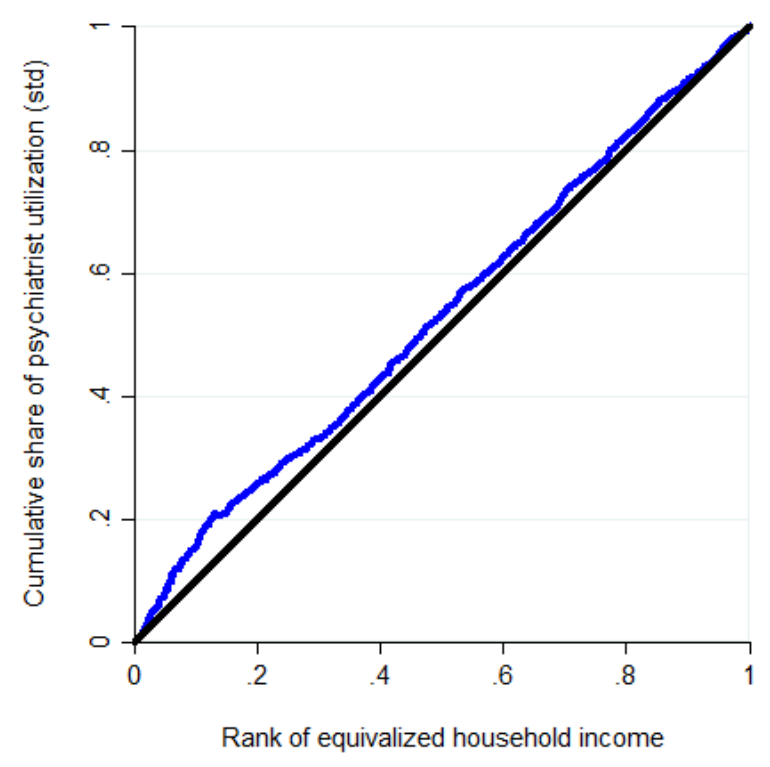


Table B 3 CCHS Annual 2013-14: Psychologists

CCHS Annual 2013-14: Need-Standardized Utilization of Psychologists for Mental Health Problems (12 mos), $n=86,764$ (NL, QC, ON, MB, BC, NT and NU only)

\begin{tabular}{lccc}
\hline & & \multicolumn{2}{c}{ Probit with controls } \\
\%tile & Actual & Need-predicted & Need-standardized \\
\hline Poorest $2 \%$ & .0322 & .0334 & .0255 \\
Poorest $5 \%$ & .0368 & .0355 & .0280 \\
Poorest $10 \%$ & .0299 & .0346 & .0220 \\
Poorest $20 \%$ & .0253 & .0301 & .0219 \\
$2^{\text {nd }}$ poorest 20\% & .0238 & .0261 & .0244 \\
Middle & .0287 & .0255 & .0299 \\
$2^{\text {nd }}$ richest 20\% & .0345 & .0265 & .0347 \\
Richest 20\% & .0316 & .0251 & .0332 \\
Mean & .0288 & .0267 & .0255 \\
CI & .0655 & -.0327 & .0958 \\
Standard error & .0114 & .0018 & .0112 \\
p-value & .0000 & .0000 & .0000 \\
\hline
\end{tabular}

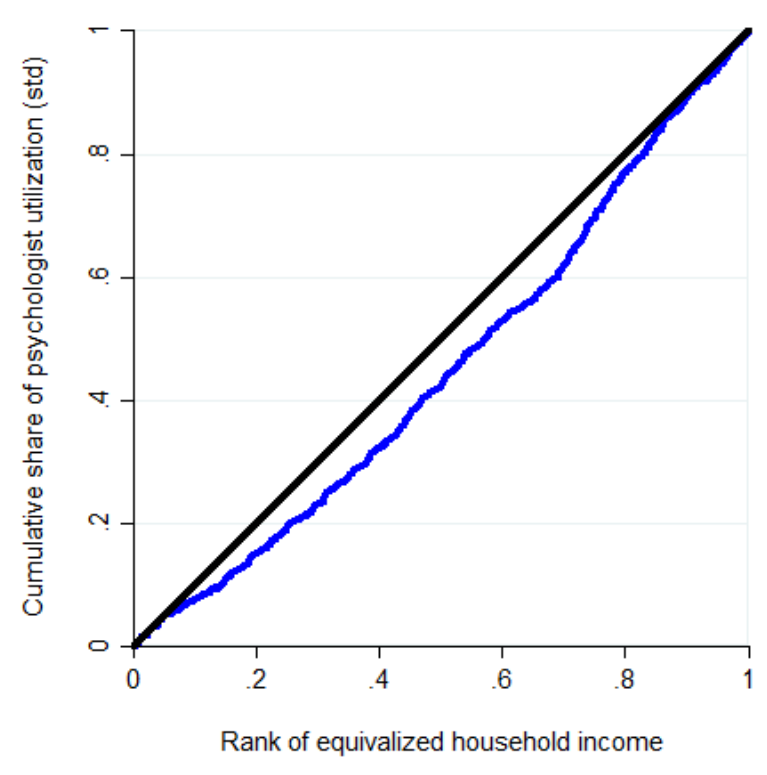


Table B 4 CCHS Annual 2013-14: Nurses

CCHS Annual 2013-14: Need-Standardized Utilization of Nurses for Mental Health Problems (12 mos), $n=86,764$ (NL, QC, ON, MB, BC, NT and NU only)

\section{Probit with controls}

\begin{tabular}{lccc} 
\%tile & Actual & Need-predicted & Need-standardized \\
\hline Poorest $2 \%$ & --- & .0076 & -.0007 \\
Poorest $5 \%$ & --- & .0085 & .0047 \\
Poorest $10 \%$ & .0101 & .0084 & .0073 \\
Poorest $20 \%$ & .0092 & .0072 & .0076 \\
$2^{\text {nd }}$ poorest $20 \%$ & .0049 & .0056 & .0049 \\
Middle & .0067 & .0052 & .0072 \\
$2^{\text {nd }}$ richest 20\% & .0059 & .0054 & .0061 \\
Richest 20\% & .0033 & .0048 & .0092 \\
Mean & .0060 & .0057 & .0060 \\
CI & -.1414 & -.0764 & -.0698 \\
Standard error & .0252 & .0031 & .0249 \\
p-value & .0000 & .0000 & .0052 \\
\hline
\end{tabular}

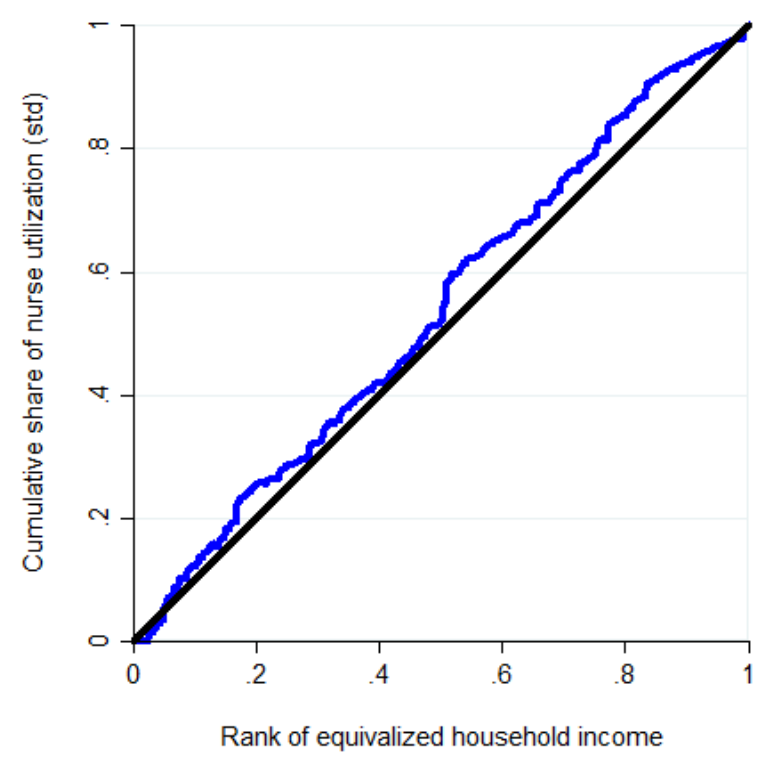


Table B 5 CCHS Annual 2013-14: Social Workers

CCHS Annual 2013-14: Need-Standardized Utilization of Social Workers for Mental Health Problems (12 mos), $n=86,764$ (NL, QC, ON, MB, BC, NT and NU only)

\begin{tabular}{lccc}
\hline & & \multicolumn{2}{c}{ Probit with controls } \\
$\%$ tile & Actual & Need-predicted & Need-standardized \\
\hline Poorest $2 \%$ & .0537 & .0352 & .0449 \\
Poorest $5 \%$ & .0537 & .0383 & .0418 \\
Poorest $10 \%$ & .0522 & .0374 & .0413 \\
Poorest $20 \%$ & .0376 & .0326 & .0320 \\
$2^{\text {nd }}$ poorest 20\% & .0235 & .0262 & .0237 \\
Middle & .0270 & .0247 & .0287 \\
$2^{\text {nd }}$ richest 20\% & .0250 & .0254 & .0261 \\
Richest 20\% & .0257 & .0234 & .0287 \\
Mean & .0278 & .0264 & .0278 \\
CI & -.0780 & -.0612 & -.0198 \\
Standard error & .0116 & .0023 & .0114 \\
p-value & .0000 & .0000 & .0004 \\
\hline
\end{tabular}

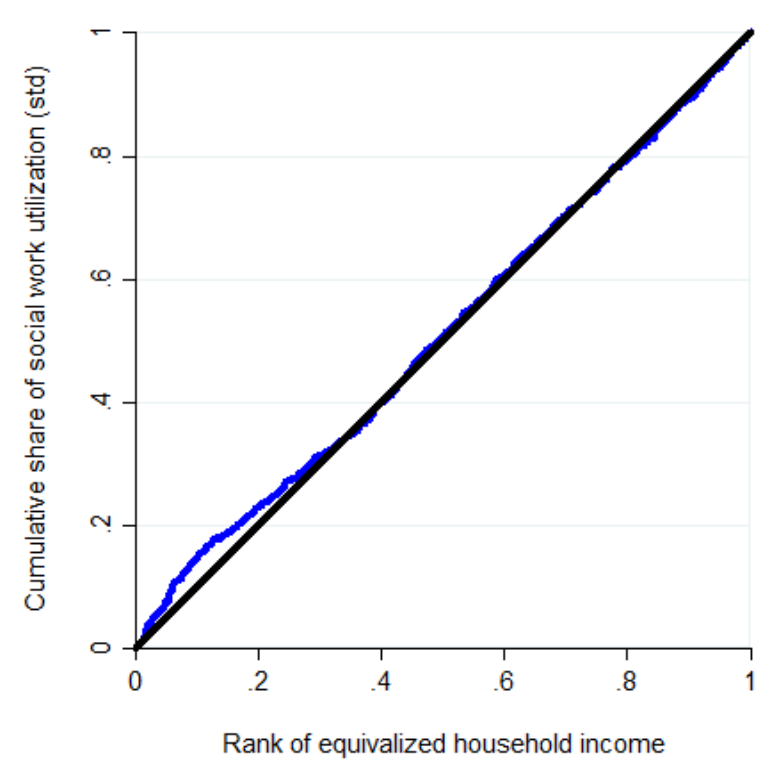


Table B 6 CCHS Annual 2013-14: Any Professional Other than Psychologists

CCHS Annual 2013-14: Need-Standardized Utilization of Any Professional Other than Psychologists for Mental Health Problems (12 mos), $n=86,764$ (NL, QC, ON, MB, BC, NT and NU only)

\section{Probit with controls}

\begin{tabular}{lccc} 
\%tile & Actual & Need-predicted & Need-standardized \\
\hline Poorest $2 \%$ & .1252 & .1144 & .1077 \\
Poorest $5 \%$ & .1526 & .1268 & .1227 \\
Poorest $10 \%$ & .1523 & .1278 & .1214 \\
Poorest 20\% & .1278 & .1147 & .1103 \\
$2^{\text {nd }}$ poorest 20\% & .0887 & .0950 & .0906 \\
Middle & .0929 & .0922 & .0976 \\
$2^{\text {nd }}$ richest 20\% & .0991 & .0939 & .1022 \\
Richest 20\% & .0851 & .0882 & .0939 \\
Mean & .0990 & .0969 &, 0990 \\
CI & -.0655 & -.0475 & -.0189 \\
Standard error & .0059 & .0019 & .0056 \\
p-value & .0000 & .0000 & .0007 \\
\hline
\end{tabular}

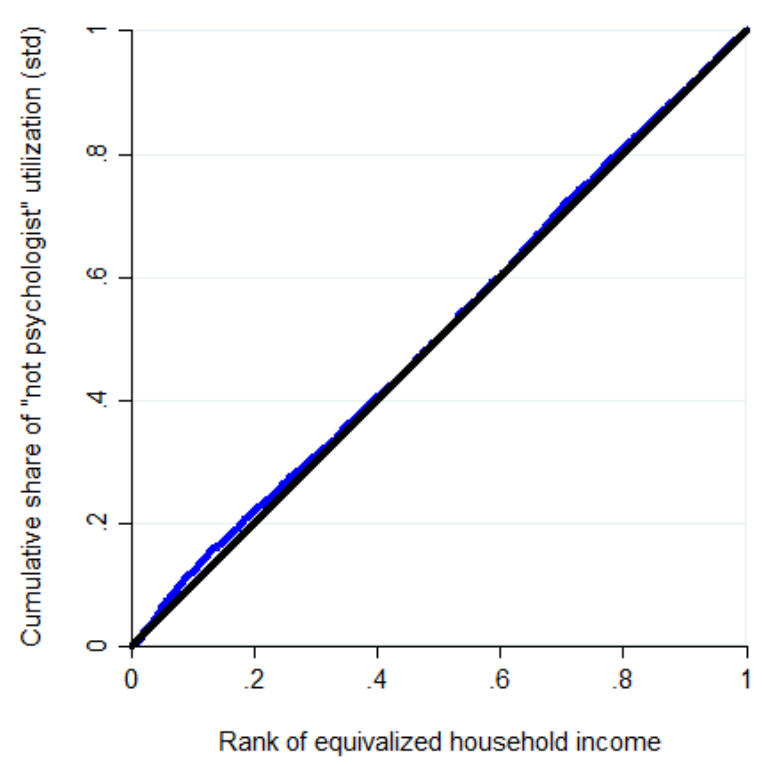


Table B 7 CCHS Annual 2011-12: GPs

CCHS Annual 2011-12: Need-Standardized Utilization of GPs for Mental Health Problems (12 mos), $n=111,859$

Probit with controls

\begin{tabular}{lccc}
$\%$ tile & Actual & Need-predicted & Need-standardized \\
\hline Poorest $2 \%$ & .0897 & .0819 & .0771 \\
Poorest $5 \%$ & .1167 & .0940 & .0919 \\
Poorest $10 \%$ & .1046 & .0883 & .0856 \\
Poorest $20 \%$ & .0891 & .0795 & .0786 \\
$2^{\text {nd }}$ poorest $20 \%$ & .0710 & .0697 & .0705 \\
Middle & .0600 & .0662 & .0630 \\
$2^{\text {nd }}$ richest $20 \%$ & .0716 & .0667 & .0742 \\
Richest 20\% & .0618 & .0638 & .0672 \\
Mean & .0707 & .0692 & .0707 \\
CI & -.0689 & -.0451 & -.0247 \\
Standard error & .0063 & .0016 & .0060 \\
p-value & .0000 & .0000 & .0000 \\
\hline
\end{tabular}

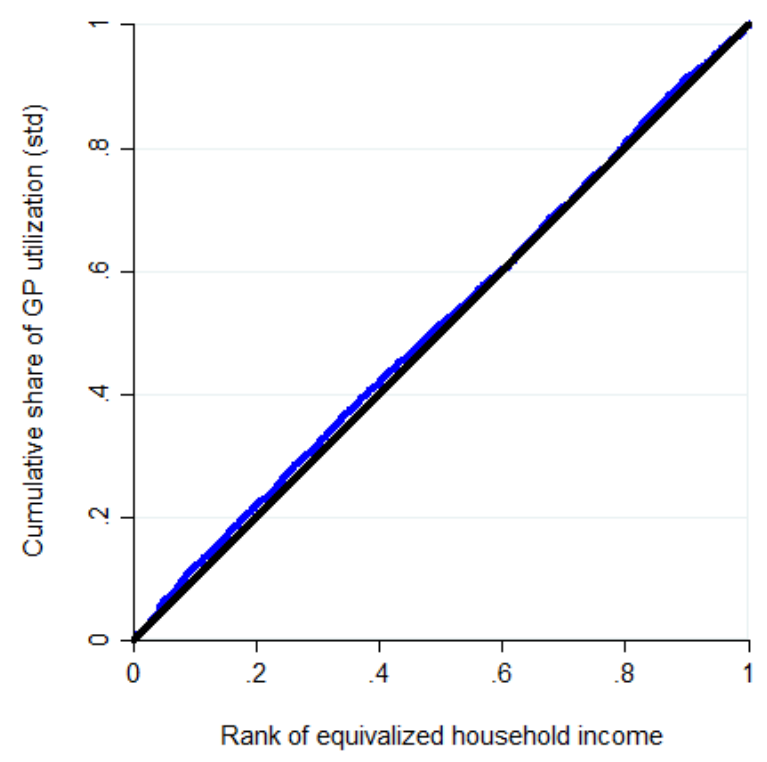


Table B 8 CCHS Annual 2011-12: Psychiatrists

CCHS Annual 2011-12: Need-Standardized Utilization of Psychiatrists for Mental Health Problems (12 mos), $n=111,859$

\begin{tabular}{lccc}
\hline & & \multicolumn{2}{c}{ Probit with controls } \\
\%otile & Actual & Need-predicted & Need-standardized \\
\hline Poorest $2 \%$ & .0355 & .0314 & .0263 \\
Poorest $5 \%$ & .0510 & .0383 & .0348 \\
Poorest $10 \%$ & .0488 & .0339 & .0370 \\
Poorest $20 \%$ & .0363 & .0288 & .0295 \\
$2^{\text {nd }}$ poorest $20 \%$ & .0221 & .0227 & .0215 \\
Middle & .0171 & .0202 & .0190 \\
$2^{\text {nd }}$ richest $20 \%$ & .0192 & .0203 & .0210 \\
Richest $20 \%$ & .0198 & .0186 & .0234 \\
Mean & .0229 & .0221 & .0229 \\
CI & -.1353 & -.0922 & -.0462 \\
Standard error & .0113 & .0028 & .0109 \\
p-value & .0000 & .0000 & .0000 \\
\hline
\end{tabular}

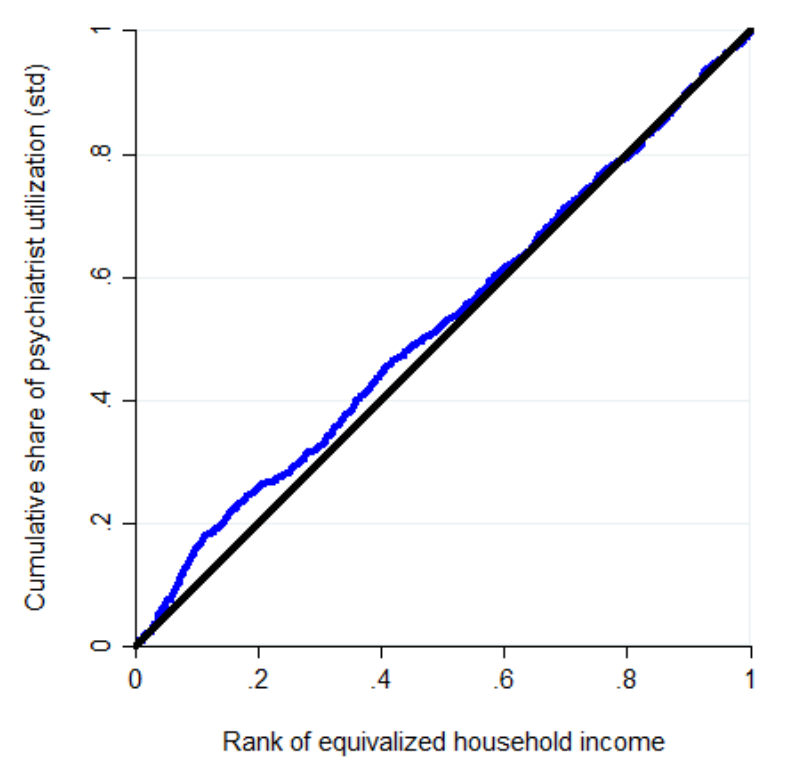


Table B 9 CCHS Annual 2011-12: Psychologists

CCHS Annual 2011-12: Need-Standardized Utilization of Psychologists for Mental Health Problems (12 mos), $n=111,859$

\begin{tabular}{lccc}
\hline & & \multicolumn{2}{c}{ Probit with controls } \\
\%tile & Actual & Need-predicted & Need-standardized \\
\hline Poorest $2 \%$ & .0304 & .0327 & .0238 \\
Poorest $5 \%$ & .0352 & .0359 & .0254 \\
Poorest $10 \%$ & .0325 & .0325 & .0261 \\
Poorest $20 \%$ & .0254 & .0283 & .0230 \\
$2^{\text {nd }}$ poorest $20 \%$ & .0242 & .0257 & .0245 \\
Middle & .0265 & .0249 & .0276 \\
$2^{\text {nd }}$ richest $20 \%$ & .0343 & .0261 & .0343 \\
Richest 20\% & .0315 & .0251 & .0324 \\
Mean & .0283 & .0260 & .0283 \\
CI & .0637 & -.0235 & .0856 \\
Standard error & .0101 & .0014 & .0100 \\
p-value & .0000 & .0000 & .0000 \\
\hline
\end{tabular}

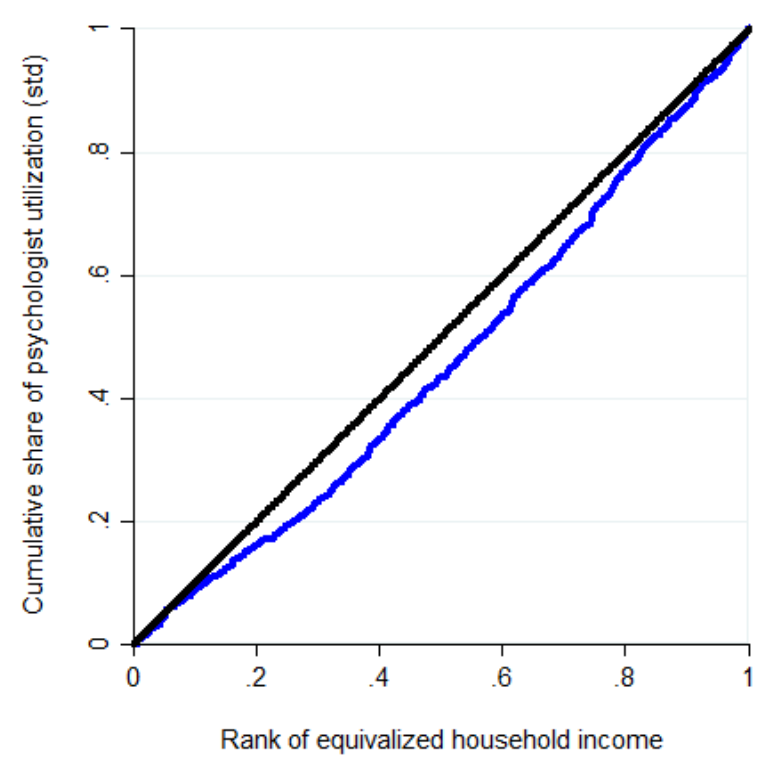


Table B 10 CCHS Annual 2011-12: Social Workers

CCHS Annual 2011-12: Need-Standardized Utilization of Social Workers for Mental Health Problems (12 mos), $n=111,859$

\begin{tabular}{lccc}
\hline \%tile & Actual & Need-predicted & Need-standardized \\
\hline Poorest $2 \%$ & .0432 & .0338 & .0347 \\
Poorest $5 \%$ & .0555 & .0376 & .0432 \\
Poorest $10 \%$ & .0477 & .0339 & .0392 \\
Poorest $20 \%$ & .0361 & .0293 & .0319 \\
$2^{\text {nd }}$ poorest $20 \%$ & .0244 & .0255 & .0242 \\
Middle & .0234 & .0240 & .0248 \\
$2^{\text {nd }}$ richest $20 \%$ & .0250 & .0247 & .0256 \\
Richest 20\% & .0246 & .0231 & .0268 \\
Mean & .0267 & .0392 & .0267 \\
CI & -.0787 & -.0482 & -.0329 \\
Standard error & .0104 & .0017 & .0103 \\
p-value & .0000 & .0000 & .0014 \\
\hline
\end{tabular}

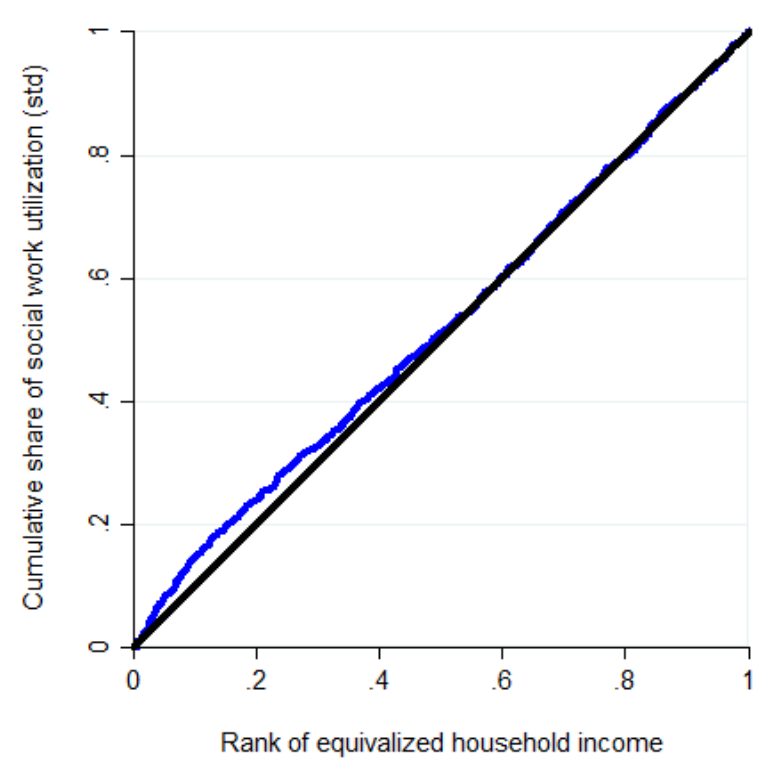


Table B 11 CCHS Annual 2011-12: Any Professional other than Psychologists

CCHS Annual 2011-12: Need-Standardized Utilization of any Professional other than Psychologists for Mental Health Problems (12 mos)

Probit with controls

\begin{tabular}{lccc} 
\%tile & Actual & Need-predicted & Need-standardized \\
\hline Poorest $2 \%$ & .1373 & .1252 & .1148 \\
Poorest $5 \%$ & .1778 & .1423 & .1382 \\
Poorest $10 \%$ & .1603 & .1322 & .1309 \\
Poorest $20 \%$ & .1335 & .1183 & .1176 \\
$2^{\text {nd }}$ poorest 20\% & .1031 & .1035 & .1024 \\
Middle & .0894 & .0981 & .0941 \\
$2^{\text {nd }}$ richest 20\% & .1031 & .0991 & .1067 \\
Richest 20\% & .0946 & .0944 & .1030 \\
Mean & .1047 & .1028 & .1047 \\
CI & -.0658 & -.0462 & -.0204 \\
Standard error & .0050 & .0015 & .0048 \\
p-value & .0000 & .0000 & .0000 \\
\hline
\end{tabular}

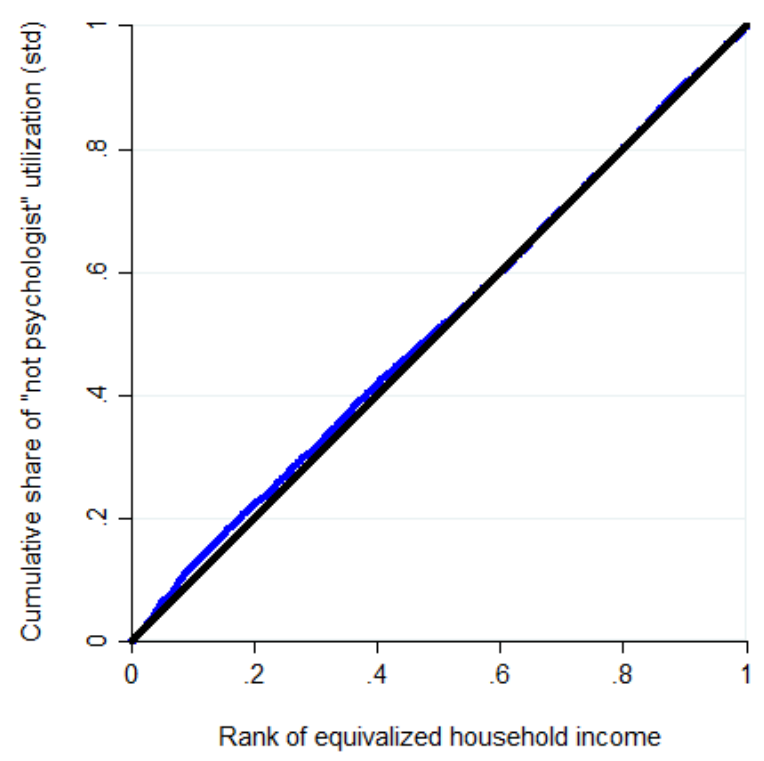


Table B 12 CCHS MH 2012: GP Sensitivity Analysis

CCHS MH 2012: Need-Standardized Utilization of GPs for Mental Health/Substance Use Problems (12 mos), $n=23,643$

Probit with controls

\begin{tabular}{|c|c|c|c|}
\hline$\%$ tile & Actual & Need-predicted & Need-standardized \\
\hline \multicolumn{4}{|c|}{$\underline{\text { Standardized for Self-Reported Mental Health }}$} \\
\hline Poorest $2 \%$ & .0960 & .0996 & .0645 \\
\hline Poorest 5\% & .1080 & .0952 & .0809 \\
\hline Poorest $10 \%$ & .1045 & .0906 & .0821 \\
\hline Poorest $20 \%$ & .0940 & .0821 & .0797 \\
\hline $2^{\text {nd }}$ poorest $20 \%$ & .0752 & .0701 & .0732 \\
\hline Middle & .0647 & .0640 & .0689 \\
\hline $2^{\text {nd }}$ richest $20 \%$ & .0551 & .0633 & .0599 \\
\hline Richest $20 \%$ & .0603 & .0601 & .0683 \\
\hline Mean & .0700 & .0996 & .0700 \\
\hline $\mathrm{CI}$ & -.1077 & -.0665 & -.0430 \\
\hline Standard error & .0137 & .0043 & .0130 \\
\hline $\mathrm{p}$-value & .0000 & .0000 & .0009 \\
\hline \multicolumn{4}{|c|}{$\underline{\text { Standardized for Any Mood Disorder }}$} \\
\hline $\mathrm{CI}$ & -.1060 & -.0625 & -.0452 \\
\hline Standard error & .0138 & .0049 & .0129 \\
\hline $\mathrm{p}$-value & .0000 & .0000 & .0005 \\
\hline \multicolumn{4}{|c|}{$\underline{\text { Standardized for Anxiety Disorder }}$} \\
\hline $\mathrm{CI}$ & -.1042 & -.0318 & -.0733 \\
\hline Standard error & .0138 & .0041 & .0132 \\
\hline $\mathrm{p}$-value & .0000 & .0000 & .0000 \\
\hline \multicolumn{4}{|c|}{$\underline{\text { Standardized for Any Substance Disorder }}$} \\
\hline CI & -.1085 & .0087 & -.1170 \\
\hline Standard error & .0000 & .0016 & .0138 \\
\hline $\mathrm{p}$-value & .0139 & .0000 & .0000 \\
\hline \multicolumn{4}{|c|}{$\underline{\text { Standardized for Distress }(\mathrm{K} 6>4)}$} \\
\hline $\mathrm{CI}$ & -.1094 & -.0649 & -.0463 \\
\hline Standard error & .0137 & .0037 & .0132 \\
\hline $\mathrm{p}$-value & .0000 & .0000 & .0005 \\
\hline
\end{tabular}



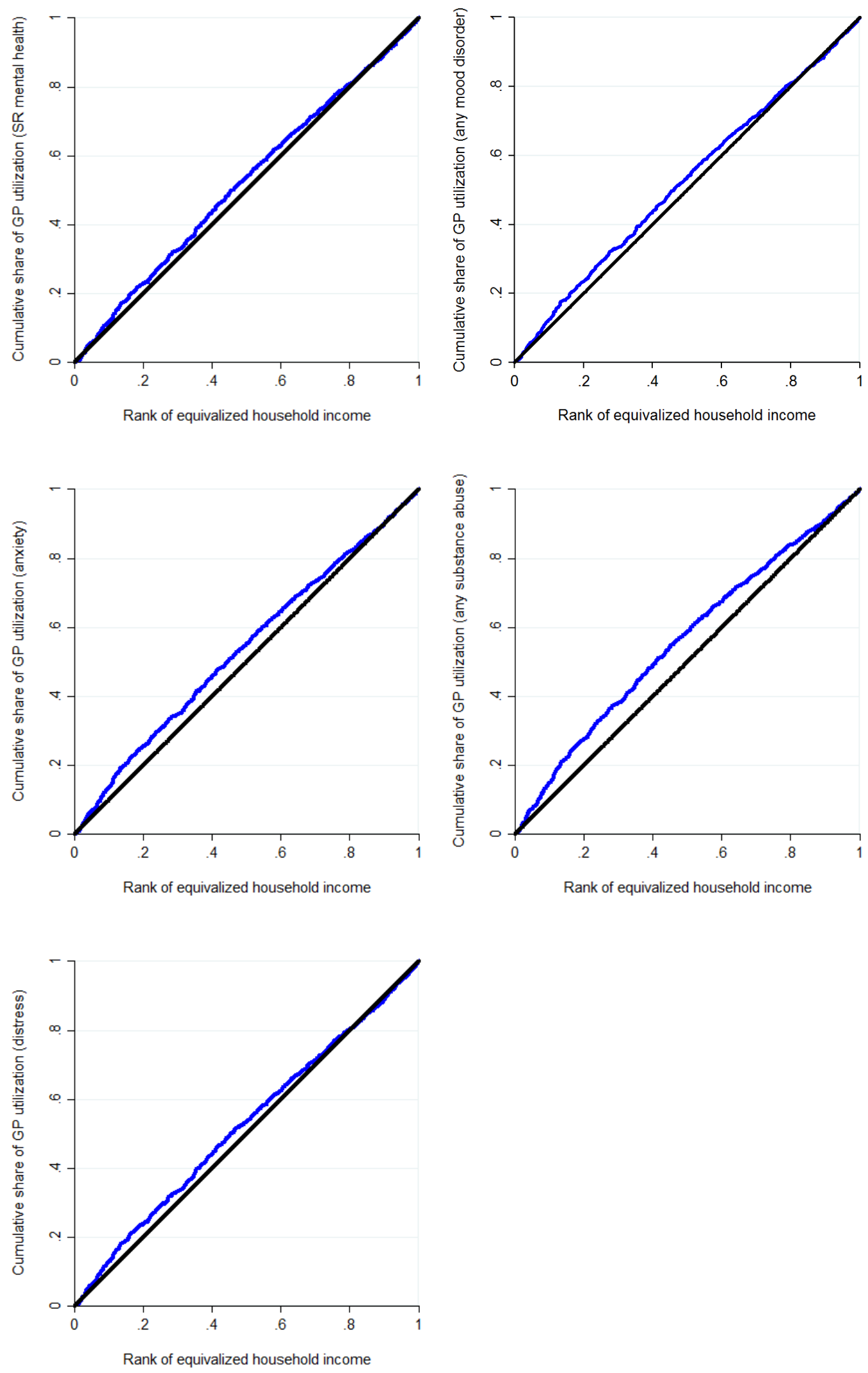
Table B 13 CCHS MH 2012: Psychiatrists

CCHS MH 2012: Need-Standardized Utilization of Psychiatrists for Mental Health/Substance Use Problems (12 mos), $n=25,113$

$\underline{\text { Probit with controls }}$

\begin{tabular}{lccc}
$\%$ tile & Actual & Need-predicted & Need-standardized \\
\hline Poorest $2 \%$ & .0385 & .0364 & .0231 \\
Poorest $5 \%$ & .0407 & .0337 & .0279 \\
Poorest $10 \%$ & .0408 & .0313 & .0304 \\
Poorest $20 \%$ & .0328 & .0274 & .0261 \\
$2^{\text {nd }}$ poorest $20 \%$ & .0265 & .0222 & .0253 \\
Middle & .0200 & .0190 & .0220 \\
$2^{\text {nd }}$ richest 20\% & .0159 & .0189 & .0180 \\
Richest 20\% & .0171 & .0170 & .0210 \\
Mean & .0225 & .0210 & .0225 \\
CI & -.1680 & -.1024 & -.0727 \\
Standard error & .0247 & .0066 & .0238 \\
p-value & .0000 & .0000 & .0023 \\
\hline
\end{tabular}

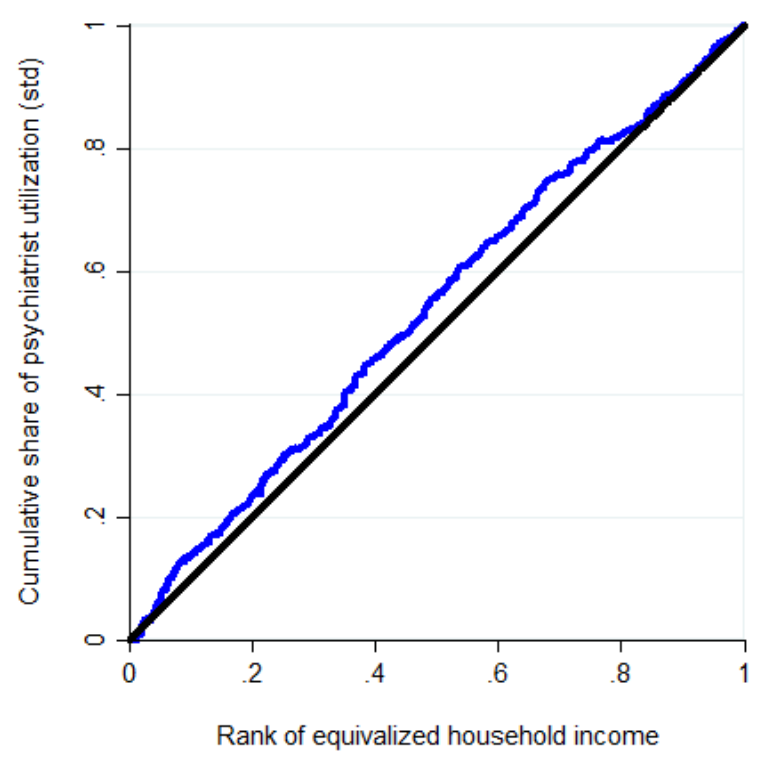


Table B 14 CCHS MH 2012: Psychologist Sensitivity Analysis

CCHS MH 2012: Need-Standardized Utilization of Psychologists for Mental Health/Substance Use Problems (12 mos), $n=23,643$

\begin{tabular}{|c|c|c|c|}
\hline \multirow[b]{2}{*}{$\%$ tile } & \multirow[b]{2}{*}{ Actual } & \multicolumn{2}{|c|}{$\underline{\text { Probit with controls }}$} \\
\hline & & Need-predicted & Need-standardized \\
\hline \multicolumn{4}{|c|}{$\underline{\text { Standardized for Self-Reported Mental Health }}$} \\
\hline Poorest $2 \%$ & --- & .0354 & .0250 \\
\hline Poorest 5\% & .0310 & .0346 & .0187 \\
\hline Poorest $10 \%$ & .0257 & .0309 & .0171 \\
\hline Poorest 20\% & .0262 & .0268 & .0217 \\
\hline $2^{\text {nd }}$ poorest $20 \%$ & .0222 & .0227 & .0218 \\
\hline Middle & .0242 & .0207 & .0257 \\
\hline $2^{\text {nd }}$ richest $20 \%$ & .0232 & .0211 & .0243 \\
\hline Richest 20\% & .0263 & .0196 & .0290 \\
\hline Mean & .0244 & .0222 & .0244 \\
\hline $\mathrm{CI}$ & -.0150 & -.0689 & .0479 \\
\hline Standard error & .0238 & .0052 & .0232 \\
\hline p-value & .5280 & .0000 & .0387 \\
\hline \multicolumn{4}{|c|}{$\underline{\text { Standardized for Any Mood Disorder }}$} \\
\hline $\mathrm{CI}$ & -.0084 & -.0679 & .0528 \\
\hline Standard error & .0240 & .0059 & .0233 \\
\hline p-value & .7266 & .0000 & .0235 \\
\hline \multicolumn{4}{|c|}{ Standardized for Anxiety Disorder } \\
\hline CI & -.0108 & -.0335 & .0194 \\
\hline Standard error & .0240 & .0049 & .0236 \\
\hline p-value & .6522 & .0000 & .4098 \\
\hline \multicolumn{4}{|c|}{ Standardized for Any Substance Disorder } \\
\hline $\mathrm{CI}$ & -.0125 & .0051 & $-.0170(-.0176)^{+}$ \\
\hline Standard error & .0242 & .0027 & .0241 \\
\hline p-value & .6072 & .0613 & .4800 \\
\hline \multicolumn{4}{|c|}{$\underline{\text { Standardized for Distress }(\mathrm{K} 6>4)}$} \\
\hline CI & -.0173 & -.0719 & $.0485(.0546)^{+}$ \\
\hline Standard error & .0238 & .0045 & .0234 \\
\hline p-value & .4689 & .0000 & .0383 \\
\hline
\end{tabular}



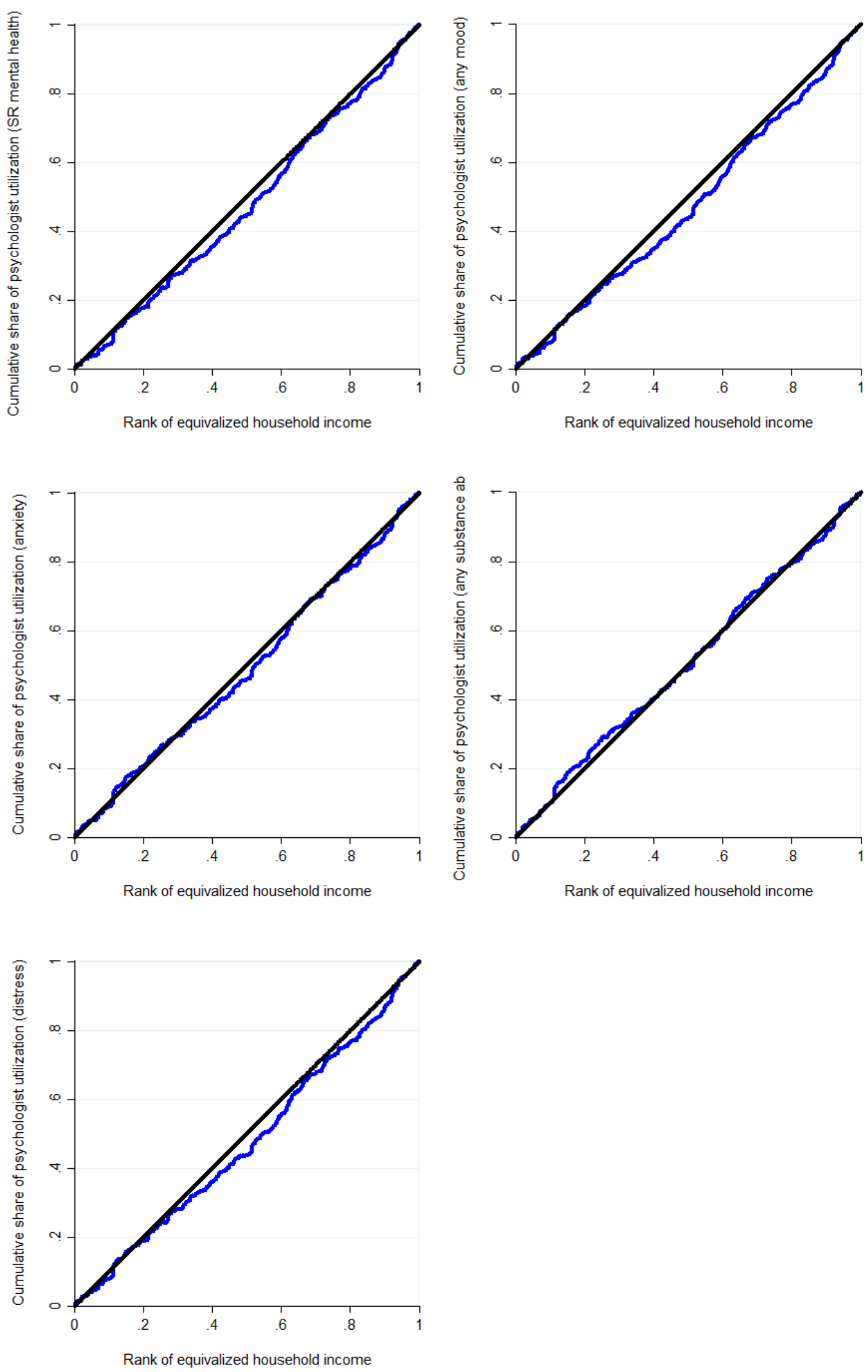
Table B 15 CCHS MH 2012: Nurses

CCHS MH 2012: Need-Standardized Utilization of Nurses for Mental Health/Substance Use Problems (12 mos), $n=25,113$

Probit with controls

\begin{tabular}{lccc} 
\%tile & Actual & Need-predicted & Need-standardized \\
\hline Poorest $2 \%$ & --- & .0128 & .0049 \\
Poorest $5 \%$ & --- & .0123 & .0075 \\
Poorest $10 \%$ & .0126 & .0114 & .0098 \\
Poorest 20\% & .0120 & .0102 & .0104 \\
$2^{\text {nd }}$ poorest 20\% & .0110 & .0090 & .0106 \\
Middle & .0094 & .0082 & .0099 \\
$2^{\text {nd }}$ richest 20\% & .0074 & .0081 & .0079 \\
Richest 20\% & .0085 & .0077 & .0095 \\
Mean & .0097 & .0086 & .0097 \\
CI & -.1007 & -.0626 & -.0446 \\
Standard error & .0380 & .0038 & .0378 \\
p-value & .0081 & .0000 & .2385 \\
\hline
\end{tabular}

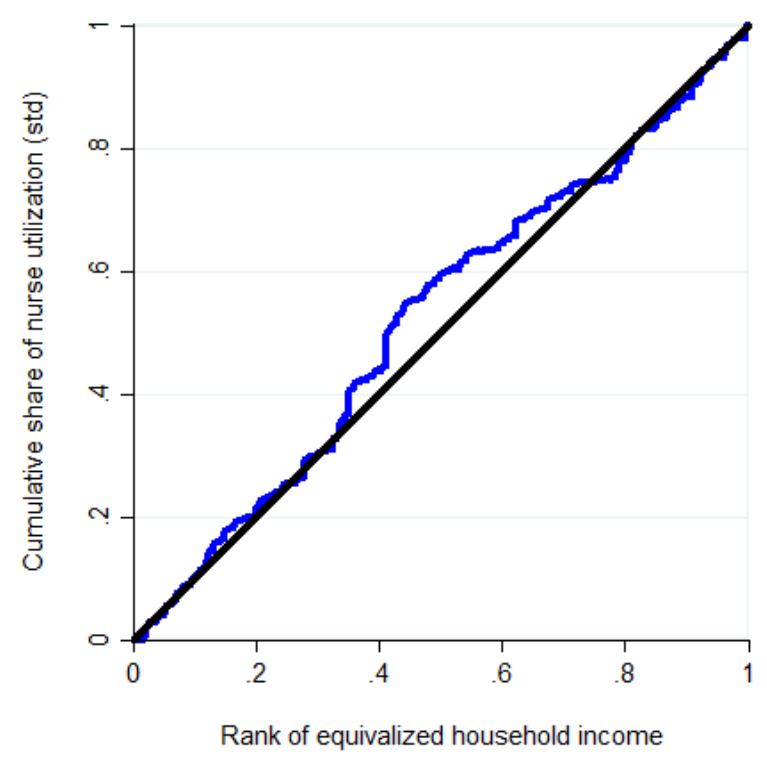


Table B 16 CCHS MH 2012: Social Workers

CCHS MH 2012: Need-Standardized Utilization of Social Workers for Mental Health/Substance Use Problems (12 mos), $n=25,113$

\begin{tabular}{lccc}
\hline \%tile & Actual & Need-predicted & Need-standardized \\
\hline Poorest $2 \%$ & .0588 & .0484 & .0402 \\
Poorest $5 \%$ & .0592 & .0464 & .0426 \\
Poorest $10 \%$ & .0523 & .0415 & .0406 \\
Poorest $20 \%$ & .0460 & .0355 & .0401 \\
$2^{\text {nd }}$ poorest $20 \%$ & .0291 & .0305 & .0284 \\
Middle & .0284 & .0277 & .0306 \\
$2^{\text {nd }}$ richest $20 \%$ & .0258 & .0284 & .0272 \\
Richest 20\% & .0271 & .0265 & .0305 \\
Mean & .0314 & .0298 & .0314 \\
CI & -.1160 & -.0657 & -.0535 \\
Standard error & .0208 & .0048 & .0207 \\
p-value & .0000 & .0000 & .0083 \\
\hline
\end{tabular}

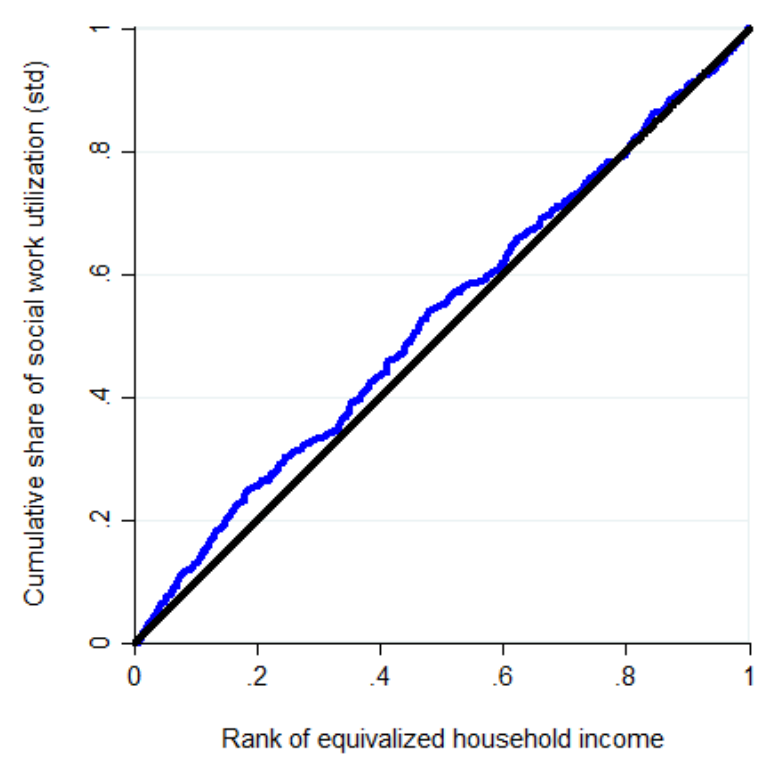


Table B 17 CCHS MH 2012: Any Professional other than Psychologists

CCHS MH 2012: Need-Standardized Utilization of any Professional other than Psychologists for Mental Health/Substance Use Problems (12 mos), $n=25,113$

\section{Probit with controls}

\begin{tabular}{lccc} 
\%tile & Actual & Need-predicted & Need-standardized \\
\hline Poorest $2 \%$ & .1560 & .1387 & .1115 \\
Poorest $5 \%$ & .1574 & .1326 & .1189 \\
Poorest $10 \%$ & .1462 & .1246 & .1157 \\
Poorest $20 \%$ & .1312 & .1125 & .1124 \\
$2^{\text {nd }}$ poorest 20\% & .0979 & .0970 & .0951 \\
Middle & .0894 & .0887 & .0949 \\
$2^{\text {nd }}$ richest 20\% & .0808 & .0882 & .0868 \\
Richest 20\% & .0833 & .0831 & .0944 \\
Mean & .0967 & .0941 & .0967 \\
CI & -.1001 & -.0647 & -.0371 \\
Standard error & .0115 & .0041 & .0107 \\
p-value &. .0000 & .0000 & .0005 \\
\hline
\end{tabular}

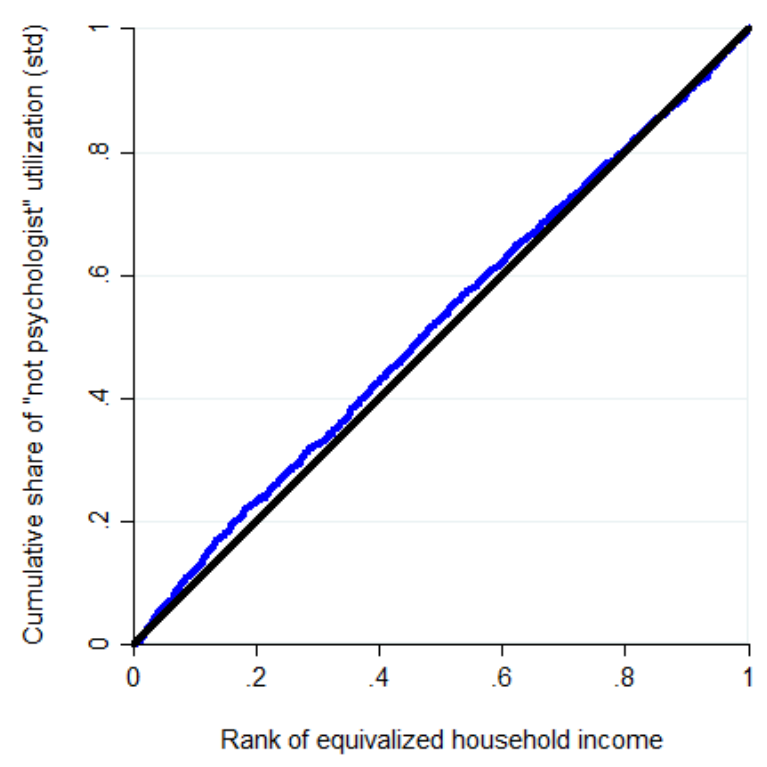


Table B 18 CCHS MH 2012: Unmet Need for Counselling

CCHS MH 2012: Need-Standardized Unmet Mental Health Service Need for Counselling (12 mos), $n=23,574$

Probit with controls

\begin{tabular}{lccc}
$\%$ tile & Actual & Need-predicted & Need-standardized \\
\hline Poorest $2 \%$ & .0795 & .0716 & .0516 \\
Poorest $5 \%$ & .0804 & .0678 & .0562 \\
Poorest $10 \%$ & .0712 & .0610 & .0538 \\
Poorest $20 \%$ & .0582 & .0524 & .0491 \\
$2^{\text {nd }}$ poorest $20 \%$ & .0442 & .0451 & .0427 \\
Middle & .0457 & .0402 & .0492 \\
$2^{\text {nd }}$ richest $20 \%$ & .0347 & .0413 & .0371 \\
Richest 20\% & .0406 & .0385 & .0457 \\
Mean & .0448 & .0436 & .0448 \\
CI & -.0950 & -.0690 & -.0278 \\
Standard error & .0174 & .0052 & .0166 \\
p-value & .0000 & .0000 & .0937 \\
\hline
\end{tabular}

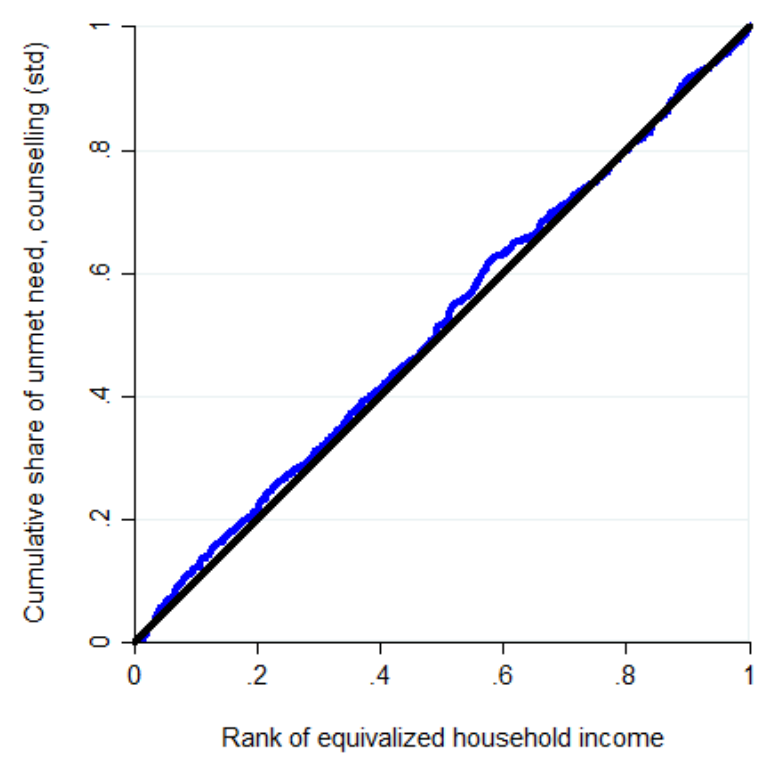


Table B 19 CCHS MH 2012: Unmet Need for Medication

CCHS MH 2012: Need-Standardized Unmet Mental Health Service Need for Medication (12 mos), $n=23,574$

Probit with controls

\begin{tabular}{lccc} 
\%tile & Actual & Need-predicted & Need-standardized \\
\hline Poorest $2 \%$ & --- & .0161 & .0095 \\
Poorest $5 \%$ & .0179 & .0148 & .0116 \\
Poorest $10 \%$ & .0222 & .0134 & .0173 \\
Poorest $20 \%$ & .0176 & .0114 & .0146 \\
$2^{\text {nd }}$ poorest $20 \%$ & .0105 & .0093 & .0097 \\
Middle & .0064 & .0074 & .0075 \\
$2^{\text {nd }}$ richest 20\% & .0052 & .0075 & .0062 \\
Richest 20\% & .0071 & .0067 & .0089 \\
Mean & .0094 & .0085 & .0094 \\
CI & -.2440 & -.1209 & -.1345 \\
Standard error & .0386 & .0077 & .0378 \\
p-value & .0000 & .0000 & .0004 \\
\hline
\end{tabular}

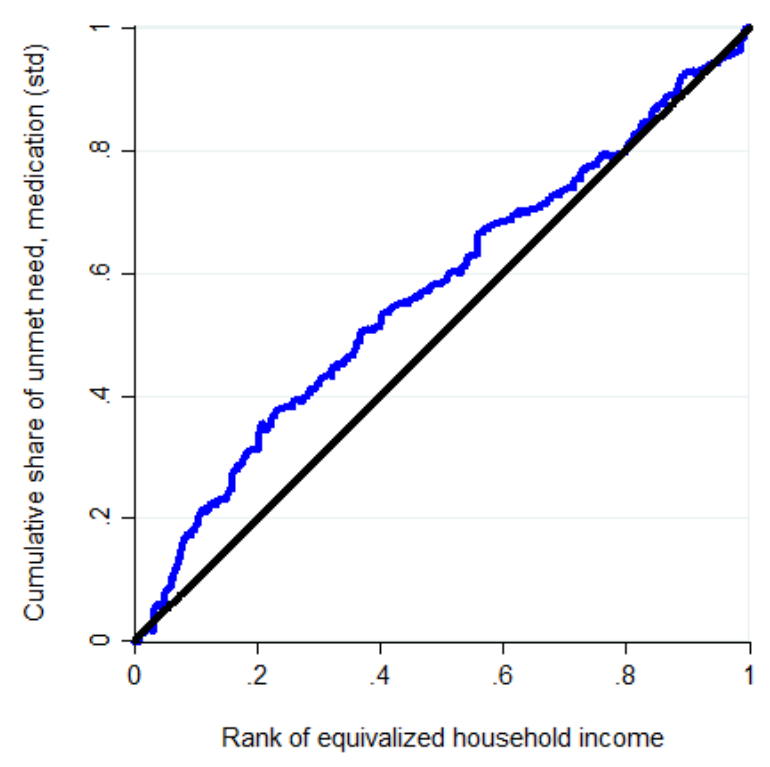


Table B 20 CCHS MH 2012: Unmet Mental Health Service Need

CCHS MH 2012: Need-Standardized Unmet Mental Health Service Need (including counselling, information, medication, other) (12 mos), $n=23,550$

$\underline{\text { Probit with controls }}$

\begin{tabular}{lccc}
$\%$ tile & Actual & Need-predicted & Need-standardized \\
\hline Poorest $2 \%$ & .1116 & .0941 & .0758 \\
Poorest $5 \%$ & .1126 & .0890 & .0820 \\
Poorest $10 \%$ & .0983 & .0812 & .0755 \\
Poorest $20 \%$ & .0792 & .0706 & .0664 \\
$2^{\text {nd }}$ poorest $20 \%$ & .0595 & .0609 & .0569 \\
Middle & .0598 & .0537 & .0644 \\
$2^{\text {nd }}$ richest $20 \%$ & .0455 & .0547 & .0491 \\
Richest 20\% & .0502 & .0510 & .0576 \\
Mean & .0590 & .0584 & .0590 \\
CI & -.1099 & -.0725 & -.0382 \\
Standard error & .0150 & .0049 & .0142 \\
p-value & .0000 & .0000 & .0070 \\
\hline
\end{tabular}

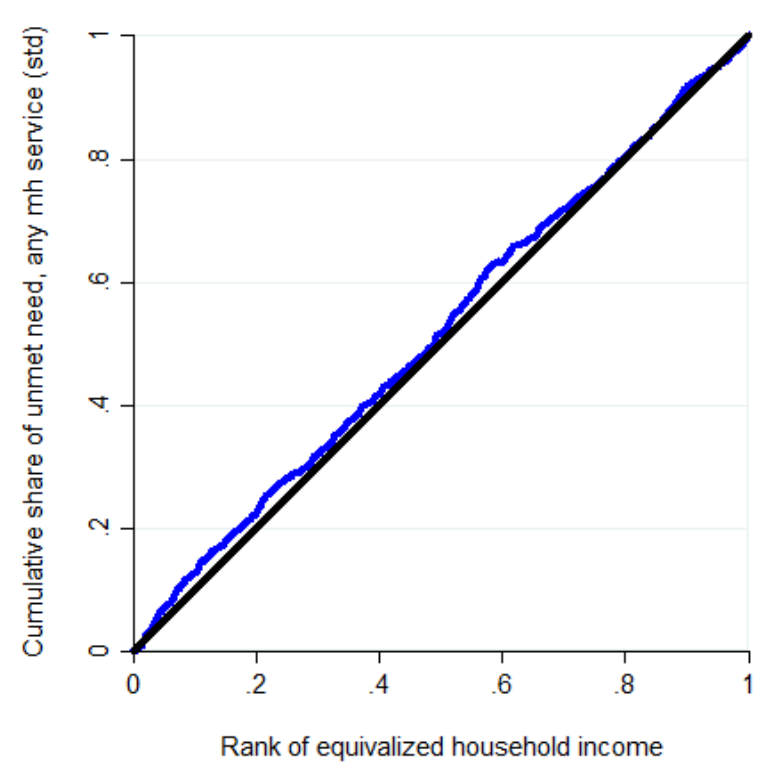


Table B 21 CCHS Annual 2013-14: Unmet Need for Physical Health Problems

CCHS Annual 2013-14: Unmet Need for Healthcare for Physical Health Problems (12 mos), Standardized for Self-Reported Physical Health, n=56,007 (NL ON, AB and NT only)

\begin{tabular}{lccc}
\hline & & \multicolumn{2}{c}{ Probit with controls } \\
\%tile & Actual & Need-predicted & Need-standardized \\
\hline Poorest $2 \%$ & .1055 & .0789 & .0936 \\
Poorest $5 \%$ & .1307 & .0859 & .1118 \\
Poorest $10 \%$ & .1026 & .0825 & .0872 \\
Poorest $20 \%$ & .0969 & .0769 & .0870 \\
$2^{\text {nd }}$ poorest $20 \%$ & .0609 & .0666 & .0613 \\
Middle & .0613 & .0653 & .0630 \\
$2^{\text {nd }}$ richest $20 \%$ & .0606 & .0654 & .0622 \\
Richest $20 \%$ & .0566 & .0673 & .0629 \\
Mean & .0673 & .0670 & .0673 \\
CI & -.1096 & -.0428 & -.0596 \\
Standard error & .0097 & .0015 & .0089 \\
p-value & .0000 & .0000 & .0000 \\
\hline
\end{tabular}

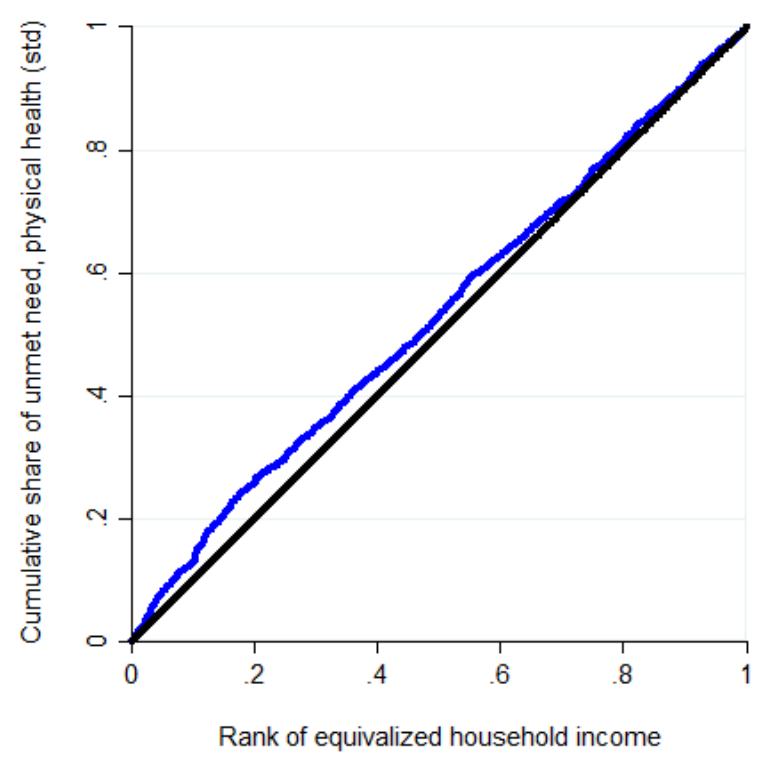


Table B 22 CCHS Annual 2013-14: Unmet Need for Mental Health Problems

CCHS Annual 2013-14: Unmet Need for Healthcare for Mental Health Problems (12 mos), Standardized for Self-Reported Mental Health, $n=54,659$, (NL ON, AB and NT only)

\begin{tabular}{lccc}
\hline & & \multicolumn{2}{c}{ Probit with controls } \\
\%tile & Actual & Need-predicted & Need-standardized \\
\hline Poorest $2 \%$ & .0236 & .0145 & .0181 \\
Poorest $5 \%$ & .0301 & .0170 & .0221 \\
Poorest $10 \%$ & .0232 & .0161 & .0160 \\
Poorest $20 \%$ & .0200 & .0130 & .0161 \\
$2^{\text {nd }}$ poorest $20 \%$ & .0080 & .0086 & .0084 \\
Middle & .0097 & .0081 & .0106 \\
$42^{\text {nd }}$ richest $20 \%$ & .0087 & .0083 & .0094 \\
Richest 20\% & .0056 & .0070 & .0077 \\
Mean & .0105 & .0090 & .0105 \\
CI & -.2367 & -.1186 & -.1348 \\
Standard error & .0240 & .0053 & .0233 \\
p-value & .0000 & .0000 & .0000 \\
\hline
\end{tabular}

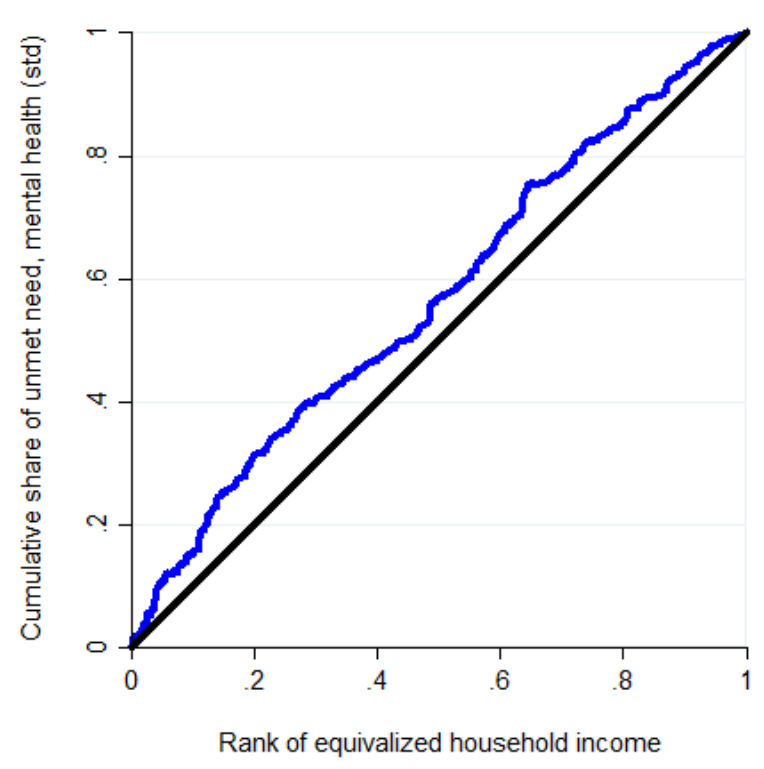


Table B 23 CCHS Annual 2011-12: Unmet Need for Physical Health Problems

CCHS Annual 2011-12: Unmet Need for Healthcare for Physical Health Problems (12 mos), Standardized for Physical Health, $n=58,767$

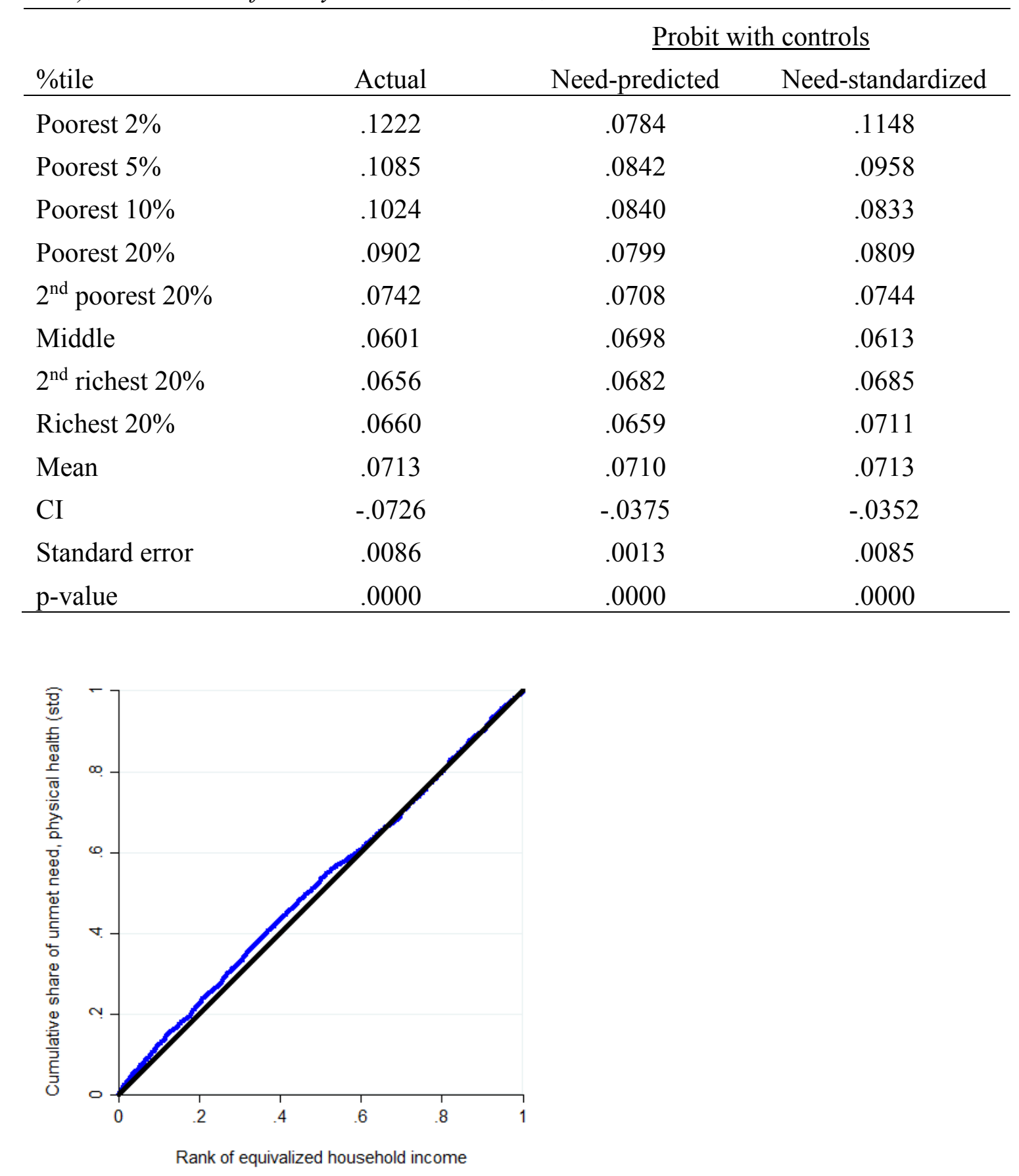


Table B 24 CCHS Annual 2011-12: Unmet Need for Mental Health Problems

CCHS Annual 2011-12: Unmet Need for Healthcare for Mental Health Problems (12 mos), Standardized for Mental Health, $n=57,311$

\begin{tabular}{lccc}
\hline & & \multicolumn{2}{c}{ Probit with controls } \\
\%tile & Actual & Need-predicted & Need-standardized \\
\hline Poorest $2 \%$ & .0122 & .0184 & .0046 \\
Poorest $5 \%$ & .0329 & .0230 & .0207 \\
Poorest $10 \%$ & .0266 & .0192 & .0181 \\
Poorest $20 \%$ & .0180 & .0155 & .0013 \\
$2^{\text {nd }}$ poorest $20 \%$ & .0151 & .0111 & .0148 \\
Middle & .0111 & .0097 & .0122 \\
$2^{\text {nd }}$ richest $20 \%$ & .0088 & .0093 & .0103 \\
Richest $20 \%$ & .0040 & .0083 & 0065 \\
Mean & .0115 & .0108 & .0115 \\
CI & -.2541 & -.1349 & -.1273 \\
Standard error & .0223 & .0051 & .0217 \\
p-value & .0000 & .0000 & .0000 \\
\hline
\end{tabular}

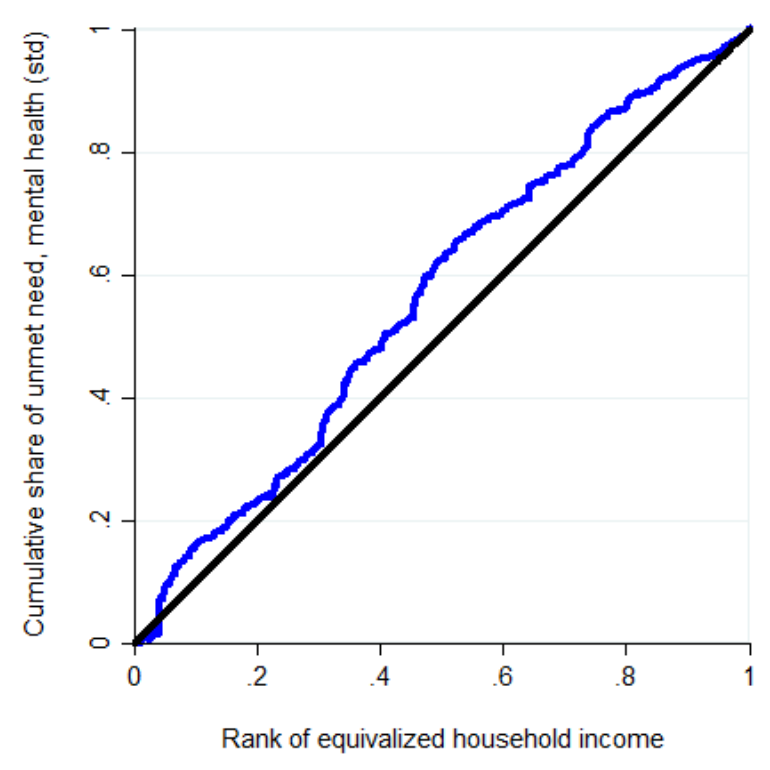




\section{Paper \#3: Income-Based Inequities in Access to Psychotherapy and other Mental Health Services in Canada and Australia}

\section{Introduction}

The first paper in this dissertation uses qualitative methods to trace the role of government structure in shaping mental health in Canada, with Canada's decentralized structure constraining public funding for psychotherapy and other mental health services. The second paper uses quantitative methods to examine the extent that access to psychotherapy and other mental health services has varied by income in Canada. This third paper uses the same methods to compare income-based inequities in access in Canada (in 2011 and 2012) and Australia (in 2007), two federal parliamentary systems with sharply contrasting responses to high rates of unmet need for psychotherapy (Australian Bureau of Statistics, 1998; Sunderland \& Findlay, 2013). While Canada has yet to expand access, Australia introduced the population-wide Better Access to Psychiatrists, Psychologists and General Practitioners through the MBS initiative in 2006 (Better Access; Australia, n.d.).

The years used for analysis mark major policy milestones for both countries. Canada's first-ever mental health strategy was released in 2012 (Mental Health Commission of Canada, 2012), and Australia was one year into the implementation of Better Access in 2007. Analyzing the distribution of access by income is particularly policy relevant in 2017 as the Canadian federal government has committed to transferring $\$ 5$ billion to provincial and territorial governments to improve access to mental health services over the next ten years (Finance Canada, 2017), and as Australia launches its 
fifth National Mental Health Plan (Council of Australian Governments Health Council, 2017).

Guided by the literature on health inequities, this comparative analysis considers access to be not just a healthcare issue but an equity issue (Hosseinpoor, Itani \& Petersen, 2012; Jiménez-Rubio, Smith \& van Doorslaer, 2008; van Doorslaer, Masseria \& the OECD Health Equity Research Group Members, 2004; Zhang et al., 2015). This paper makes a significant contribution to this literature be being the first to compare needstandardized concentration indices (CIs) for access to psychotherapy and other mental health services in Canada and Australia. CIs are used to measure income-based inequities in access to mental health services (including psychotherapy) after standardizing for the fact that mental health needs are themselves highly concentrated at lower income levels. Equity in access is measured in two ways. First, we examine the distribution of utilization of professional services for mental health problems by income. Second, we examine the distribution of unmet needs for psychotherapy by income. This analysis is supported by the similarity of the Canadian Community Health Survey (CCHS) and the Australian National Survey of Mental Health and Well-Being (NSMHWB) in both the questions asked and the population sampled.

This paper first compares the two-tier Canadian and more hybrid Australian service systems, and predicts that inequities will be greater in Canada than in Australia, and greater for the services of psychologists and other non-physician providers than for physicians. Second, the methodology for need-standardized CIs is briefly reviewed, along with more detailed descriptions of the variables and how the Australian and Canadian data has been adjusted to be comparable. Third, the results are presented. As expected, 
need-standardized CIs for utilization of psychologist services are the most concentrated of all of the provider groups at higher income levels (i.e. pro-rich), and are more pro-rich in Canada than in Australia. While the distribution of unmet need for psychotherapy was expected (as a negative indicator of access) to be more concentrated at lower income levels (i.e. pro-poor) under Canada's two-tier system, this result was unexpectedly more pro-poor in Australia. Possible explanations and policy implications for these findings are discussed, including a potential backlog effect from the introduction of Better Access in 2006.

\section{Comparison of Service Systems and Predicted Implications for Concentration}

\section{Indices}

Psychotherapy in Canada is currently provided through a two-tier system. Firstdollar public financing covers a narrow range of services that are either provided by physicians in general practice, in hospitals, or in publicly-funded clinics. Private financing (either through employment-based insurance or out-of-pocket payments) covers the broader range of services that are provided by psychologists, social workers, and other mental health professionals (non-physician providers). Accordingly, the price at time-of-service (marginal cost for service users) for psychotherapy services provided by general practitioners and psychiatrists is the same regardless of the service user's income level. For the broader range of mental health services, the price at time-of-service will vary by income. The estimated twelve million Canadians who do not have employmentbased benefits (largely lower-income Canadians) face a higher price for psychotherapy services that are not covered by their provincial or territorial insurance plans than those who do have such benefits (largely middle and higher-income Canadians) (Canadian Life 
and Health Insurance Industry, 2016). Further, higher-income Canadians are most able to afford to pay out-of-pocket (i.e. directly) for non-physician psychotherapy. These differences in financial barriers would appear to make it less likely for lower-income Canadians with mental health problems to utilize non-physician psychotherapy than higher-income Canadians, and more likely to have unmet needs for mental health services as a result.

Canadian research provides mixed evidence of such income-based inequities in access to psychotherapy and other mental health services. On the one hand, regression analysis of survey data has found that need is the strongest predictor of service utilization, suggesting a relatively equitable system (Lewis, 2013; Vasiliadis, Tempier, Lesage \& Kates, 2009). However, income and education have also been found to be significant predictors of mental health service utilization (Hunsley, Lee \& Aubrey, 1999; Vasiliadis et al., 2009). Further, after standardizing for need, the Canada-only analysis in the second paper found evidence of income-based inequities in access.

The two tiers in Australia's mental health system are less distinct, as private financing plays a stronger role in the provision of all health services. Australian Medicare allows providers considerable discretion with regard to billing, essentially allowing a form of price discrimination. Providers can offer care free at the point of delivery by billing the government directly (known as bulk-billing), thus avoiding the costs and risks of billing and debt collection, and removing financial barriers for low-income service users. Alternatively, they can charge co-payments of $15 \%$ or more depending on a service user's ability to pay, through direct billing of the service user (OECD, 2015a). Further, the commonwealth government provides incentives for Australians to purchase private 
insurance by both providing rebates for those who do, and increasing the Medicare levy for those who do not (Australia, 2017a). Accordingly, out-of-pocket health costs (for both co-payments and private insurance) are higher in Australia than in Canada (20\% vs $15 \%$; OECD, 2015b). Private insurance cannot be used to cover co-payments for Medicare services that are not bulk-billed (Australia, 2006).

Australian Medicare started to cover psychotherapy provided by non-physician mental health providers in 2006 with the introduction of Better Access, which allows the same discretion over co-payments. There is some evidence to suggest that the rate of copayments is higher under Better Access than under Medicare in general. In 2007-2008, 73 per cent of Medicare services as whole were bulk-billed; however, only 47 per cent of allied health services (which includes the non-physician Better Access items as well as other allied health services) were bulk-billed (Australia, 2017b; Australia, 2017c). Moreover, between 2007 and 2010, 65.5 per cent of Better Access users made a copayment, meaning that only 34.5 per cent were bulk-billed (Harris, 2016).

Private insurance is largely irrelevant to this study. Over the past decade, just over half of the Australian population has had private health insurance, and this coverage has been more concentrated at higher income levels (Australia, Private Health Insurance Administration Council, 2015; Australian Bureau of Statistics, 2013). However, only some insurance plans have covered psychotherapy services, and none of the plans have covered the full cost. Just as with co-payments under Better Access, private insurance holders are required to cover the remaining costs out-of-pocket. In this sense, access to psychotherapy as provided by private insurance plans is at best equivalent to Better Access. 
From this overview of the Australian service system, it is apparent that lowerincome Australians face either a lower price (free if providers opt to bulk-bill) or the same price (if providers charge the same co-payment) as higher-income Australians for psychotherapy services. This difference is less pronounced for non-physician providers: lower rates of bulk-billing mean that lower-income Australians are less likely to face a lower price for the services of non-physician providers than they are to face a lower price for physician providers. These differences in financial barriers would appear to make it more likely for low income Australians with mental health problems to utilize psychotherapy than higher-income Australians, and to have lower rates of unmet needs as a result. However this tendency is counterbalanced by the fact that the same co-payment is more affordable for higher-income Australians than for lower-income Australians.

This ambiguity regarding the equity impacts of Australian policy is also evident in Australian research, which has been both mixed and controversial. Since the outset of Better Access in 2006, there was concern that a Medicare-based model would create incentives for psychologists and other non-physician providers to target their services to higher-income clients who can afford co-payments. Controversy heightened when the 2011 evaluation found that inequities in access were not a significant problem, only to be criticized for basing this conclusion on too small of a sample (Hickie, Rosenberg, \& Davenport, 2011; Pirkis, Harris, Hall \& Ftanou, 2011). A more recent study concluded that utilization of Better Access services is much higher in urban than in rural areas, and much lower in areas with greater socio-economic disadvantage (Meadows, Enticott, Inder, Russell, \& Gurr, 2015). 
Notwithstanding these Australian research debates, the differences between the Canadian and Australian systems suggest that income-based inequities in access to psychotherapy may be more pronounced in Canada (see Table 11). Lower-income Canadians face either a higher price (because they are less likely to have access to employment-based benefits that cover non-physician services) or the same free price (for psychotherapy services provided free-at-point-of-delivery by physicians) as higherincome Canadians. By contrast, lower-income Australians face either a lower price (through bulk-billing) or the same price (through co-payments) as higher-income Australians. While it is true that lower-income Australians are more likely to face a copayment for non-physician than physician services given the lower rates of bulk-billing by non-physician providers, lower-income Australians do not face higher prices for psychotherapy than higher-income Australians as is the case in Canada.

Accordingly, the main hypothesis for this paper is that income-based inequities in access to psychotherapy will be more pronounced in Canada than in Australia. Utilization of non-physician psychotherapy services is expected to be more concentrated among higher-income people with mental health problems in Canada than in Australia (H1). The second hypothesis is that in both countries, inequities in the utilization of non-physician providers will be more pro-rich than inequities in utilization of physician providers (H2).

H1: Utilization of non-physician psychotherapy more pro-rich in Canada than in

\section{Australia}

H2: Utilization of non-physician providers more pro-rich than physician providers in both countries. 
Following from predictions regarding inequities in utilization (a positive indicator of access), unmet need for psychotherapy services (a negative indictor of access) is expected to be more concentrated among lower-income people with mental health problems in Canada than in Australia (H3).

H3: Unmet need for psychotherapy more pro-poor in Canada than in Australia

\section{Methodology}

Basic CIs illustrate how the share of various health and social outcomes is concentrated along the distribution of income or other indicators of socio-economic advantage, with a positive value indicating a pro-rich concentration and a negative value indicating a pro-poor concentration (O’Donnell, O’Neill, Van Ourti, \& Walsh, 2016). This study uses basic CIs to compare the distribution of access to psychotherapy and other mental health services by income in Australia and Canada. Both utilization and unmet need are included as indicators of access, and need, immigration, and various other socio-demographic variables are included as factors that contribute to variations in access (Anderson, 1995; Riegle \& Stewart, 2013). According to the guidelines set out by O’Donnell and the World Bank (2008), CIs are standardized for need and controlled for non-need variables that would introduce bias if omitted (details regarding this method can be found in the second-paper). Wagstaff CIs are often used for cross-county comparisons as they normalize differences in the mean values of binomial outcome variables; however, they are not needed for this study as the mean values are too low to require this adjustment (.112 or less, see Table 12; O’Donnell \& the World Bank, 2008; O'Donnell et al., 2016; Wagstaff, 2005). 
Before testing the hypotheses set out above, this study first assesses the degree of income-based inequity in the distribution of mental health need in Australia and Canada. This preliminary analysis establishes the importance of standardizing for need by first confirming the income gradient in mental health problems, and also assesses the comparability of mental health need in the two countries. Next, the hypotheses are tested by comparing the degree of income-based inequity in mental health service utilization (broken out by various provider types) and unmet need for psychotherapy. All CIs are standardized for need and controlling for non-need socio-demographic variables.

As a descriptive study, the results presented here describe the nature of the association between income, access, and the socio-demographic control variables that are included in the analysis. The strengths of this approach are that predictions and measurements can be made based on descriptive statistics such as regression analysis and inequality indices. However, as a descriptive study there is no claim of any causal relationships between income and access or vice versa. Questions such as whether higher income causes higher rates of utilization of psychotherapy, or whether unmet need for psychotherapy causes lower income are beyond the scope of this study.

\section{Data}

Two surveys are the sources of Canadian data: the CCHS Annual 2011-12 (for the utilization comparison) and the CCHS Mental Health (CCHS MH) 2012 (for the unmet need comparison). The CCHS Annual is a cross-sectional survey on health status, health care utilization and health determinants for the Canadian population (Statistics Canada, 2015a). It is a self-report survey with large sample (age 12+, $\mathrm{N} \sim 65,000$ annually) designed to provide reliable estimates at the health region level in all provinces and 
territories. Both single year and two-year versions (which roll up two years together) are released by Statistics Canada. Three sample frames are used to select households, with approximately half of the sample based on the multistage stratified cluster design used in the Canadian Labour Force Survey, half based on a list frame of telephone numbers, and $1 \%$ on Random Digit Dialing. While the survey excludes several population groups, some of these exclusions are helpful for the purposes of this study. For example, the CCHS Annual excludes groups (such as members of the Canadian Forces and people living on reserves or in prisons) who are eligible for federally-funded mental health services that fall outside of Medicare. On the other hand, the CCHS Annual also excludes people who live in institutional settings such as long-term care and hospitals, thus limiting the relevance of this study to important population groups that are covered by public health insurance.

The CCHS MH 2012 (age 15+, N=25,113 from all ten provinces but none of the territories) is a more in-depth survey regarding mental health issues, attitudes and service utilization (Statistics Canada, 2013). The CCHS MH 2012 excludes the same populations as the CCHS Annual.

The source of Australian data is the Australian NSMHWB 2007. Like the CCHS MH 2012, the NSMHWB 2007 is a cross-sectional, self-report survey regarding mental disorders and service utilization (Australian Bureau of Statistics, 2009). However the NSMHWB 2007 has a smaller sample of 8,800 Australians between 16-85 years of age. The NSMHWB 2007 also excludes people living in institutional settings, but does not exclude indigenous people or members of the military. 
There are two key reasons why the NSMHWB 2007 is compared with the CCHS Annual 2011-12 and the CCHS MH 2012, rather than with CCHS 2007-08 or with the more recent CCHS Annual from 2013-14 and 2015. First, the combination of the two CCHS from 2012 and 2011-2012 provides the best set of comparable variables to NSMHWB 2007. As the CCHS MH has not been replicated since 2012, it was not possible to match the CCHS Annual 2013-14 or the CCHS 2015 with more recent $C C H S$ $M H$ data. Second, as noted above, the NSMHWB 2007 and the combination of CCHS Annual 2011-12 and CCHS MH 2012 provide baseline data for the period just before significant policy developments in both countries.

Four kinds of variables are needed to apply O'Donnell and the World Bank's (2008) method for calculating need-standardized income-based inequities in access to mental health services: outcome, need, non-need (control), and ranking variables. Descriptive statistics for Canada and Australia are presented below, along with narrative descriptions of how the variables are coded to make the data from the $C C H S$ and the NSMHWB as comparable as possible, and how missing variables are addressed.

Outcome variables. This study includes two kinds of outcome variables from both CCHS and NSMHWB: utilization of professional services for mental health problems, and unmet need for mental health care (see Table 12 for frequencies). Utilization variables are compared between CCHS Annual 2011-12 and NSMHWB 2007. These variables are distinguished by the provider of care: general practitioners (GPs), psychiatrists, psychologists, and other mental health professionals. As the Australian survey does not collect specific data on social workers, the "other mental health professional" variable from the Australian survey is compared with a recoded "other 
mental health professional" variable that combines the social worker and other mental health professional variables from CCHS Annual 2011-12. Data from CCHS MH 2012 was not used for the utilization variables because the addition of substance use to the survey questions is not comparable to the NSMHWB. While CCHS Annual 2011-12 asks about consultations for "emotions and mental health" and NSMHWB 2007 asks about consultations for "mental health," CCHS MH 2012 asks about consultations for "emotions, mental health, or use of alcohol or drugs." As substance use is more evenly distributed across the income gradient, this addition changes the analysis of income-based inequity.

Unmet need for psychotherapy is compared using data from NSMHWB 2007 and CCHS MH 2012. Both surveys collected the same variables on unmet need (in the past 12 months) for mental health services, broken out to all mental health services, counselling, information and medication. Here the focus is on unmet need for counselling, which can be reasonably equated with unmet need for psychotherapy. Dichotomous variables were created, coding unmet need or partially met need as 1 , and met need or no need as 0 . Unmet need includes both respondents who accessed psychotherapy but did not receive enough, and respondents who needed psychotherapy but did not access it. While it is not an indicator of inequity per se, it is worth noting the high rates of unmet need for psychotherapy in both countries ( $4.5 \%$ of both samples; see Table 12$)$.

Need variables. This study uses age, sex, and self-reported mental health as need variables for both Australia and Canada (see Table 13 for frequencies). The age range for both of the CCHS surveys has been constrained to align with the 16-85 age range of the NSMHWB. This adjustment dropped people aged 12-15 and over 85 from the CCHS 
Annual 2011-12 and people who are 15 years of age and people who are over 85 from the CCHS MH 2012. The three samples are broadly similar, although the Australian sample is a bit younger. There is also some variation in the reporting of poor/fair mental health (8.7\% in NSMHWB, 5.8\% in CCHS Annual 2011-12, and 7.8\% in CCHS MH 2012).

While other mental health need variables were considered, self-reported mental health was selected for several reasons. First, it is the only specific mental health variable that is collected by both $C C H S$ and $N S M H W B$ and by all of the provinces in each of the CCHS surveys; collection is less comprehensive for data on the prevalence of meeting screening criteria for mental disorders, or for the Kessler distress scale. Second, selfreported mental health (with poor or fair indicating need, and good, very good and excellent indicating no need) is theoretically relevant in so far as it is useful for capturing a broader range of mental health needs that could benefit from access to psychotherapy prior to the onset of diagnosable symptoms. Finally, the sensitivity analysis in the second paper found that CIs standardized for self-reported mental health have similar values to those standardized for both distress and any mood disorder.

Non-need variables. Four socio-demographic non-need variables are included in this comparative analysis: education, immigration, residence in non-urban areas, and equivalized household income (see Tables 14 and 15 for frequencies). These four variables have the potential to play a role in both mental health need and access to mental health care, and could, if not controlled for, potentially bias the results of the probit. For example if income were not included as a non-need variable, the coefficients on selfreported mental health (the key need variable) would not only measure the relationship 
between need and access to mental health services (the outcome variables), but would also include the effect of income on both self-reported mental health and access.

The first three non-need variables are coded as follows. To align the CCHS with the respondent-only educational attainment categories in $N M H S W B$, education is divided into four dummy variables according to the highest level of educational attainment by the respondent: "less than secondary school", "secondary school", "post-secondary qualification, not university", and "post-secondary qualification, university". This approach results in a much lower percentage of the sample in the highest educational attainment category for the comparative analysis (28\%) than in the Canada-only analysis (78-80\%), in which data on educational attainment is collected for households and the highest level includes all kinds of post-secondary graduates (non-university and university). The differences in educational attainment (with $31 \%$ having less than secondary education in the $N S M H W B$ vs $15-17 \%$ in the $C C H S$ ) are consistent with OECD findings (OECD, 2017). As with the Canada-only analysis, immigration is coded as a dichotomous variable, coded as one for people born outside of Canada or Australia. Non-urban refers to people living outside of urban areas (urban or secondary core for CCHS and major or other urban for $N S M H W B$ ). The differences in non-urban residence (34\% for $N S M H W B$ vs $27-29 \%$ for $C C H S$ ) is consistent with higher percentage of urban dwellers in Canada than in Australia. The fourth non-need variable, equivalized household income, is also the ranking variable and is described below.

Ranking variable. This comparative analysis uses equivalized household income both as a non-need variable for the calculation of need-standardized predicted access, and as a ranking variable for the calculation of CIs (see Table 15 for means and Gini 
coefficients). The household income variables are transformed in three ways. First, household income has been equivalized (divided by the square root of household size) to account for differences in the purchasing power of different-sized households (OECD, n.d.). The household size used for the equivalization formula has been capped at 8 to match the Australian data. Second, annual $C C H S$ equivalized household income has been divided by 52 to obtain weekly amounts as per $N S M H W B$. Third, for use as a ranking variable, a random unique amount (the observation number divided by 10000 , with values ranging from .000001 to 12 ) has been added to equivalized household income. This transformation breaks ties between identical income values, thus ensuring that each income value is unique and allowing for the effective use of household income as ranking variable.

Missing values. Observations with missing values from need and non-need variables have been dropped from the study (details for each variable can be found in Tables 12-15). Missing values for CCHS Annual 2011-12, which has a total sample size of 65,000 annually, range from a handful to larger numbers such as 5,573 missing values for each of the utilization variables and 4,639 missing values for education. Dropping observations that have missing values for some variables is most likely to have led to an underestimation of income-based inequity in access for the Canadian data, as these missing values are generally concentrated at lower income levels; the inclusion of more lower-income respondents in the analysis would likely have strengthened the findings in the direction of greater inequity. There are no missing household income variables in CCHS, because CCHS uses an imputation process to generate a full set of household income values (Statistics Canada, n.d.). 
Unlike the CCHS, the NSMHWB did not use an imputation process for its household income variable. The NSMHWB has next to no missing values for any variable except for 1,041 missing household income values. As the NSMHSB sample size is only 8,800 , this raises the possibility of considerable bias. While it is not possible to know the income distribution of these missing values, an analysis of their distribution across the four levels of educational attainment suggests that the missing income values are fairly evenly distributed across the social gradient. This even distribution suggests that while the missing values for self-reported mental health, education and immigration in the CCHS data (which tend to be concentrated at lower income levels) may underestimate income-based inequity, the potential for a similar bias in the Australian survey data is lower.

\section{Results}

The results confirm that there is indeed an income gradient in the distribution of mental health need in both countries, with a similarly negative (pro-poor) CI value in Australia (-.267) and Canada (-.235 and -.238; see Table 16). This result underscores the importance of first standardizing for need before measuring income-based inequity in access to mental health services. For example, to be equitable, utilization should be as concentrated at lower income levels as need, while inequitable utilization is less concentrated at lower income levels than need.

The next set of results compares the degree of income-based inequity in Canada and Australia in the utilization of the services of various types of mental health professionals, after standardizing for need and controlling for non-need demographic variables (see Table 17 for summary results, and Tables C1-C8 for further details). As 
predicted in H1, the utilization of non-physician psychotherapy is more pro-rich in Canada than in Australia. This finding is strongest for psychologists, with the Canadian need-standardized CI (CIst) of +.100 compared to the Australian CIst of +.018 (the result for psychologists is not statistically significant in Australia at $p<.59)$. For utilization of other non-physician providers such as social workers, the CIst is not pro-rich in either country, but is more pro-poor in Australia (CIst of -.164) than in Canada (CIst of -.025).

Similarly, the prediction in $\mathrm{H} 2$ holds for psychologists but not for other nonphysician providers. As predicted in $\mathrm{H} 2$, the utilization of non-physician providers is more pro-rich than physician providers in both countries, but only for psychologists and not for other non-physician providers. For example, the need-standardized CIs for utilization of GPs, psychologists and other mental health providers in Australia are -.094, +.018 , and -.164 respectively, and in Canada are $-.023,+.100$ and -.025 respectively.

The last set of results compares the income distribution of unmet need for psychotherapy in Australia and Canada. Specifically, to what extent is unmet need for psychotherapy even more concentrated at lower income levels than the distribution of mental health needs? Summary results can be found in Table 18, with more detailed findings in Tables C9-C10. The results do not support $\mathrm{H} 3$, which predicted that unmet need for psychotherapy (as a negative indictor of access) would be more pro-poor under Canada's two-tier system than in Australia, with its Better Access initiative. Rather, the need-standardized CI for unmet need for psychotherapy is more pro-poor in Australia than in Canada (-.057 vs -.021 , although with $\mathrm{p}<.208$ the CIst is not significant for Canada). 


\section{Discussion}

The results of this comparative analysis are mixed. The first two hypotheses predicting more inequitable distributions of service utilization in Canada than in Australia (H1) and for non-physicians as opposed to physicians (H2) are confirmed (although only for psychologists). However, unmet need for psychotherapy is not found to be more inequitable in Canada as predicted in H3, but rather to be more inequitable in Australia. Further, the Australian results are more pro-poor across the board, an outcome that was not foreseen. Possible explanations for these mixed results, implications for future research, and policy implications are discussed below.

The hypotheses regarding utilization are supported, but only for psychologists rather than for all non-physician providers. After standardizing for the higher concentration of mental health need at lower income levels, the utilization of psychologists is still more concentrated at higher income levels (pro-rich) in Canada than in Australia as predicted in H1. The utilization of psychologist services is more also more pro-rich in both countries than the utilization of mental health services provided by physicians, confirming H2. While no causal inferences can be drawn from the descriptive CI statistics used in this study, these results nevertheless suggests that lower-income people's facing a higher price in Canada than in Australia for psychologist services may contribute to higher concentrations of utilization at higher levels of income. Further, the lack of either public or employment-based insurance coverage for psychologist services in Canada, and the lower bulk billing rates for psychologists in Australia, would seem to contribute to lower-income service users facing higher financial barriers for psychologist services than for physician services. The finding that these hypotheses do not hold for 
other non-physician service providers likely stems from a higher concentration of psychologists in private practice, where financial barriers are more salient, and a higher concentration of non-physician providers such as social workers in public sector settings such as hospitals (Hunsley, Ronson \& Cohen, 2013).

The results regarding unmet need for psychotherapy are the opposite of the prediction in H3. Rather than finding more unmet need for psychotherapy at lower income levels than would be predicted by the higher concentration of mental health needs overall in Canada, the study finds a more pro-poor distribution of unmet need for psychotherapy in Australia. In other words, unmet need for psychotherapy does not follow the same pattern as service utilization. Even through lower-income Australians would seem to face fewer financial barriers to accessing psychotherapy than their Canadian counterparts, they would also seem to have higher rates of unmet need.

This unexpected result is illustrative of an unforeseen and broader finding, namely that the Australian results are more pro-poor than the Canadian results for every variable. Whether for the utilization of psychiatrists, psychologists, GPs, or other mental health service providers, or for unmet need for psychotherapy, the Australian CIs are either less positive or more negative. This finding calls for some additional interpretation of the main results. For example, while $\mathrm{H} 2$ holds to the extent that the utilization of psychological services has a more pro-rich distribution than the utilization of physician services in both countries, in Canada the need-standardized CI is strongly positive for psychologists (+1.00) and almost equitable for GPs (-.023; see Table 17). In Australia, however, the need-standardized $\mathrm{CI}$ is nearly equitable for psychologists (+.018) and strongly pro-poor for GPs (-.094). The reasons for the more pro-poor results in Australia 
(as opposed to in Canada) are unclear. In Australia in 2007, why would use of mental health services (unless provided by psychologists) exceed need among lower-income people? Further, if more low-income people are using services, why do they also have greater unmet need?

Some possible explanations can be ruled out. First, the more pro-poor results in Australia are not attributable to differences between the Australian and Canadian samples regarding age, sex, or self-reported mental health (the need variables), or regarding educational attainment, immigration levels, rural residence, or equivalized household income (the non-need variables). This conclusion is evident from the fact that the differences between Australian and Canadian results originate in the actual CI values, rather than in the need-predicted or need-standardized CI values. For example, the actual CI for GP utilization in Australia is -.151 compared with -.074 in Canada, and the actual CI for utilization of other mental health professionals is -.218 in Australia and -.079 in Canada (see Tables C1, C2, C7 and C8).

Second, the potential bias arising from missing values can also be ruled out. As discussed above, the missing $C C H S$ values most likely resulted in an underestimation of inequity; the Canadian CIst for unmet need may have been more pro-poor than the Australian CIst if there were fewer missing values in CCHS. However, the missing values for $N S M H W B$ are less likely to have biased the results; if there were fewer missing values, the puzzling combination of high rates of service utilization and unmet need at lower income levers in Australia would likely stand.

Policy differences hold some promise as explanations. Canada in 2011 and 2012 was holding steady with its long-standing two-tier policy. However, there is some 
possibility that the introduction of Better Access in 2007 provided incentives for lowerincome Australians to seek out psychotherapy in way that both drove up utilization rates and unmet need. Better Access provided more affordable access to psychotherapy for the first time to a population with long-high rates of unmet need, and provided GPs with new referral options. This high-profile reform could have had a backlog effect, driving up utilization rates among lower-income Australians such that use outstripped need, while at the same time exacerbating unmet need for psychotherapy to the extent that demand from lower-income Australians exceeded supply in the first phase of implementation.

Moreover, the introduction of Better Access followed six years after the 2000 launch of beyondblue, a major anti-stigma initiative in Australia (beyondblue, n.d.). As stigma decreased and more people became willing to seek help, both demand and unmet need could have been driven up across the population.

Further research and data collection would need to be undertaken to test this backlog effect hypothesis. CIs of the same variables from the 1997 NSMHWB could be calculated to see if the distributions of utilization and unmet need were more similar to Canada circa 2012 (i.e. less pro-poor) prior to the introduction of Better Access. If the Australian government were to conduct a new $N S M H W B$, it would be possible to see whether the pro-poor results from 2007 evened out over time. If this new survey had a larger sample size, and if the Canadian government also collected data on unmet need for psychotherapy from a larger sample, it might be possible to have enough statistical power to confirm the results that are not statistically significant in this study (i.e. needstandardized CIs for utilization of psychologists in Australia, and for unmet need for psychotherapy in Canada). Comparative analysis could be undertaken of income-based 
inequities in access to psychotherapy using Canadian and Australian administrative as opposed to survey data, to the extent that matching administrative data can be found. Finally, qualitative research could be undertaken with Australian service users, service providers, and other stakeholders to explore possible explanations for the pro-poor concentrations of both utilization and unmet need in 2007.

There are several policy implications of this study. First, by removing financial barriers that see lower-income Canadians facing the highest prices for psychotherapy, a Better Access-like reform has the potential to reduce (but not necessarily eliminate) income-based inequities in access. Second, even 11 years after the introduction of Better Access and as the fifth national mental health plan is launched in Australia, there would appear to be significant gaps in knowledge regarding such inequities. Australia studies on inequities in access to psychotherapy have been characterized by controversies over both methodology and policy implications. Results from Canadian studies have also been mixed. Accordingly, both Canada and Australia would do well to strengthen their monitoring of income-based inequities in access, including both utilization and unmet need rather than just one or the other. These monitoring efforts should be supported by data collection from a range of sources, including surveys, administrative data and qualitative research.

Canada is poised to invest $\$ 5 \mathrm{~B}$ over the next ten years to improve access to mental health services. To the extent that a backlog effect may have indeed occurred in Australia upon the introduction of Better Access in 2006, Canada would be wise to prepare for a possible surge of both utilization and unmet need as it rolls out new efforts to improve access to psychotherapy. Were such a surge to be more concentrated at lower 
income levels than even need would predict, surely this could only be a good thing given the long-standing over-representation of lower-income Canadians among those living with mental health problems and illnesses. 


\section{References}

Anderson, R. M. (1995). Revisiting the behavioral model and access to medical care: Does it matter? Journal of Health and Social Behavior, 36, 1-10.

Australia. (n.d.) Better Access to Psychiatrists, Psychologists and General Practitioners through the MBS initiative [website]. Retrieved from http://www.health.gov.au/internet/main/publishing.nsf/Content/mental-ba

Australia. (2006). Better access to mental health care: Questions and answers [website]. Canberra: Author. Retrieved from http://www.health.gov.au/internet/main/publishing.nsf/Content/coag-mentalq\&a.htm

Australia. (2017a). Private health insurance rebate [website]. Canberra: Author. Retrieved from https://www.ato.gov.au/individuals/medicare-levy/private-healthinsurance-rebate/

Australia. (2017b). Medicare benefits schedule book 2017. Canberra: Author. Retrieved from http://www.health.gov.au/internet/main/publishing.nsf/Content/AnnualMedicare-Statistics

Australia. (2017c). Annual Medicare statistics 1984-85 to 2016-17. Canberra: Author. Retrieved from http://www.health.gov.au/internet/main/publishing.nsf/Content/Annual-Medicare$\underline{\text { Statistics }}$

Australia, Private Health Insurance Administration Council. (2015). Membership and coverage. Canberra: Author. Retrieved from http://www.apra.gov.au/PHI/PHIACArchive/Documents/MembCoverage-Mar15.pdf 
Australian Bureau of Statistics. (1998). Mental health and wellbeing: profile of adults, Australia, 1997. Canberra: Australian Bureau of Statistics. Retrieved from http://www.ausstats.abs.gov.au/ausstats/subscriber.nsf/0/CA25687100069892CA 25688900233CAF/\$File/43260_1997.pdf

Australian Bureau of Statistics. (2009). National Survey of Mental Health and WellBeing: Users' guide 2007 [website]. Retrieved from http://www.abs.gov.au/ausstats/abs@.nsf/PrimaryMainFeatures/4327.0?OpenDoc $\underline{\text { ument }}$

Australian Bureau of Statistics. (2013). Australian Health Survey: Health service usage and health-related actions, 2011-12: Private health insurance. Canberra: Author. Retrieved from http://www.abs.gov.au/ausstats/abs@.nsf/lookup/E334D0A98272E4DCCA257B3 9000F2DCF? opendocument

Australian Psychological Society. (2017). Medicare rebates for mental health services provided by psychologists: Information for clients [website]. Retrieved from https://www.psychology.org.au/medicare/fact_sheet/

beyondblue. (n.d.). Our history [website]. Retrieved from https://www.beyondblue.org.au/about-us/who-we-are-and-what-we-do/ourhistory2

Canadian Life and Health Insurance Industry. (2016). Canadian life and health insurance facts [website]. Toronto: Author. Retrieved from https://www.clhia.ca/domino/html/clhia/CLHIA_LP4W_LND_Webstation.nsf/res ources/Factbook_2/\$file/2016+CLHIA+Factbook+ENG.pdf 
Council of Australian Governments Health Council. (2017). The fifth national mental health and suicide prevention plan. Canberra: Commonwealth of Australia, Department of Health. Retrieved from https://www.coaghealthcouncil.gov.au/Portals/0/Fifth\%20National\%20Mental\%2 0Health\%20and\%20Suicide\%20Prevention\%20Plan.pdf

Esmail, N., \& Bacchus, B. (2015). Drug coverage for low income families: The Canadian reality and lessons from Switzerland and the Netherlands. Fraser Institute.

Gagnon, M.-A., Hébert, G. (2010). The economic case for universal pharmacare: Costs and benefits of publicly funded drug coverage for all Canadians. Ottawa; Montréal: Canadian Centre for Policy Alternatives ; Institut de recherche et d'information socio-économiques.

Harris, M. (2016). Psychological therapy services in Australia [Powerpoint slides]. Presented at Sharing learnings from early implementation of stepped care: A PHN collaborative workshop, Canberra. Retrieved from http:/qcmhr.uq.edu.au/wp-content/uploads/2017/02/Session-6_MeredithHarris.pdf

Hickie, I. B., Rosenberg, S., \& Davenport, T. A. (2011). Australia's Better Access Initiative: Still Awaiting Serious Evaluation? Australian \& New Zealand Journal of Psychiatry, 45(10), 814-823.

Hosseinpoor, A. R., Itani, L., \& Petersen, P. E. (2012). Socio-economic Inequality in Oral Healthcare Coverage: Results from the World Health Survey. Journal of Dental Research, 91(3), 275-281. 
Hunsley, J., Lee, C. M., \& Aubry, T. (1999). Who uses psychological services in Canada? Canadian Psychology/Psychologie Canadienne, 40(3), 232-240.

Hunsley, J., Ronson, A., \& Cohen, K. R. (2013). Professional psychology in Canada: A survey of demographic and practice characteristics. Professional Psychology: Research and Practice, 44(2), 118-126.

Jiménez-Rubio, D., Smith, P. C., \& Van Doorslaer, E. (2008). Equity in health and health care in a decentralised context: Evidence from Canada. Health Economics, 17(3), $377-392$.

Lewis, J. D. (2013). Mental health services in Canada: Building a model of mental health care utilization (Unpublished doctoral dissertation). University of Regina, Regina. Retrieved from http://ourspace.uregina.ca/bitstream/handle/10294/3842/Lewis John Dufton 20 0230739 PhD ClinPsyc Fall2013.pdf?sequence $=1$

Meadows, G. N., Enticott, J. C., Inder, B., Russell, G. M., \& Gurr, R. (2015). Better access to mental health care and the failure of the Medicare principle of universality. The Medical Journal of Australia, 202(4), 190-194.

Mental Health Commission of Canada. (2012). Changing directions, changing lives: The mental health strategy for Canada. Calgary, AB: Author.

O’Donnell, O., O’Neill, S., Van Ourti, T., \& Walsh, B. (2016). conindex: Estimation of concentration indices. Stata Journal, 16(1), 112-138.

O’Donnell, O. \& World Bank (Eds.). (2008). Analyzing health equity using household survey data: a guide to techniques and their implementation. Washington, D.C: World Bank. 
OECD. (n.d.). What are equivalence scales? Project on Income Distribution and Poverty. Paris: Author. Retrieved from http://www.oecd.org/eco/growth/OECD-NoteEquivalenceScales.pdf

OECD. (2015a). OECD reviews of health care quality: Australia 2015: Raising standards. Paris: Author. Retrieved from http://www.oecd-ilibrary.org/social-issuesmigration-health/oecd-reviews-of-health-care-quality-australia2015 9789264233836-en

OECD. (2015b). Health at a glance: How does Australia compare? Paris: Author. Retrieved from https://www.oecd.org/australia/Health-at-a-Glance-2015-KeyFindings-AUSTRALIA.pdf

OECD. (2017). Adult education level (indicator). Paris, Author. Retrieved from https://data.oecd.org/eduatt/adult-education-level.htm

Piketty, T. (2013). Capital in the twenty-first century. Cambridge Massachusetts: The Belknap Press of Harvard University Press.

Pirkis, J., Harris, M., Hall, W., \& Ftanou, M. (2011). Evaluation of the Better Access to Psychiatrists, Psychologists and General Practitioners through the Medicare Benefits Schedule initiative: Summative evaluation. Melbourne: Centre for Health Policy, Programs and Economics, University of Melbourne.

Riegle, A. L., \& Steward, S. D. (2013). Health care access and utilization among the poor. In M. K. Fitzpatrick (Ed.), Poverty and health: a crisis among America's most vulnerable (pp. 183-208). Santa Barbara, California: Praeger.

Statistics Canada. (n.d.). Income imputation for the CCHS. Ottawa: Author. 
Statistics Canada. (2013). Canadian Community Health Survey - Mental Health:

Detailed information for 2012 [website]. Retrieved from

http://www23.statcan.gc.ca/imdb/p2SV.pl?Function=getSurvey\&SDDS=5015

Statistics Canada. (2015a). Canadian Community Health Survey - Annual Component:

Detailed information for 2015 [website]. Retrieved from

http://www23.statcan.gc.ca/imdb/p2SV.pl?Function=getSurvey\&Id=164081

Sunderland, A. \& Findlay, L. C. (2013). Perceived need for mental health care in Canada:

Results from the 2012 Canadian Community Health Survey-Mental Health.

Statistics Canada Health Reports, 24(9), 3-9.

Van Doorslaer, E., Masseria, C. \& the OECD Health Equity Research Group Members. (2004). Income-related inequality in the use of medical care in 21 OECD countries. OECD Health Working Paper \#14. Paris: OECD.

Vasiliadis, H.-M., Tempier, R., Lesage, A., \& Kates, N. (2009). General practice and mental health care: determinants of outpatient service use. Canadian Journal of Psychiatry. Revue Canadienne De Psychiatrie, 54(7), 468-476.

Zhang, X., Wu, Q., Shao, Y., Fu, W., Liu, G., \& Coyte, P. C. (2015). Socioeconomic inequities in health care utilization in China. Asia-Pacific Journal of Public Health, 27(4), 429-438. 
Table 11 Price Faced by Service Users

Price Faced by Lower-Income vs Higher-Income Service Users

$\underline{\text { Canada }}$

$\underline{\text { Australia }}$

Psychotherapy

By physician $\quad$ SAME (free) LOWER (free) $\rightarrow \rightarrow$ SAME (co-payment)*

By non-physician $\quad$ HIGHER (out-of-pocket) $\quad$ LOWER (free) $\rightarrow$ SAME (co-payment)*

*Note that the same co-payment will pose more of a financial barrier to lower-income than to higher-income service users; $\rightarrow \rightarrow$ the two arrows symbolize that lower-income service users are more likely to be bulk-billed by physician than non-physician providers, creating a wider range for physician services than for non-physician services. 
Table 12 Outcome Variable Frequencies

Outcome Variable Frequencies: Service Utilization and Unmet Need (12 mos)*

CCHS Annual

$\underline{\text { NSMHWB } 2007}$

$\underline{2011-12}$

CCHS MH 2012

$\%$ of weighted sample

$\%$ of weighted

sample

$\%$ of weighted

sample

$\underline{\text { Utilization }}$

GP

8.3

7.3

NA

Psychiatrist

2.3

2.6

NA

Psychologist

3.7

2.9

NA

Other ${ }^{\#}$

3.3

NA

$\underline{\text { Unmet need }}$

Psychotherapy

4.5

NA

4.5

*Missing values from all outcome variables were dropped, including 5,573 missing values for the utilization variables from CCHS Annual 2011-12, and 102 missing values for unmet need for psychotherapy (counselling) from $C C H S M H$. The numbers were too low to report missing values from the NSMHWB utilization variables.

"NSMHWB - other is "other mental health professional"; CCHS - other is "other mental health professional" and/or "social workers or counsellor". 
Table 13 Need Variables Frequencies

Need Variables Frequencies: Age, Sex, Mental Health Need

\begin{tabular}{lccc}
\hline Need & NSMHWB 2007 & $\frac{\text { CCHS Annual }}{2011-12}$ & CCHS MH 2012 \\
variable & \% of weighted sample & $\begin{array}{c}\text { \% of weighted } \\
\text { sample }\end{array}$ & $\begin{array}{c}\text { \% of weighted } \\
\text { sample }\end{array}$ \\
\hline Age 16-24 & 14.5 & 14.9 & 14.6 \\
Age 25-34 & 17.7 & 17.0 & 16.3 \\
Age 35-44 & 20.1 & 17.3 & 17.6 \\
Age 45-54 & 18.1 & 18.7 & 19.1 \\
Age 55-64 & 14.4 & 16.8 & 16.3 \\
Age 65-74 & 9.4 & 10.1 & 10.6 \\
Age 75-85 & 6.2 & 5.2 & 5.8 \\
Female & 50.3 & 50.8 & 50.7 \\
$\begin{array}{l}\text { Male } \\
\text { Poor/fair }\end{array}$ & 49.7 & 49.2 & 49.3 \\
mental \\
health*
\end{tabular}

* Missing values for self-reported mental health were dropped from the analysis $(2,064$ for CCHS Annual 2011-12, and 19 for CCHS MH 2012). 
Table 14 Non-Need (Control) Variable Frequencies

Non-Need (Control) Variable Frequencies: Education, Immigration, Non-Urban, Household Income*

\begin{tabular}{|c|c|c|c|}
\hline & NSMHWB 2007 & $\frac{\text { CCHS Annual }}{\underline{2011-12}}$ & $\underline{C C H S M H} 2012$ \\
\hline $\begin{array}{l}\text { Non-need } \\
\text { variable }\end{array}$ & $\%$ of weighted sample & $\begin{array}{c}\% \text { of weighted } \\
\text { sample }\end{array}$ & $\begin{array}{c}\% \text { of weighted } \\
\text { sample }\end{array}$ \\
\hline $\begin{array}{l}\text { Educ: Less } \\
\text { than } \\
\text { secondary }\end{array}$ & 31.0 & 15.0 & 16.5 \\
\hline $\begin{array}{l}\text { Educ: } \\
\text { Secondary }\end{array}$ & 13.7 & 24.3 & 23.2 \\
\hline $\begin{array}{l}\text { Educ: Post- } \\
\text { secondary, } \\
\text { not univ. }\end{array}$ & 24.0 & 33.0 & 32.5 \\
\hline $\begin{array}{l}\text { Educ: Post- } \\
\text { secondary, } \\
\text { univ. }\end{array}$ & 31.3 & 27.7 & 27.8 \\
\hline Immigrant & 26.3 & 23.5 & 25.3 \\
\hline Non-Urban & 34.4 & 28.6 & 27.3 \\
\hline
\end{tabular}

*4,639 missing values for education and 4,256 missing values for immigration were dropped from CCHS 2011-12, and 138 missing values for education, 177 for immigration and 19 for non-urban were dropped from CCHS MH 2012. 
Table 15 Equivalized Household Income

Equivalized Household Income: Non-Need (Control) and Ranking Variable*

\begin{tabular}{|c|c|c|c|}
\hline & \multicolumn{3}{|c|}{$\underline{C C H S \text { Annual }}$} \\
\hline & NSMHWB 2007 & $\underline{2011-12}$ & CCHS MH 2012 \\
\hline & weighted sample & weighted sample & weighted sample \\
\hline $\begin{array}{l}\text { Mean } \\
(\text { weekly) }\end{array}$ & 1,059 & 980 & 962 \\
\hline Gini & .414 & .388 & .387 \\
\hline
\end{tabular}

*1,041 missing income values were dropped from NSMHWB

${ }^{\#}$ NSMHWB weekly equivalized household income, 2007 AUD\$; CCHS Annual equivalized household income divided by 52, 2011-12 CAD\$; in 2007, 1 CAD\$ equaled \$1.11 AUS\$ and the Australian Purchasing Power Parity (PPP) to 1 CDN\$ was 1.176; in 2011, 1 CAD\$ equaled .98 AUD\$ and the Australia PPP to 1 CDN\$ was 1.212. 
Table 16 Concentration Indices for Self-Reported Mental Health

Concentration Indices for Self-Reported Poor or Fair Mental Health

\begin{tabular}{lcc}
\hline & CI & p-value \\
\hline NSMHWB 2007 & -.267 & .000 \\
CCHS Annual 2011-12 & -.258 & .000 \\
CCHS MH 2012 & -.235 & .000 \\
\hline
\end{tabular}


Table 17 CIs for Utilization

Need-Standardized CIs for Utilization of Professional Services*

\begin{tabular}{|c|c|c|c|c|c|c|}
\hline & \multicolumn{3}{|c|}{$\underline{N S M H W B} 2007$} & \multicolumn{3}{|c|}{ CCHS Annual 2011-12 } \\
\hline & Mean & $\mathrm{CI}_{\mathrm{st}}$ & $\mathrm{p}$-value & Mean & $\mathrm{CI}_{\mathrm{st}}$ & $\mathrm{p}$-value \\
\hline GP & .083 & -.094 & .000 & .073 & -.023 & .000 \\
\hline Psychiatrist & .023 & -.185 & .000 & .024 & -.049 & .000 \\
\hline Psychologist & .037 & +.018 & .590 & .029 & +.100 & .000 \\
\hline Other & .023 & -.164 & .000 & .033 & -.025 & .006 \\
\hline
\end{tabular}

*Need variables - age, sex, self-reported mental health; control variables - immigration, education, non-urban and equivalized household income. 
Table 18 CIs for Unmet Need for Psychotherapy

Need-Standardized CIs for Unmet Need for Psychotherapy (past $12 \mathrm{mos}$ )*

\begin{tabular}{cccccccc}
\hline & \multicolumn{3}{c}{$\frac{N S M H W B 2007}{2}$} & & \multicolumn{3}{c}{ CCHS Annual 2011-12 } \\
& Mean & $\mathrm{CI}_{\text {st }}$ & p-value & Mean & $\mathrm{CI}_{\text {st }}$ & p-value \\
\hline Psychotherapy & .045 & -.057 & .049 & .045 & -.021 & .208 \\
\hline
\end{tabular}

*Need variables - age, sex, self-reported mental health; control variables - immigration, education, non-urban and household income. 


\section{Appendix C: Detailed Access Tables}

Notes for all:

All values are weighted.

Need variables - age, sex, self-reported mental health; control variables - immigration, education, non-urban and household income. 
Table C 1 NSMHWB 2007: GPs

NSMHWB 2007: Need-Standardized Utilization of GPs for Mental Health Problems (12 mos) $n=7799$

\begin{tabular}{lccc}
\hline \%tile & \multicolumn{3}{c}{ Probit with controls } \\
Poorest $10 \%$ & Actual & Need-predicted & Need-standardized \\
\hline $2^{\text {nd }}$ decile & .1325 & .0966 & .1157 \\
$3^{\text {rd }}$ decile & .1045 & .0885 & .0958 \\
$4^{\text {th }}$ decile & .0944 & .0824 & .0918 \\
$5^{\text {th }}$ decile & .0706 & .0818 & .0685 \\
$6^{\text {th }}$ decile & .0810 & .0816 & .0792 \\
$7^{\text {th }}$ decile & .1061 & .0838 & .1020 \\
$8^{\text {th }}$ decile & .0693 & .0734 & .0757 \\
$9^{\text {th }}$ decile & .0595 & .0699 & .0694 \\
Richest $10 \%$ & .0633 & .0743 & .0688 \\
Mean & .0458 & .0655 & .0601 \\
CI & .0828 & .0798 & .0828 \\
Standard error & -.1514 & -.0594 & -.0942 \\
p-value & .0217 & .0069 & .0206 \\
\hline
\end{tabular}


Table C 2 CCHS Annual 2011-12: GPs

CCHS Annual 2011-12: Need-Standardized Utilization of GPs for Mental Health Problems (12 mos) $n=108,623$

\begin{tabular}{lccc}
\hline & & Probit with controls & \\
\hline Poorile & Actual & Need-predicted & Need-standardized \\
\hline $2^{\text {nd }}$ decile & .1108 & .0930 & .0897 \\
$3^{\text {rd }}$ decile & .0761 & .0748 & .0731 \\
$4^{\text {th }}$ decile & .0735 & .0743 & .0709 \\
$5^{\text {th }}$ decile & .0734 & .0710 & .0741 \\
$6^{\text {th }}$ decile & .0659 & .0695 & .0682 \\
$7^{\text {th }}$ decile & .0593 & .0669 & .0642 \\
$8^{\text {th }}$ decile & .0744 & .0688 & .0774 \\
$9^{\text {th }}$ decile & .0749 & .0684 & .0783 \\
Richest $10 \%$ & .0716 & .0678 & .0756 \\
Mean & .0542 & .0628 & .0632 \\
CI & .0734 & .0718 & .0734 \\
Standard error & -.0736 & -.0515 & -.0232 \\
p-value & .0062 & .0016 & .0060 \\
\hline
\end{tabular}


Table C 3 NSMHWB 2007: Psychiatrists

NSMHWB 2007: Need-Standardized Utilization of Psychiatrists for Mental Health Problems (12 mos) $n=7799$

\begin{tabular}{lccc}
\hline \%tile & \multicolumn{3}{c}{ Probit with controls } \\
\cline { 2 - 3 } Poorest $10 \%$ & Actual & Need-predicted & Need-standardized \\
$2^{\text {nd }}$ decile & .0494 & .0278 & .0432 \\
$3^{\text {td }}$ decile & .0456 & .0246 & .0425 \\
$4^{\text {th }}$ decile & .0140 & .0224 & .0132 \\
$5^{\text {th }}$ decile & .0168 & .0218 & .0165 \\
$6^{\text {th }}$ decile & .0313 & .0226 & .0303 \\
$7^{\text {th }}$ decile & .0269 & .0232 & .0252 \\
$8^{\text {th }}$ decile & .0085 & .0189 & .0112 \\
$9^{\text {th }}$ decile & .0121 & .0178 & .0159 \\
Richest $10 \%$ & .0193 & .0200 & .0209 \\
Mean & .0084 & .0167 & .0132 \\
CI & .0232 & .0216 & .0232 \\
Standard error & -.2569 & -.0769 & -.1854 \\
p-value & .0423 & .0101 & .0410 \\
\hline
\end{tabular}


Table C 4 CCHS Annual 2011-12: Psychiatrists

CCHS Annual 2011-12: Need-Standardized Utilization of Psychiatrists for Mental Health Problems (12 mos) $n=108,623$

\begin{tabular}{lccc}
\hline \%tile & & Probit with controls & \\
\cline { 2 - 3 } Poorest $10 \%$ & Actual & Need-predicted & Need-standardized \\
$2^{\text {nd }}$ decile & .0513 & .0351 & .0391 \\
$3^{\text {rd }}$ decile & .0230 & .0251 & .0206 \\
$4^{\text {th }}$ decile & .0190 & .0244 & .0173 \\
$5^{\text {th }}$ decile & .0273 & .0224 & .0275 \\
$6^{\text {th }}$ decile & .0170 & .0211 & .0186 \\
$7^{\text {th }}$ decile & .0179 & .0200 & .0206 \\
$8^{\text {th }}$ decile & .0229 & .0208 & .0248 \\
$9^{\text {th }}$ decile & .0178 & .0204 & .0201 \\
Richest $10 \%$ & .0211 & .0199 & .0240 \\
Mean & .0175 & .0175 & .0228 \\
CI & .0235 & .0227 & .0235 \\
Standard error & -.1452 & -.1000 & -.0487 \\
p-value & .0113 & .0029 & .0109 \\
\hline
\end{tabular}


Table C 5 NSMHWB 2007: Psychologists

NSMHWB 2007: Need-Standardized Utilization of Psychologists for Mental Health Problems (12 mos) $n=7799$

\begin{tabular}{lccc}
\hline \%tile & \multicolumn{3}{c}{ Probit with controls } \\
Poorest $10 \%$ & Actual & Need-predicted & Need-standardized \\
\hline $2^{\text {nd }}$ decile & .0335 & .0360 & .0308 \\
$3^{\text {rd }}$ decile & .0412 & .0317 & .0429 \\
$4^{\text {th }}$ decile & .0442 & .0328 & .0448 \\
$5^{\text {th }}$ decile & .0264 & .0348 & .0250 \\
$6^{\text {th }}$ decile & .0309 & .0349 & .0294 \\
$7^{\text {th }}$ decile & .0405 & .0371 & .0367 \\
$8^{\text {th }}$ decile & .0384 & .0319 & .0400 \\
$9^{\text {th }}$ decile & .0371 & .0315 & .0390 \\
Richest $10 \%$ & .0325 & .0334 & .0325 \\
Mean & .0405 & .0296 & .0443 \\
CI & .0365 & .0334 & .0365 \\
Standard error &. .0012 & -.0182 & +.0178 \\
p-value & .0336 & .0071 & .0329 \\
\hline
\end{tabular}


Table C 6 CCHS Annual 2011-12: Psychologists

CCHS Annual 2011-12: Need-Standardized Utilization of Psychologists for Mental Health Problems (12 mos) $n=108,623$

\begin{tabular}{|c|c|c|c|}
\hline \multirow[b]{2}{*}{$\%$ tile } & \multicolumn{3}{|c|}{$\underline{\text { Probit with controls }}$} \\
\hline & Actual & Need-predicted & Need-standardized \\
\hline Poorest 10\% & .0331 & .0344 & .0251 \\
\hline $2^{\text {nd }}$ decile & .0181 & .0255 & .0190 \\
\hline $3^{\text {rd }}$ decile & .0207 & .0262 & .0210 \\
\hline $4^{\text {th }}$ decile & .0302 & .0267 & .0300 \\
\hline $5^{\text {th }}$ decile & .0263 & .0252 & .0275 \\
\hline $6^{\text {th }}$ decile & .0263 & .0247 & .0280 \\
\hline $7^{\text {th }}$ decile & .0327 & .0258 & .0333 \\
\hline $8^{\text {th }}$ decile & .0379 & .0262 & .0381 \\
\hline $9^{\text {th }}$ decile & .0304 & .0256 & .0312 \\
\hline Richest 10\% & .0341 & .0240 & .0366 \\
\hline Mean & .0289 & .0265 & .0289 \\
\hline $\mathrm{CI}$ & +.0653 & -.0378 & +.0999 \\
\hline Standard error & .0102 & .0015 & .0101 \\
\hline $\mathrm{p}$-value & .0000 & .0000 & .0000 \\
\hline
\end{tabular}


Table C 7 NSMHWB 2007: Other

NSMHWB 2007: Need-Standardized Utilization of other Mental Health Professionals for Mental Health Problems (12 mos) $n=7799$

$\underline{\text { Probit with controls }}$

\begin{tabular}{lccc}
$\%$ tile & Actual & Need-predicted & Need-standardized \\
\hline Poorest $10 \%$ & .0390 & .0216 & .0352 \\
$2^{\text {nd }}$ decile & .0289 & .0185 & .0283 \\
$3^{\text {rd }}$ decile & .0238 & .0193 & .0224 \\
$4^{\text {th }}$ decile & .0143 & .0181 & .0140 \\
$5^{\text {th }}$ decile & .0192 & .0186 & .0185 \\
$6^{\text {th }}$ decile & .0162 & .0187 & .0154 \\
$7^{\text {th }}$ decile & .0113 & .0169 & .0122 \\
$8^{\text {th }}$ decile & .0128 & .0162 & .0144 \\
$9^{\text {th }}$ decile & .0173 & .0173 & .0178 \\
Richest $10 \%$ & .0086 & .0134 & .0131 \\
Mean & .0192 & .0179 & .0192 \\
CI & -.2183 & -.0586 & -.1637 \\
Standard error & .0467 & .0099 & .0458 \\
p-value & .0000 & .0000 & .0004 \\
\hline
\end{tabular}


Table C 8 CCHS Annual 2011-12: Other

CCHS Annual 2011-12: Need-Standardized Utilization of other Mental Health Professionals for Mental Health Problems (12 mos) $n=108,623$

Probit with controls

\begin{tabular}{lccc}
$\%$ tile & Actual & Need-predicted & Need-standardized \\
\hline Poorest $10 \%$ & .0575 & .0433 & .0462 \\
$2^{\text {nd }}$ decile & .0292 & .0324 & .0289 \\
$3^{\text {rd }}$ decile & .0301 & .0324 & .0297 \\
$4^{\text {th }}$ decile & .0324 & .0325 & .0319 \\
$5^{\text {th }}$ decile & .0326 & .0308 & .0338 \\
$6^{\text {th }}$ decile & .0308 & .0297 & .0332 \\
$7^{\text {th }}$ decile & .0352 & .0307 & .0365 \\
$8^{\text {th }}$ decile & .0288 & .0309 & .0299 \\
$9^{\text {th }}$ decile & .0289 & .0300 & .0310 \\
Richest $10 \%$ & .0288 & .0274 & .0335 \\
Mean & .0334 & .0320 & .0334 \\
CI & -.0794 & -.0564 & -.0253 \\
Standard error & .0094 & .0017 & .0093 \\
p-value & .0000 & .0000 & .0063 \\
\hline
\end{tabular}


Table C 9 NSMHWB 2007: Unmet Need for Psychotherapy

NSMHWB 2007: Need-Standardized Unmet Need for Psychotherapy (12 mos) $n=7799$

Probit with controls

\begin{tabular}{lccc}
$\%$ tile & Actual & Need-predicted & Need-standardized \\
\hline Poorest $10 \%$ & .0678 & .0488 & .0617 \\
$2^{\text {nd }}$ decile & .0487 & .0430 & .0484 \\
$3^{\text {rd }}$ decile & .0434 & .0436 & .0424 \\
$4^{\text {th }}$ decile & .0381 & .0438 & .0370 \\
$5^{\text {th }}$ decile & .0472 & .0451 & .0448 \\
$6^{\text {th }}$ decile & .0619 & .0456 & .0589 \\
$7^{\text {th }}$ decile & .0399 & .0410 & .0416 \\
$8^{\text {th }}$ decile & .0377 & .0395 & .0408 \\
$9^{\text {th }}$ decile & .0390 & .0420 & .0397 \\
Richest $10 \%$ & .0264 & .0341 & .0349 \\
Mean & .0450 &. .0427 & .0450 \\
CI & -.0952 & -.0407 & -.0566 \\
Standard error & .0302 & .0085 & .0288 \\
p-value & .0016 & .0000 & .0492 \\
\hline
\end{tabular}


Table C 10: CCHS MH 2012: Unmet Need for Psychotherapy

CCHS MH 2012: Need-Standardized Unmet Need for Psychotherapy (12 mos) $n=23,863$

\begin{tabular}{lccc}
\hline \%tile & \multicolumn{3}{c}{ Probit with controls } \\
\cline { 2 - 3 } Poorest $10 \%$ & Actual & Need-predicted & Need-standardized \\
$2^{\text {nd }}$ decile & .0742 & .0615 & .0564 \\
$3^{\text {rd }}$ decile & .0433 & .0460 & .0411 \\
$4^{\text {th }}$ decile & .0473 & .0482 & .0428 \\
$5^{\text {th }}$ decile & .0403 & .0421 & .0420 \\
$6^{\text {th }}$ decile & .0451 & .0419 & .0469 \\
$7^{\text {th }}$ decile & .0493 & .0413 & .0518 \\
$8^{\text {th }}$ decile & .0336 & .0387 & .0386 \\
$9^{\text {th }}$ decile & .0384 & .0437 & .0384 \\
Richest $10 \%$ & .0450 & .0374 & .0514 \\
Mean & .0323 & .0364 & .0396 \\
CI & .0449 & .0437 & .0449 \\
Standard error & -.0946 & -.0757 & -.0208 \\
p-value & .0172 & .0050 & .0165 \\
\hline
\end{tabular}




\section{Paper \#4: Government Structure, Service System Design and Equity in Access to Psychotherapy}

\section{Introduction}

The first paper in this dissertation found evidence of the critical role of government structure in shaping social policy in Canada, with Canada's decentralized structure in constraining public funding for psychotherapy and other mental health services. The second paper established that there are indeed income-based inequities associated with the exclusion of psychotherapy from public insurance coverage in Canada, and the third paper found a mix of pro-poor and pro-rich equity impacts from initial efforts to improve access to psychotherapy in Australia. Building on the findings from these first three papers, this fourth paper uses interviews with key informants in Australia, the United Kingdom (UK) and Canada to delve more deeply into the relationship between government structure, service system design and equity in access to psychotherapy.

As has been described in the previous papers, both Australia and the United Kingdom have implemented wide-reaching reforms to improve access to psychotherapy over the past 10-15 years. The Australian government launched the Better Access to Psychiatrists, Psychologists and General Practitioners through the Medical Benefits Schedule (Better Access) initiative in 2006, expanding universal Medicare coverage to include psychologists and other mental health professionals (Australia, 2015). Improving Access to Psychological Therapies (IAPT) is a stand-alone psychotherapy service that was launched by the UK government in 2008 , and directly implemented in every district of England with oversight from National Health Service England (NHS England, n.d.). 
This kind of population-wide reform has yet to be introduced in Canada. While physician and hospital services are covered by public health insurance, access to psychological services and other non-physician mental health professionals is not. As a result, higher-income Canadians either pay out-of-pocket or through employment-based insurance, and lower-income Canadians face considerable financial barriers or long waits for limited community-based services. In March 2017, the Canadian federal government announced a targeted transfer of $\$ 5$ billion over ten years $(\$ 500$ million per year on average, starting in 2017-18) to support provincial and territorial governments in improving access to mental health services (Finance Canada, 2017). It remains to be seen how far this new transfer will go toward improving access to mental health services, and how much will go toward improving access to psychotherapy in particular (Bartram \& Lurie, 2017). As Canadian provincial and territorial governments are planning how to spend new targeted federal transfers, this paper provides timely and practical policy guidance regarding service system design and equitable access to psychotherapy in the Canadian context.

\section{Guiding Literature regarding Government Capacity and Equitable Access}

The interviews with key informants from Australia, the UK and Canada are guided by the literature on two key policy questions that are the focus of the previous papers in this dissertation. First, in keeping with the findings from the first paper, the interviews go in to more depth regarding the capacity of more and less centralized forms of government for policy reform. Second, as a follow-up from the findings from the two quantitative papers regarding income-based inequities in access to psychotherapy and 
other mental health services, the interviews explore the equity impacts of various service system designs.

More centralized forms of government are generally associated with greater capacity for policy reform. Parliamentary systems are more centralized than presidential systems, and thus have greater capacity to push through policy reform even over the objectives of powerful stakeholders (Weaver \& Rockman, 1993). At the same time, in federal parliamentary systems, the centralizing effect of the parliamentary structure is counterbalanced by the decentralizing effect of multi-level government. In federal systems, agreement from both regional and national levels of government is required in many policy domains, which in turn creates incentives for shifting blame between different levels of government (Banting \& Corbett, 2002). To the extent that jurisdiction over a particularly policy issue is shared between different levels of government, jurisdictional tensions are even more likely to complicate decision-making (Pierson, 1995).

These differences have implications for the capacity of the three states in this study to push through policy reforms in the health sector. While the UK, Australia and Canada all have parliamentary systems, the UK is by far the most unitary (at least as far as England is concerned), with a command-and-control health system run by the National Health Service. Australia and Canada are both federations but the Australian commonwealth government is stronger, particularly in the health sector where it has jurisdiction over Medicare and contributes $61 \%$ of total public spending on health (Australia, Australian Institute of Health and Welfare, 2017; Flood, 2001). The Canadian federation is much more decentralized, nowhere more so than in the health sector; health 
is under provincial and territorial jurisdiction, and transfers from the Canadian federal government amount to only $23 \%$ of provincial and territorial spending on health (Banting \& Corbett, 2002; Ouimet, 2014; Phillips, 2016). By asking key informants from these three countries for their perspectives on the key factors driving (or preventing) reforms to improve access to psychotherapy, this study further explores the relationship between government structure and other contributing factors such as the fiscal environment, public support, and evidence of effectiveness.

The literature on service system design and equity also guided the questions for key informants. Much of this literature developed as a critical response to EspingAndersen's 1990 theory regarding welfare state regimes, which grouped western countries into three broad types of redistributive social policies. According to the original theory, the mobilization of class interests, the dynamics of political coalitions, and institutional legacies shape distinct social relations between state, market and the caregiving role of the family. The United States, the United Kingdom, Australia and Canada were grouped under the so-called liberal regime, with a relatively minimal role for the state and stronger role for the market and families in comparison to European corporatist and Scandinavian social democratic approaches to social policy.

New typologies have developed to address the over-simplification inherent in Esping-Andersen's original theory. For example, Korpi's (2000) typology brought in class and gender as core dimensions, and Wood and Gough (2006) developed a global framework for comparing welfare regimes. Other critiques of particular relevance for this study have focused on how Esping-Andersen's regimes overlooked the complex and dynamic mix of social policies and program designs within a particular country (Mahon, 
2008; Myles, 1998). Several healthcare-specific typologies have also been developed. For example, Bambra (2005) grouped Organization for Economic Development and Cooperation (OECD) countries according to the strength of the private market in each healthcare system, and Wendt (2009) developed a taxonomy of twenty-seven healthcare systems with every possible combination of three dimensions (financing, service provision and regulation) and three actors (state, market and non-state).

Accordingly, while the overall array of social programs in the UK, Australia and Canada relies more on a strong role for market and family, universal health insurance models are more in line with a social democratic approach. Moreover, on closer inspection, the private market still plays a role in health policy in each country in different ways, creating financial barriers that have important implications for incomebased inequities in access to services. In Australia, this liberalism is evident in the ability of physicians (and now psychologists and other mental health professionals) to charge copayments under the Medicare scheme. In the UK health services in the public system are free at the point of delivery, but physicians are permitted to work in both the private and public health sector, with the private sector more likely to provide services to those who can afford to pay out-of-pocket. In Canada, neither co-payments nor mixed practices are permitted for physicians under the Canada Health Act. Nevertheless, $30 \%$ of health expenditures are made in the private sector, largely for items that are not covered by Medicare such as medications, dental care, homecare and psychotherapy that is provided by psychologists and other non-physician providers. These private sector costs are borne by both employment-based insurance and out-of-pocket payments, and families often play a key role in providing care at home. 
Other literature on service system design and equity has taken a more normative approach, assessing the redistributive effectiveness of different social policy approaches. Korpi and Palme (1998) argue that there is paradox of redistribution, whereby the more social policies are targeted to the most disadvantaged, the less effective they are at reducing inequality. Their classification of social insurance policies maps fairly close onto Esping-Andersen's welfare state regimes. Social insurance policies can be universal, targeted, corporatist (i.e. tied to employment or membership in an employment group), or encompassing (a mix of universal and employment-based). Liberal states such as Canada, Australia, and the UK tend to have more targeted approaches, European states tend to have more corporatist policies, and social democratic Scandinavian countries tend to have either encompassing or universal approaches. In other words, liberal states where the market and families play a strong role in welfare provision tend to limit the role of the state to targeted programming.

According to Korpi and Palme (1998), targeted approaches generate less political buy-in and thus a smaller pool of financial resources to support redistribution than either universal or encompassing approaches. Encompassing approaches are the most effective at reducing inequality, to the extent that employment-based benefits remove the incentive for middle and upper class citizens to purchase premium insurance on the private market.

By contrast, with his work on social determinants of health and the social gradient, Marmot (2010) has come to different conclusions regarding the best way to reduce inequality in health outcomes. Marmot advocates for proportional universality:

Focusing solely on the most disadvantaged will not reduce health inequalities sufficiently. To reduce the steepness of the social gradient in health, actions must be universal, but with a scale and intensity that is proportionate to the level of disadvantage. We call this proportionate universalism. (p. 9) 
Proportionate universalism works to improve everyone's health, but at the same time to flatten the health gradient by improving the health of those who are most disadvantaged the fastest. Proportionate universalism also has the advantage of garnering broad political support, which in turn helps to ensure high service quality and strong funding from general tax revenues, and to reduce the risk of stigma associated with targeted programs (National Health Services, Health Scotland, 2014).

In keeping with the evolving theory on government structure and welfare state regimes, each service system has its unique mix of elements: centralized and decentralized, private and public, universal and targeted, and insured and programmatic. The interviews with key informants in the Australia, the UK and Canada provided an opportunity to explore the equity dimensions of three contrasting mental health systems in three contrasting governance contexts.

\section{Methodology}

This paper is a small-N comparative study of the relationship between government structure, service system design and equity in access to psychotherapy in the UK, Australia and Canada. These three countries are selected as cases not only because of the high-level similarities in political structure and health policy, but also to draw lessons from a comparison of two positive cases (Australia and the UK) that have launched major initiatives to expand access to psychotherapy with a negative case (Canada) that has not (Mahoney \& Goertz, 2004). The analysis of UK policy was limited to England, with the relationship between UK policy and reforms in Scotland, Wales and Northern Ireland beyond the scope of this paper. Psychotherapy is defined broadly to include psychotherapy, psychological therapies, clinical counselling, and talk therapy. 
The primary source of data is 22 key informant interviews with policy-makers, stakeholders and researchers (see the sample frame in Table 19), supplemented by studies of the outcomes of these policy initiatives and related government reports. Interviews were conducted by Skype, by telephone or in-person between April and June 2017. The CUREB-approved recruitment email, information/consent form and interview guide can be found in Appendix A. Quotes are attributed by country and type of key informant (for example, AUS_R1 is an Australian researcher, UK_PM1 is policy-maker from the UK, and CDA_SH1 is a Canadian stakeholder). At the same time, many key informants brought more than one perspective. For example, a service provider might also conduct research and may move in and out of policy-making roles. To further strengthen the diversity of perspectives, particular attention was paid to ensuring a mix of service users and service providers, as well as a mix of central and regional/local levels of government and administration. Interviews were transcribed and analysed using NVivo. Initial coding was based on the themes identified in the literature on government capacity, service system design and equity as reviewed above, and refined over the course of the analysis.

\section{Results}

In keeping with the focus of the study, findings from the interviews and document review are grouped under two headings: key factors driving or preventing policy reform (including government/constitutional structure), and equity (including both equity impacts and efforts to address these impacts). Key informants' reflections on lessons learned are divided accordingly. Results are summarized in Tables 20 and 21. 


\section{Key factors for policy reform}

Key informants were asked to identify the key factors that have either enabled Australia and the UK to introduce wide-scale initiatives to expand access to psychotherapy over the past decade, or that have prevented Canada from doing the same. Prompts included stakeholders, evidence, professionals, stigma, business case, constitutional structure, economic context, and political context.

Three contrasting narratives emerge from the three countries, with government structure playing a strong role throughout. In Australia, survey data regarding high rates of unmet need coupled with the Commonwealth government's jurisdiction over Medicare were the key factors behind the introduction of the Better Access program in 2006, with its expansion of public health insurance to include psychologists and other allied mental health professionals. In the UK, a very strong business case coupled with a more unitary state were the key factors behind the introduction of $I A P T$ in 2008 , with targets and standards set by the government of the UK, administered by NHS England, and delivered by local clinical commission groups or trusts. In Canada's highly decentralized federation, the key factors identified that have thus far prevented reform include jurisdictional tensions, coupled with related policy legacies from the Canada Health Act and fiscal constraints on provincial and territorial governments. While these factors were all at play during the 2016 Health Accord negotiations between federal, provincial and territorial governments, a window of opportunity for reform has opened with the new federal transfer for mental health starting in 2017 (Bartram, 2016; Bartram, 2017; Bartram \& Lurie, 2017; Finance Canada, 2017). 
Australia was a leader in mental health reform, starting with the release of its first national mental health plan in 1992 (the fifth plan has just been launched; Council of Australian Governments Health Council, 2017). The original focus was on better meeting the needs of people with relatively uncommon but generally more serious mental illnesses such as schizophrenia and bipolar disorder. However, national survey data released in 1997 brought new attention to both the prevalence of anxiety and depression, and to the unmet need for services for these more common mental disorders. The 1997 National Survey of Mental Health and Wellbeing found that one out of every five Australian adults had experienced one or more mood, anxiety or substance use disorder in the past year, but that nearly two thirds of people with these mental disorders were not using health services (McLennan \& Australian Bureau of Statistics, 1998). As can be seen in the quotes below from interviewees, these survey results were a key impetus for expanded psychological services for people with anxiety and depression.

That was the first time we'd done a big national, epidemiological survey of that kind. And one of the findings was for anxiety and depression, and they hadn't been catered for very well in the early national mental health plans. But also, people with those conditions, the vast majority of them didn't go anywhere near mental healthcare. (AUS_R3)

A lot of that was sequential of understanding that prevalence was high, the burden was high, that most people weren't getting treatment. Those that were, were getting it in primary care. Primary care doctors were busy and probably not skilled particularly in mental health psychological treatments. We needed to find another provider group. Psychologists were that provider group so on referral from primary care doctors, psychologists could access to the national insurance system Medicare. (AUS_R4)

While this quote makes it seem that the decision to expand Medicare flowed automatically from the recognition of the unmet need, other key informants pointed to the Commonwealth government's jurisdiction over Medicare as a deciding factor in the form 
of the government's response. Having jurisdiction over public health insurance for physicians made it a good fit for the Commonwealth government to extend coverage to psychologists and other non-physician mental health service providers under the Better Access program, rather than expanding a smaller more grant-based program called Access to Allied Psychological Services (ATAPS).

The Commonwealth government wanted something done and wanted something done quickly. There is the question of what levers they can pull. The levers of things like the ATAPS services were more complex, and involved taking on a whole lot of additional responsibility, you have to set up and plan and deliver some kind of a stepped care model and you have to triage and you have to run in effect 100 little different mental health care systems one for each division. In contrast to which, what you have to do to get the funding out through Medicare is you create some Medicare benefit schedule entitlements and you create a process which legitimizes people to use them and away they go, the rest of it is done by the private sector. (AUS_R1)

The Commonwealth government's jurisdiction over Medicare also made it easier to push through a Medicare-based reform without having to negotiate across levels of government.

There is no question that Australia is different than Canada as I understand it, where we have the Australian government federally having responsibility for primary health care and for the specialist medical and allied health care in the ambulatory setting. The fact that they had responsibility was key, so it was one level of government. The commonwealth government didn't need the states to be on board, they could do it regardless. (AUS_SH2)

The role played by government structure and areas of jurisdiction becomes even more evident when Australia's reforms are contrasted with those in the UK. Rather than expanding public health insurance as Australia did with Better Access, the UK opted to introduce IAPT, a centrally-driven program overseen by NHS England. Interestingly, key informants from Canada were more likely than key informants from the UK to make the connection between government structure and reform approaches. 
Australia and the UK have both been more nimble. The reason why, I think, is that the UK has the NHS, and in Australia primary care is also a federal responsibility. It is easier to get it done, there is only one governmental authority for the service. (CDA_SH2)

Canadian key informants also pointed to the government structure in both the UK and

Australia being central to their ability to move forward with reforms.

Australia has a more powerful federal government. And the UK has a more unitary system. What is odd in Canada is that provincial systems are large, they have resources, they could tax and expand services but they don't. (CDA_PM3) [Australia and the UK] had all of the levers and they could lay out a plan. (CDA_PM2)

Key informants in the UK pointed to the high potential return on investment as a key factor in the development of $I A P T$, coupled with a well-connected influencer in the form of Lord Richard Layard. The case for public investment was essentially that if access to evidence-based treatments could be increased, people's mental health status could improve such that productivity would increase (Layard, Clark, Knapp, \& Mayraz, 2007).

If you think about the whole business case, it was this will pay for itself. If we treat mental health problems we will save the Exchequer because we're returning people to work... There was money in the system, and it was a government who had a mandate to spend that money. (UK_R2)

[Mental health problems] are the biggest cause of disability among the working age population and as a consequence if there is one health problem that you should address in order to help your economy it's not cancer, it's not cardiovascular disease, it's not even diabetes, it's mental health because that's the thing which will allow the nation to be more productive, reduce unemployment and grow GDP and so if you don't address it, then you don't have the money to pay for treating the other problems, which tend to strike people in retirement and old age... It's economic madness not to do this because actually the costs of implementing evidence-based psychological treatments is much smaller than the economic benefits that follow from them. And so if you're in a difficult economic time then it's very definitely the thing you should do. (UK_R3) 
This case for public investment attracted the interest of politicians, and the strong evidence-base and approach to monitoring made $I A P T$ a compelling option. With his strong political connections and expertise in the mental health field, Lord Richard Layard was able to sell the proposal to policy-makers.

So in 2002, [the National Institute for Health and Care Excellence - NICE] started issuing guidelines on mental health ... [T] hose guidelines make it very clear that certain psychological treatments have passed the test of being effective for different mental health conditions. And in anxiety and depression that they really should be the first choice intervention because although medication also does well, the evidence is pretty clear cut that it's effects are less enduring. So NICE said, first choice psychological treatment, second choice medication or the combination for the more severe cases. (UK_R3)

Basically it was a professor of economics ... who made a case, an economic case, as well as a case that it would be good to implement NICE guidelines on depression and anxiety. The thing that probably swung it, influenced the government, is that he is also married to a Labour politician, so he got in to see Gordon Brown who at the time was Chancellor of the Exchequer, shortly before he become Prime Minister. He made an economic case that if we were more effective at implementing NICE guidelines, it would get people back into work and therefore it would increase the tax income and reduce the benefit costs to the country. He made quite a strong economic case which was accepted. (UK_R1)

It was immense good fortune that Lord Layard, the chap who wrote the report, happens to be very good friends with Gordon Brown, who at the time was Chancellor of the Exchequer... The story is ... this idea that we should have something like IAPT was Lord Layard sitting down and chatting with Gordon Brown over a meal. (UK_R2)

The political factors that contributed to the introduction of IAPT also attracted criticism

from UK key informants.

I think they saw an opportunity. It is all terribly political. The Labour government had gamed the system. They managed to reduce apparent unemployment by pushing a lot of people onto sickness benefit, to look like unemployment figures were lower. And then ... somebody realized that this was incredibly expensive. There were two conditions that accounted for something like $80 \%$ of the people who were on sickness benefit, one was back pain and the other was anxiety and depression. (UK_R4) 
In Canada's highly decentralized federation, neither high rates of unmet need nor the strong case for public investment have overcome barriers to reform as yet. Key informants stressed jurisdictional tensions as a key barrier, coupled with related policy legacies associated with the Canada Health Act and fiscal constraints on provincial and territorial governments. Key informants linked jurisdictional issues to the structure of the federation, and noted the ensuing constraints on the policy levers available for reform.

The first and obvious one is that you have a much more centralized system with the NHS. We do not have a national health service, we have a provincial and territorial service and a very skimpy federal health service for the populations that you know well, whether you are a prisoner or Aboriginal or in the military or the Mounties. There is no central control, that is the first thing. (CDA_SH1)

How to get from where you are to where you want to go is extremely complicated and most of the provinces don't have the horsepower to figure it out. (CDA_PM1)

There is something to be said about the smoke and mirrors, about a public policy or a strategy, because it ups the public's awareness. But it doesn't guarantee a direct road... Laying out a plan in Canada is a very complicated thing, you have provinces who say that is not quite my plan, those aren't quite my priorities, I have already done that therefore compensate me for something we have already done, it is just very difficult form of government that we have. (CDA_PM2)

There is ... an underlying dysfunctional relationship between the federal, provincial and territorial governments, where provinces and territories have greater autonomy and don't want conditions, and the federal government is increasingly needing to be more accountable for public investments. It is a prisoner's dilemma which prevents us from moving forward. (CDA_PM3)

The disadvantages/costs of the Canada's decentralized federal structure are starting to rise. I wouldn't want to see more centralization along the lines of what happens in the US, where the federal government can impose programs across the board. But Canada needs to regain a sense of focus. (CDA_R1)

Key informants also pointed to policy legacies associated with the 1984 Canada

Health Act (CHA), with its entrenchment of decisions from the 50s and 60s to provide first-dollar coverage but only of services provided by physicians and hospitals (often 
referred to as deep but narrow coverage). Some people linked these legacies to

underlying jurisdictional dynamics.

We can't have the same first dollar coverage [for psychotherapy], we can't be prescriptive. (CDA_PM3)

The key factor was that Medicare was defined as covering doctors and hospitals. That is how it got defined, there are reasons in history for that, and that is what we are stuck with... The irony in both cases [the UK and Australia] these advances have happened in systems with two-tier care, and Canada with one-tier care supposedly, lags behind. (CDA_SH1)

The real challenge for us to get even close to what the UK and Australia have done is the nature of our constitutional reality and how healthcare is administered. What the CHA means and how it is interpreted. The fact that there are so many service providers, especially when it comes to mental health, the two main treatments are generally not covered under that Act. We have no pharmacare program and while the bulk of psychotherapy is delivered by psychologists and others, only the services of physicians are covered by our public health insurance plans. That is a huge inequity. (CDA_SH2)

An opposing perspective minimized jurisdictional barriers and put the emphasis squarely

on the decision to provide first-dollar coverage.

When other things developed why were services not expanded? That comes fundamentally from the underlying mistake in Medicare, which is not true in the UK and not true in Australia, which is that we provided first dollar coverage to everybody regardless of income. We interpreted universal to mean universally free. That unfortunately has become what is commonly called the third rail of Canadian politics, so try to change that at your peril. The minute a government contemplates universal coverage of psychotherapy, well that is really stupid. ...All kinds of people in this country have Employee Assistance Programs (EAPs) which cover let's say 6-8 sessions. ... So if the government suddenly decided to provide that free to everybody, all of that money which is now going in to buying services would vanish. Similarly, lots of people can afford to pay out-of-pocket for psychotherapy services, so again you are just wasting money. The road block to what they did in the UK and Australia is the first dollar coverage for everything. And trying to change that is very difficult....The reason the provinces didn't do it is because there is no way they could possibly afford to add anything under the CHA. (CDA_SH3) 
These fiscal constraints on provincial and territorial governments, while clearly related to jurisdictional dynamics and policy legacies, were identified as another key barrier to reform in and of themselves.

There is no focused objective around health policy, and there is no willingness to take on associated fiscal risk. Most provinces and territories (except Quebec) would love to vacate the field of prescription drug coverage, to have the federal government take on full responsibility for some aspect of the health system. The fiscal pressures they face are greater than their concerns about jurisdiction. (CDA_R1)

The key factor is that demand-driven stuff is just not on. Expanding anything that is demand-driven where you can't have a good estimate of the cost or control the cost, expanding anything else whether its homecare or pharmaceuticals for that matter, it is just not something that there is any willingness to consider because there is just such worry about the sustainability of the system that we have now. (CDA_PM1)

The unique features of Canada's context, from its decentralized structure to its deep but narrow style of public health insurance to the vertical fiscal imbalance that leaves provincial and territorial governments with little fiscal room, have been key barriers to reform. While these factors were all at play during the 2016 Health Accord negotiations between federal, provincial and territorial governments, a window of opportunity for reform has opened with the new federal transfer for mental health starting in 2017 (Bartram, 2016; Bartram, 2017; Bartram \& Lurie, 2017). Many of the same factors which contributed to reform in Australia and the UK have also been central to the introduction of this new transfer, including high rates of unmet need, a clear case for public investment coupled with the potential for measureable outcomes, and political leadership. For example, federal Minister of Finance Bill Morneau has stressed how “[m]ental health investments help people get back to work faster... [b]ut we need to show that investments really result in that outcome" (Hall \& Morneau, 2017). With a promise 
to provide "better access for as many as 500,000 Canadians under 25 who cannot currently receive even basic mental health services," the 2017 federal budget focused on the unmet needs of children and youth (Finance Canada, 2017, p. 156). According to one key informant:

The key opportunities are strong federal leadership, backed by significant federal investment, and a strong commitment to showing results. (CDA_PM3)

Nevertheless, the long-standing challenges remain, and the impact of the new transfer is a work in progress.

The new \$11B [ \$6B for homecare and \$5B for mental health] that has been promised in the bilateral agreements of 2017 may be so dissipated that it has little impact. Maybe it will have an impact, but it will be up to provinces and territories and they only have so many levers. (CDA_R1)

In addition to the key factors highlighted in the three main narratives, key informants mentioned a few other factors that bear mentioning: workforce supply, policy champions, and growing public support. While the UK had to train up the IAPT workforce, in Australia Better Access was introduced after a period of investment in expanding the psychological workforce.

When it became evident to the membership of the Australian Psychological Society that they were likely to get into the Medicare rebate system ... the demand for university places exploded. (AUS_R4)

Well-connected policy champions such as Lord Richard Layard played a key role in the UK, but key informants from Australia and the Canada spoke to this factor as well.

It is quite clear that in Australia, as I look back at the major reform moments, in particular the major injections of funds, they almost universally depended on a deep personal sponsorship from either the Prime Minister or the Minister of Health at the Commonwealth level. (AUS_SH1)

Now I think the problem is all of that, who is going to get down to the nitty gritty here. Who wants to face the unions, GPs, psychiatrists, who wants to face all of these people? There will be a governing body who will put all of these people 
together and try and figure it out, or it is going to be the Ministry of Health and government and the premier that are going to say, we have enough evidence, we want to offer this to the population. It just takes one ministry, one minister. (CDA_R2)

What it will take is simply ... political will on the part of the government. That is all it takes, that is the only barrier left. (CDA_SH3)

Of course, political will and public support often go hand in hand, and public support for mental health, and specifically for better access to psychotherapy, has been growing in all three countries.

Over time we have put the question to our constituents and service users and service providers in the publicly-funded tertiary-quaternary system where we have asked questions about what should the system look like and what should the system do, with a very frequent response being: more talk therapy would be wonderful. (AUS_PM1)

The reality is that the public now, specifically if you are targeting kids, you will be absolutely fine... Over the past decade, look at how far we have come. I would be willing to bet a decade from now... once the ball starts rolling you can't stop it. Nobody really wants to stop it, they just want to do it in a fiscally responsible way that doesn't get them killed for not having followed the Canada Health Act. (CDA_SH3)

Mental health services have been historically enormously underfunded. There's a complete lack of parity of esteem. Physical health problems are given a level of esteem and a level of input that mental health problems never have in the NHS, so I think ... I think [IAPT] became accepted by all the political parties because it was an answer to the question "What are you doing?" or "What will you do to address the mental health problems within the UK?" (UK_R2)

Lessons learned regarding factors for policy reform. Key informants identified

several lessons learned regarding factors for both introducing, implementing and sustaining policy reform, including government structure, accountability, scope and implementation support. There was considerable consensus that the policy levers associated with particular constitutional structures play a key role in determining the approach to reform. This relationship helps to explain why the commonwealth 
government in Australia opted to pull the "lever they can pull" (AUS_R1) by expanding Medicare, a program under its jurisdiction, while the "more unitary" (CDA_PM3) UK government opted instead to roll out a program through NHS England. Canada, with the "prisoner's dilemma" (CDA_PM3) built into its decentralized federation and first-dollar CHA, has had limited success to date in negotiating terms for a reform.

Whatever approach to reform is taken, setting clear objectives, gathering appropriate data and reporting publicly on results are seen as critical for demonstrating that reforms are having the desired effect. In the UK, IAPT's strengths in this area are seen as key to its political success and sustainability.

[W]hy would you want to invest in something that's set up in a way where you won't know whether it works. Aren't you accountable to your electorate? You want to be able to show when you next run for office that it worked. (UK_R3)

The ability of Better Access to demonstrate significant increases in access to psychotherapy is also seen as having been critical for its sustained funding.

These successes notwithstanding, concerns have been raised in both countries about the approach to performance monitoring. In Australia, where most data comes from Medicare billings, concerns have been raised regarding quality overall.

I think we're getting access to care by paying more providers, but that is only the first step. ... [T] he missing thing is peering inside the box of the services that you'll be paying for, if you put taxpayer's money into it. The thing we commonly don't know is what actually, what intervention the person gets. (AUS_R4)

In the UK, where $I A P T$ collects data at every session and reports results by local area teams on a monthly basis, there are concerns about not paying enough attention to the experience of service users and providers.

One of the things that people who use our services say is how fed up they get with filling out forms. There is just a battery that they have to complete, some every week and some at the beginning and the end....The people who commission 
medical services in this country, clinical commission groups, introduced this thing called payment by results. ... You have to show that, on whatever set of measures you are using, that after 12 weeks this person has improved. ... I think that the idea that physical and mental health are the same thing is just daft. As someone who has suffered from both it is just not the same. (UK_R4)

[W] hen IAPT was set up, there were very, very strict targets and expectations set ..., and it's tight and managed within an inch of its life. Often, what strikes me is it's set up to work in a way that really work[s] against what's best for the patient... You end up distorting good clinical practice to meet targets... (UK_R2)

You could if you're not careful find yourself as a clinician working in a service where you feel, you know, the outcome data is like a sword of Damocles hanging over you all the time... What you need to do is create a situation where you put in charge of these services really inspirational clinical leaders who are interested in the data, not because it's meeting targets and things, but instead because it's telling them and the service something really interesting about how they can achieve what they want to achieve with patients. (UK_R3)

In Canada, where accountability for federal transfers to provincial and territorial

governments has proven to be particularly challenging, the role of stakeholders is viewed as particularly critical.

There was no way you could track [federal investments in childcare], except, and this is where it is effective, the childcare advocates in the provinces could go to the province and say, hey the federal government gave you \$200M. ...In the same way that you could hope that if there was a coordinated mental health lobby, tell us where is the money going. (CDA_PM2)

Another lesson learned regarding implementation is the importance of focusing

reforms rather than trying to be all things to all people. Part of IAPT's success has been

its ability to focus on people with less complex needs.

[F]or the sake of staff and clients..., mainly [I'm] trying to be adherent to an IAPT model for that part of the service, and not expecting that that service can meet everyone's needs. $[\mathrm{P}]$ sychological therapies as a whole is much broader than IAPT. (UK_SH1)

In Australia, Better Access was scoped very broadly, uptake far exceeded expectations, and the commonwealth government had to reduce the cap on the number of sessions to contain 
both supply and demand. In Canada, where policy-makers face greater political, jurisdictional and financial barriers, some kind of narrow scope would seem to make sense, whether on different levels of acuity, different population groups, or different levels of socio-economic advantage.

[W] hat governments need to do is identify pressure points, and focus on something thoughtfully, planfully, to address whatever their priority issue is instead of trying to cover everything with one solution. (CDA_SH2)

$[\mathrm{P}]$ sychotherapy for adults would be a much harder sell than psychotherapy for kids.... It has one of those wonderfully emotive [appeals] that really works. (CDA_SH3)

Lastly, key informants pointed to the essential role of implementation planning and supports for the success of policy reform, including workforce considerations. In Australia, little implementation planning was undertaken for the expansion of Medicare under Better Access, and the commonwealth government was caught off-guard by the surge in demand. In England, hands-on support was a key feature of the IAPT roll-out.

I think that it is often not realized that just announcing a policy and setting out targets and some money is not a very good way of getting things to happen. If you are rolling out something that is genuinely innovative and not just fine-tuning something that already exists, we really need to put the support in place at a local level... This isn't about telling people what to do, it's about facilitating learning across different parts of the NHS and across different agencies. (UK_PM1)

In Canada, similar implementation challenges arise, but between different governments as well as between different agencies.

[W]e are going to have a dozen different governments developing new service delivery models and programs to spend this [ $\$ 5$ billion] and, just by definition they are not all going to be the best. It is important to find out which ones are working best so that that information can be shared... That is a key challenge I think. How to set up a learning system in relation to these new investments. (CDA_PM1) 
The importance of including workforce considerations in implementation planning was a strong theme throughout the interviews, whether in relation to supply, the range of eligible providers, incentives, training, or clinical leadership.

\section{Equity}

While equity concerns were only mentioned occasionally as a contributing factors in the introduction of reforms, several interview questions specifically asked about the equity impacts of current policies, and efforts to address such impacts.

Equity impacts. Key informants were asked to identify the equity impacts of the approach to psychotherapy service provision in all or any of Australia, the UK and Canada. Specifically, to what extent is access to psychotherapy determined by need as opposed to by other factors? Prompts included income, rurality, education, cultural background, and language spoken. Annual reports, evaluations, and other research are also important sources of data for this question and are woven through the analysis of the key informant interviews below.

Despite the introduction of major reforms in Australia and the UK, all three countries have struggled in different ways with equity issues related to the provision of psychotherapy services. The focus of attention in Australia has been on inequities in utilization of Better Access in rural and more socially-disadvantage regions, with a tentative consensus emerging around inequitable access after a period of significant controversy. In the UK, more attention has focused on inequities between districts and ethnic groups, with an emerging interest in social disadvantage. Inequities in access to psychotherapy services, particularly income-based inequities, are considered to be self- 
evident and serious in Canada, with some hope for new federal funding to go toward removing financial barriers.

In Australia, there has been controversy over potential inequities in access for people with lower socio-economic status from the outset of Better Access in 2006. A primary concern was that a Medicare-based model would create incentives for psychologists and other non-physician providers to target their services to higher-income clients who can afford co-payments. Co-payments are allowed under Australian Medicare; to take a more recent illustrative example, in $2014-15,51 \%$ of sessions under Better Access included a patient co-payment, with an average co-payment of \$51 (Harris, 2016). Controversy heightened when the 2011 evaluation finding that inequities in access were not a significant problem, only to be criticized for basing this conclusion on too small a sample (Hickie, Rosenberg, \& Davenport, 2011; Pirkis, Harris, Hall \& Ftanou, 2011). A more recent study concluded that utilization of Better Access services is much higher in urban than in rural areas, and much lower in areas with greater socio-economic disadvantage (Meadows, Enticott, Inder, Russell, \& Gurr, 2015). To further complicate matters, in the third paper in this dissertation this author found higher concentrations of both service utilization and unmet need at lower income levels.

There was a fair degree of consensus among key informants from Australia regarding the at least some degree of inequity in access to psychotherapy, and a belief that workforce supply and incentives were key factors driving this inequity.

If you look at rates of clinical psychologists and psychiatrist services, they may be typically three times higher in the most advantaged areas compared to the most disadvantaged, and if you look at psychiatric morbidity, it may be three times higher in the most disadvantaged areas than in the most advantaged areas. So you have a 9-fold disparity in access for people with equivalent levels of need. I think as an example of trying to get services out in an equitable way, this a train wreck. 
It is getting more services to more people but those funds are not in a targeted way blowing to the areas that need it most. (AUS_R1)

The principle challenge is creating a system that sees psychotherapies alongside of other health services in an equal sense. Even with the Better Access scheme there is still some rationing which I think probably has an impact most on those least able to afford additional services. (AUS_SH1)

In theory, access is equitable, in practice it is much more limited. You are much more likely to get that if you live in a capital city as opposed to in a rural area, and you are much more likely to get it if you are in a higher socio-economic group. ...But you have to have a psychologist who is willing to do that, there aren't a lot of psychologists sitting around twiddling their thumbs waiting for someone to walk through the door. Just because they make it available it doesn't necessarily mean that the psychologists are going to have the free spots. (AUS_SH2)

Why would you as a business person trying to make a livelihood, why would you go and maybe earn 150-200,000 AUS\$ a year in a poorer area, when you can go and earn $250-300 \mathrm{k}$ treating people who are more like you and who are also quite needy and have needs for care, but they have more control over their lives, are more likely to turn up for appointments, and they pay more? (AUS_R1)

Notwithstanding this recognition of inequities in access, key informants also stressed how many people living in rural and/or socio-economically disadvantaged areas were benefiting from Better Access.

It made psychological services including psychotherapy affordable to the masses. ...Farmers tell me that they will sit on their tractors and nobody knows that they are participating in an e-mental health program. ... I am aware of the research, but what I am saying to you is from my experience from the streets of highly multicultural disadvantaged communities to outback towns, and I know the difference, whether it is face to face or whether it is web-based, I know the difference people having access to psychological services is making. (AUS_R2)

Prior to Better Access, psychology services were only available to people who could pay the full weight or had private health insurance, at least in what's the equivalent of the primary mental healthcare system. In those circumstances, virtually no one in the lower SES groups would have been receiving services. (AUS_R3)

While $I A P T$ was implemented systematically across England through Clinical Commission Groups with accountability to the NHS, inequities have still been an issue. 
Data from early the first annual report showed considerable variability in access between Local Area Teams and between ethnic groups. While white people made up $86 \%$ of population, they made up $89 \%$ of the $70 \%$ of people accessing $I A P T$ who declared an ethnicity (Community and Mental Health statistics team, Health and Social Care Information Centre, 2014). IAPT reported outcomes related to deprivation for the first time in 2015-16. While referral rates increase as deprivation increases, treatment completion rates drop off. Further, recovery rates in the most deprived decile were only $35 \%$, compared with $55 \%$ in the least deprived decile (Community and Mental Health team, 2016). These inequity findings suggest that in England, as in Australia, overall improvements in access may not be narrowing the gap.

We did wonder if there could be an irony, if while you are simultaneously improving access you are also simultaneously further increasing health inequalities. We wondered whether actually you are increasing access for the white British middle classes who already have lots of advantages in terms of health, there are already marked health inequalities in the UK, and whether that would just further widen. (UK_R2)

The way in which targets constrain the ability of IAPT to reach out to more disadvantaged people on the ground came through very strongly.

When IAPT was set up, the mandate was to go for big numbers and get big coverage and get the first $10-12 \%$, now $15 \%$ of the population. In order to get your $15 \%$, you tend to go for the low-hanging fruit. The people that are going to come, in order to get your numbers up and it is still only $15 \%$ of the total. Some of the groups that we are talking about would be the bottom $15 \%$ not the top $15 \%$. That requires a lot more effort, and so that is going to vary enormously from borough to borough depending on the importance they give to the public health approach. (UK_R1)

[Equitable access] is not going to happen under this current set of key performance indicators. In fact, people have been disincentivized to go find a hard-to-reach population who may, for all sorts of reasons, respond less well to treatment, because you're just making sure figures look worse each month. (UK_R2) 
We're oversubscribed from [more affluent part of district]. And the challenge for us is that we are commissioned based on our activity by the Clinical Commissioning Group... But in terms of where I put the staff resource, I need to put the staff resource where the demand is, because if I don't do that, then I've got an issue around my Key Performance Indicators that are linked to waiting times. I've got to deliver 95 per cent within 18 weeks, 75 per cent within six weeks. Lots of people entering treatment. I've got this challenge between I need to deliver the activity in [less affluent, undersubscribed part of district] and promote referrals there, but I need to be careful of my waiting times in [more affluent part of district]. (UK_SH1)

Other possible explanations for inequity issues with $I A P T$ were related to broader social determinants of health, and to lower-quality services being just another aspect of living in a more deprived area.

That reinforces what I suspect everybody knew but doesn't always think about, which is that you cannot just deal with psychological factors in isolation. You have to look at the social context in which peoples' psychological problems have developed and are likely to be being sustained....You've got to look for the community and social context in which you are providing therapy and not just assume that by providing high-quality evidence-based psychological therapies you will be meeting the needs of the full community. (UK_PM1)

[B]roadly speaking in psychology they are two views... One of them was to say, is to say, look, if you're in a socially deprived area, then your environment is just so difficult, that psychology ...can only do so much for you. And so this is a direct effect of social deprivation, the slings and arrows of outrageous fortune. The alternative view is that in most societies if you live in a socially deprived area, you're deprived of almost everything, and that includes good mental health services. One reason why you may get less good outcomes is that the services aren't so good. (UK_R3)

While inequities in access have generally taken a back seat to broader concerns over unmet need in Australia and productivity in the UK, income-based inequities in access to psychotherapy are considered to be self-evident and serious in Canada.

People who have [employment-based] insurance coverage have way better access than anyone else in Canada, and coverage is probably negatively correlated to level of need. (CDA_PM1)

Obviously there is a profound lack of equity of access, of parity, when you have treatments that are out of sight financially [and] when they require private payment for people in lower SES groups. (CDA_SH1) 
Canadian quantitative research has borne out these qualitative findings. Both income and education have been found to be significant predictors of mental health service utilization (Vasiliadis, Tempier, Lesage \& Kates, 2009). Moreover, the second and third papers in this dissertation found a range of income-based inequities in access to psychotherapy and other mental health services.

At the same time, Canadian key informants pointed to the broader range of psychotherapy benefits that the federal government provides to populations under its jurisdiction (such as indigenous people, military personnel, and federal inmates), and to the relatively minor role of access to psychotherapy in tackling inequities in mental health outcomes among vulnerable populations.

To the extent that the federal populations have higher mental health needs, which I think is accurate across the board, the fact that they are federal populations does result in more targeted programing for those groups. (CDA_PM1)

If you are trying to tackle inequity, part of it and only part of it is access, is this covered or not. The big part of it is do I have housing, am I hungry, am I unhealthy in pure simple physical terms, therefore I have a mental health issue. (CDA_PM2)

Before turning to an analysis of efforts in all three countries to address the equity impacts identified above, it is important to first consider the equity impacts of Better Access and IAPT on people living with what are sometimes termed SMI (for 'serious mental illness' such as schizophrenia and bi-polar disorder). Views in the UK and Australia were mixed. On the one hand, in the UK there were concerns that the quality of services for SMI may be diminishing even as IAPT is expanding access to psychotherapy for the population as a whole.

[My care coordinator] would come to my house at 8 o'clock in the morning every four to six weeks and make sure that everything was alright, and if everything wasn't alright. For me, and for a lot of people it worked very well. And then 
increasingly we have had what is called step down, and people who have had that kind of service are returned to their GPs because there isn't the money to fund it. (UK_R4)

On the other hand, in Australia Better Access has generally had a positive impact, with some concerns regarding financial barriers.

For people with low prevalence and severe conditions, it has been really good for them as well... Our public mental health service finds it so difficult to offer psychological therapists... Learning how to live with the panic attacks that certain voices bring on or certain hallucinations that feelings bring on, learning how to manage those has made a huge difference... A lot of people with severe mental illness, whether depression or anxiety or psychosis, may not be able to afford to have a GP. And the GPs are the gatekeepers to the scheme. (AUS_R2)

Both Australia and the UK have announced an intention to improve access for people living with SMI to Better Access and IAPT in the next wave of reforms. It is unclear as yet to what extent the new federal transfer in Canada will focus on meeting unmet needs for people living with SMI, for people with higher-prevalence lower-acuity disorders such as depression and anxiety, or both.

Equity efforts. Key informants were asked to describe the efforts being made to reduce inequities in access to psychotherapy, and whether or not these efforts are working. While both Australia and the UK are increasingly turning their attention to equity issues, the UK is further ahead in already having integrated e-mental health and data-informed quality improvement at the local level into IAPT. In Canada there is some hope that the new federal transfer will go toward reducing financial barriers, although this will be up to provincial and territorial governments.

In response to recommendations from an extensive review of the Australia mental health system (National Mental Health Commission, 2014), the commonwealth government is taking action to reduce inequities in access in rural and socio-economically 
disadvantaged communities. Coverage of e-mentalhealth and telemental health services

are being expanded under Better Access, and funding for the smaller but more targeted

ATAPS initiative is being rolled into new Primary Health Networks (PHNs).

[W]ith this initiative we will see some of those Better Access services delivered by telehealth and yet still billable to Medicare. One of the problems with Better Access has been geographic maldistribution based on the location of providers largely, so I think this is a step in the right direction. (AUS_SH1)

[W]e we now have PHNs and they will have a role in trying to improve access to at-risk groups including people experiencing socio-economic disadvantage. (AUS_R2)

There is this recognition that Medicare is going to give you the broad coverage, but if you want to really try to address specific levels of needs that might not be catered for well by Medicare, then you might need parallel programs that are specifically designed to try to address things. For example, the PHNs have all had to do these mental health needs assessments in their areas. And that's guiding the commissioning processes. (AUS_R3)

Despite general support, key informants expressed some concerns about cost-shifting with these new initiatives.

It's always a coordination and integration piece. ...We are largely supportive of [the PHN] initiative but there have been some concerns. Obviously if you are commissioning new services you are defunding old services. (AUS_SH1)

[Expanded telehealth coverage under Better Access] might encourage more psychologists who are working in the public system to work in the private system, which of course just denudes the public system of the workforce. (AUS_SH2)

[W]e should be transparent about cost-shifting, and get out of the other's space, or get into the other's space if the other can't or isn't in there is possibly the challenge for all of us [state and commonwealth levels of government]. (AUS_PM1)

In the UK, e-mental health approaches have been integrated into IAPT from the start, with a large share of programming delivered through low-intensity manualized Cognitive Behavioural Therapy (supported by entry-level psychologists). Moreover, while $I A P T$ efforts to reduce socio-economic inequities are relatively recent, there is 
wealth of data at the Clinical Commission Group and Local Area Team-level (not to

mention at the level of individual therapists and clients) to guide these efforts.

Basically IAPT is devolved to Clinical Commission Groups to make sure that they are meeting the needs of their local populations. It is up to them to make sure that they meet needs related to equality and diversity. If there is anything specific and tailored going on, it would be going on at that level. (UK_PM2)

In terms of recovery, we historically have very low recovery rates in our city area, which was always linked to the demographic, predominantly BME [black and ethnic minority], high rates of deprivation, etc. And they were hovering around recovery rate of 10 per cent. ...[L]ast year we averaged 47 per cent, so we were close to the 50 per cent target. ... [T] here were several things that we did. ...[I]t just happened that that particular team was probably the least IAPT adherent. ...[W]e introduced ... a recovery master class for staff... and we also moved to an IAPT-based IT system. That meant the staff ... could analyze the data ... and use that in therapy. [In terms of engagement], we've rebranded ourselves as a wellbeing college, and we have adopted an educational culture. ...People are coming in as students and they're enrolling on classes. I think that helps. ...[W]e seem to be doing better at engaging those groups. (UK_SH1)

Nevertheless, concerns were expressed regarding the capacity of Clinical Commissioning

Groups to tailor IAPT to local needs with any degree of consistency.

Although they had the biggest population they had the lowest provision [for IAPT]....At the time, they as a borough received less money to spend on the population. Part of it was they had less central funding. But also it was partly I suspect because the commissioners gave lower priority to mental health. (UK_R1)

It is fair to say that that sort of commissioning is not that common. It does take place in a few places. ...[T]his is where public health supposedly does a needs assessment of the local area and the priorities, and in so doing should be trying to ensure that people who may benefit from the service but are less likely to take it up even if it's been offered get a chance. That isn't as strong as it could be. There is still work going on to try and improve it. (UK_PM1)

In Canada, the barriers described above have thus far prevented wide-scale

reforms to reduce inequities in access to psychotherapy. However, there is some expectation that new federal funding could go toward removing financial barriers. In pointing out that most people who require counselling "have to pay out-of-pocket, or 
more often, try to manage without," Former federal Minister of Health Jane Philpott indicated that financial barriers are an important part of the rationale for the new federal transfer (Canada, 2016). Opinions from key informants ranged from the rather blunt "it would be really stupid" (CDA_SH3) to expand public funding for psychotherapy services to those who are already covered by employment-based benefits or able to afford to pay out-of-pocket, to the more tentative:

Maybe on the accountability side [of the new federal transfer], to the extent that the focus on results focuses on unmet need, this might loop back to financial equity. (CDA_PM3)

Moreover, key informants identified the Quebec pharmacare model as a promising approach that has been able to move forward with available policy levers at the provincial/territorial level. This model provides universal coverage for medications through a mix of employment-based coverage and public coverage for residents who do not have employment-based coverage.

[B]ecause there are also the EAP programs, that medication-type drug coverage, if we were to use it here, I think that would work very very well. ...[T] concentrates on people who do not have access to it. (CDA_R2)

It is a little more complicated now, but what Quebec said is exactly what I am saying, if somebody is covered by an employer plan we are not going to replace it. (CDA_SH3)

However, political factors have played a key role, including timing and whether more universal or more targeted approaches have the most political appeal for a specific policy reform. In the run-up to an election, the Ontario government recently announced universal coverage of medications for children and youth under 25 , but this policy reform only covers a small percentage of the population.

Anyone that is on the eve of an election, that is why the broader Ontario under 25 plan made it out. It is a straight political calculus. Somebody right after a majority 
government will do a targeted program, [when] they have got four years to weather it. (CDA_SH3)

Whichever approach meets the political feasibility test has the potential to improve access, both at the population level and for more socio-economically disadvantage groups.

When you are starting at the floor, no one has access, arguably anything we do is better. (CDA_SH2)

Lessons learned regarding equity. Key informants identified two complementary lessons learned regarding equity. First and foremost, improving equity in access to psychotherapy requires making this objective explicit, and diligently monitoring progress. In discussing equity impacts of both the Better Access and IAPT reforms, key informants noted that universal public funding has provided equitable access in theory but not always in practice. Key informant offered the following lesson learned from the Australian experience:

Consider the equity issues from the outset, and embed them in reform. Because the other challenge of big reforms is that they are hard to revisit. So I think that a clear focus on those issues from the outset might help [Canada] to embed some of the principles around equity and so forth. (AUS_SH1)

The question about whether or not a single monitoring body is going to produce better [equity outcomes], our own example probably gives me some concern. ....Even if we did have a path through from the commonwealth to spend ... as we wished, we should take the obligation seriously about being more fine-tuned. (AUS_PM1)

At the same time, universal approaches may reach more absolute numbers of people with low socio-economic status. To the "farmer on his tractor" (AUS_R2) who is able to afford telemental health services for the first time as a result of Better Access, it does not matter whether the equity gap is not getting narrower. 


\section{Discussion}

By comparing interviews with key informants in Australia, the UK and Canada regarding the relationship between government structure, the design of psychotherapy services, and equity in access, this paper deepens and enriches the findings from the first three papers in this dissertation. In particular, the interviews provide insights into the relationship between government structure and other factors for policy reform, and the ways in equity requires explicit focus regardless of government structure, service system design or social insurance model. These insights are discussed below, followed by a consideration of the limitations of this study and its applicability to the Canadian policy context.

The comparative analysis of key informant interviews provides further evidence for the role of centralization in a government's capacity for policy reform, and the first paper's finding regarding decentralization as the greatest barrier. While $I A P T$ is not without critics, the unitary nature of the UK government (and NHS England) has made it possible to launch and sustain a program with a strong record of success. Australia less unitary federation nevertheless features a strong role for the commonwealth government. The commonwealth government's jurisdiction over Medicare has made it politically expedient to expand Medicare coverage of psychotherapy with Better Access, but more challenging to introduce the same level of accountability as IAPT. Canadian key informants confirmed the critical role of Canada's decentralized government structure, as well as related policy legacies embedded in the Canada Health Act and fiscal constraints, in impeding reform. The lessons learned regarding factors for policy reform that were identified by key informants are largely related to government structure. The more 
centralized the government, the fewer the fiscal constraints, the stronger the approach to accountability, the sharper the focus, and the stronger the support for implementation.

At the same time, key informants provided insight into the interplay between government structure and at least one other critical factor for policy reform, whether the survey evidence regarding high rates of unmet need in Australia or the strong case for public investment put forward in the UK. Moreover, other policy factors have had important roles, including workforce supply, influential policy champions, and growing public support.

With regard to equity, the comparative analysis of key informant interviews suggests that neither centralized government structure, service system design, nor social insurance model can guarantee equitable access to psychotherapy. Canadian key informants confirmed the findings from the second and third papers, namely that the absence of both universal and targeted coverage of non-physician psychotherapy has had significant equity impacts, particularly with regard to income. In keeping with the mixed findings from the third paper, the evidence from Australian key informants and other quantitative studies suggests that uptake has been inequitable in rural and socioeconomically disadvantaged areas, but also that Better Access has increased access in absolute terms for lower-income Australians (such as the "farmer on his tractor"). IAPT data shows that uptake has been somewhat equitable, but recovery rates have not, and key informants in the UK expressed considerable concern regarding inequitable access. As a result of these equity concerns, key informants suggested that progress requires making equity an explicit objective and careful monitoring. 
The comparative analysis points to a dynamic tension between universal and targeted approaches, whereby universal approaches can potentially result in higher absolute levels of access at lower income levels even if equity gaps remain. This tension is consistent with Korpi and Palme's paradox of redistribution (1998). According to this theory, targeted approaches are likely to be the last effective because they garner the narrowest political support, and thus the smallest pool of funds to put toward redistribution. The bigger the pie, the more funds are distributed to everyone, the more lower-income people benefit in absolute terms.

The optimal approach for reducing inequities may well be what Marmot (2010) calls proportionate universalism, with some mix of universal and targeted approaches. Where universal approaches provide access in theory for anyone regardless of financial means, targeted approaches can help to ensure that access improves in practice across the social gradient, and outcomes as well. Targeted approaches can work on the social context surrounding psychological problems, taking a community development approach in partnership with local organizations. With a dual focus on social determinants of health and improving access to mental health services, this two-track approach is in keeping with best practices for mental health services for immigrants, refugees, ethno-cultural and racialized populations (Mental Health Commission of Canada, 2016).

At the same time, Korpi and Palme's (1998) paradox suggests that the targeted component may struggle to garner enough resources to have an impact, and may also risk weakening the political impetus for better-funded universal components. These complexities further underscore the need to track and monitor progress toward clear equity objectives. 
The comparative qualitative design of this study has both strengths and limitations. The interviews with 22 key informants and document review have provided rich insights into the relationship between government structure, service system design and equity in access to psychotherapy. However, the analysis would have been more objective if the interviews and coding had been done by more than one person. Further, while Australia, the UK and Canada provide a sharp contrast with regard to government structure and service system design, other countries have also implemented significant reforms in this area. For example, future research could consider similar questions with regard to the United States, which provides public insurance coverage for non-physician psychotherapy for low-income people and seniors through Medicaid and Medicare, and with regard to the Netherlands, which has provided public insurance coverage of psychological services since 1978 (Peachey, Hicks \& Adams, 2013).

Despite these limitations, this study provides timely and relevant guidance to Canadian policy-makers from experiences in comparable countries, at the outset of the new ten-year federal transfer to improve access to mental health services. The comparative analysis highlights the importance of aligning reforms with the strongest available policy levers. While the federal government in Canada does not have access to the same levers as its UK and Australian counterparts, Canadian provincial and territorial governments do have full jurisdiction over mental health services and are thus actually well-placed to institute strong accountability mechanisms and implementation supports. The federal government for its part is well-placed to set high-level targets for the new transfer, and to foster a learning system, both directly and through federally-funded panCanadian health organizations such as the Mental Health Commission of Canada, the 
Canadian Institute for Health Information, the Canadian Institutes for Health Research, and the Canadian Foundation for Healthcare Improvement.

The comparative analysis also highlights the importance of making equity, particularly income-based inequity, an explicit objective in the Canadian context, where the two-tier system has resulted in the most self-evident financial barriers. Canada's decentralized government structure presents opportunities as well as challenges, and there is an opportunity to conduct a natural experiment as each province and territory uses the new federal transfer in different ways. Some jurisdictions may opt for more targeted approaches, others for more universal approaches; some may opt for direct service delivery models, others for insurance approaches. The Quebec pharmacare model, with its mix of public and private insurance, may be adapted to psychotherapy provision. If clear equity objectives are set and monitored, Canada stands to make significant progress in reducing long-standing inequities in access and in mental health outcomes. The amount of funding ( $\$ 5$ billion over ten years) for the new federal mental health transfer is public knowledge (Finance Canada, 2017). Stakeholders could be even more effective at holding governments to account if the bilateral agreements were made public (Bartram, 2017). 


\section{References}

Australia. (2015). Better Access to Psychiatrists, Psychologists and General Practitioners through the MBS initiative [website]. Canberra: Author. Retrieved from http://www.health.gov.au/mentalhealth-betteraccess

Australia, Australian Institute of Health and Welfare. (2017). Health expenditure Australia 2015-16. Canberra: Author.

Bambra, C. (2005). Worlds of welfare and the health care discrepancy. Social Policy and Society, 4(1), 31-41.

Banting, K. G., \& Corbett, S. M. (2002). Health policy and federalism: An introduction. In K. G. Banting \& S. M. Corbett (Eds.), Health policy and federalism: A comparative perspective on multi-level governance (pp. 1-38). Kingston, ON: Institute of Intergovernmental Relations, Queen's University.

Bartram, M. (2016). A targeted federal mental health transfer: Are prospects better under the Trudeau Liberals? In G. B. Doern \& C. Stoney (Eds.), How Ottawa Spends 2016-2017 (pp. 216-239). Ottawa: Carleton University.

Bartram, M. (2017). Making the most of the new $\$ 5$ billion for mental health. Canadian Medical Association Journal, 189(44), E1360-E1363.

Bartram, M., \& Lurie, S. (2017). Closing the mental health gap: The long and winding road? Canadian Journal of Community Mental Health, 17, 1-14. 
Canada. (2016). Remarks from the Honourable Jane Philpott, Minister of Health, to the Canada 2020 Health Summit: A new Health Accord for all Canadians [speech posted on the Internet]. Retrieved from https://www.canada.ca/en/healthcanada/news/2016/10/remarks-honourable-jane-philpott-minister-health-canada2020-health-summit-new-health-accordcanadians.html? $=$ undefined\&wbdisable $=$ true

Community and Mental Health statistics team, Health and Social Care Information Centre. (2014). Psychological therapies, England: Annual report on the use of Improving Access to Psychological Therapies services - 2012/13. Leeds: Health and Social Care Information Centre.

Community and Mental Health team. (2016). Psychological therapies: Annual report on the use of IAPT services, England 2015-16. Leeds: Health and Social Care Information Centre.

Council of Australian Governments Health Council. (2017). The fifth national mental health and suicide prevention plan. Canberra: Commonwealth of Australia, Department of Health. Retrieved from https://www.coaghealthcouncil.gov.au/Portals/0/Fifth\%20National\%20Mental\%2 0Health\%20and\%20Suicide\%20Prevention\%20Plan.pdf

Esping-Andersen, G. (1990). The three worlds of welfare capitalism. Princeton, N.J.: Princeton University Press.

Finance Canada. (2017). Building a strong middle class. Ottawa, ON: Author. 
Flood, C. M. (2001). Profiles of six health care systems: Canada, Australia, the Netherlands, New Zealand, the UK and the US. Ottawa, ON: Prepared for the Standing Senate Commitee of Social Affairs, Science and Technology. Retrieved from http://www.parl.gc.ca/Content/SEN/Committee/371/soci/rep/volume3ver1e.pdf

Hall, C., \& Morneau, B. (2017). The House with Chris Hall: Bill Morneau discusses health care funding [Audio, 9:33 min.]. Ottawa: CBC Player. Retrieved from http://www.cbc.ca/player/play/835118659826

Hickie, I. B., Rosenberg, S., \& Davenport, T. A. (2011). Australia's Better Access Initiative: Still Awaiting Serious Evaluation? Australian \& New Zealand Journal of Psychiatry, 45(10), 814-823.

Korpi, W. (2000). Faces of inequality: Gender, class, and patterns of inequalities in different types of welfare states. Social Politics: International Studies in Gender, State \& Society, 7(2), 127-191.

Korpi, W., \& Palme, J. (1998). The paradox of redistribution and strategies of equality: Welfare state institutions, inequality, and poverty in the Western countries. American Sociological Review, 63(5), 661-687.

Layard, R., Clark, D., Knapp, M., \& Mayraz, G. (2007). Cost-benefit analysis of psychological therapy. National Institute Economic Review, 202(1), 90-98.

Mahon, R. (2008). Varieties of Liberalism: Canadian Social Policy from the Golden Age to the Present. Social Policy \& Administration, 42(4), 342-361.

Mahoney, J., \& Goertz, G. (2004). The Possibility Principle: Choosing Negative Cases in Comparative Research. American Political Science Review, 98(04). 
Marmot, M. G. (2010). Fair society, healthy lives: The Marmot review; Strategic review of health inequalities in England post-2010. London, UK: Marmot Review.

McLennan, W., \& Australian Bureau of Statistics. (1998). Mental health and wellbeing: Profile of adults, Australia, 1997. Canberra: Australian Bureau of Statistics. Meadows, G. N., Enticott, J. C., Inder, B., Russell, G. M., \& Gurr, R. (2015). Better access to mental health care and the failure of the Medicare principle of universality. The Medical Journal of Australia, 202(4), 190-194.

Mental Health Commission of Canada. (2016). The case for diversity: Building the case to improve mental health services for immigrant, refugee, ethno-cultural and racialized populations. Ottawa: Author.

Myles, J. (1998). How to design a "liberal" welfare state: A comparison of Canada and the United States. Social Policy and Administration, 32(4), 341-364. National Mental Health Commission. (2014). Contributing lives, thriving communities: Report of the national review of mental health programs and services. Sydney: Author.

NHS England. (n.d.). Adult Improving Access to Psychological Therapies programme [website]. London: Author. Retrieved from https://www.england.nhs.uk/mentalhealth/adults/iapt/

NHS Scotland. (2014). Proportionate universalism and health inequalities [briefing]. Edinburgh: Author. Retrieved from http://www.healthscotland.com/uploads/documents/24296ProportionateUniversalismBriefing.pdf 
Ouimet, H. R. (2014). Quebec and Canadian fiscal federalism: From Tremblay to Séguin and beyond. Canadian Journal of Political Science, 47, 47-69.

Peachey, D., Hicks, V., \& Adams, O. (2013). An imperative for change: Access to psychological services for Canada. Toronto, ON: Health Intelligence Inc., for the Canadian Psychological Association.

Phillips, K. (2016). Federal health care funding in the current economic context. Ottawa: Library of Parliament. Retrieved from https://hillnotes.ca/2016/02/03/federalhealth-care-funding-in-the-current-economic-context/

Pierson, P. (1995). Fragmented welfare states: Federal institutions and the development of social policy. Governance, 8(4), 449 - 478.

Pirkis, J., Harris, M., Hall, W., \& Ftanou, M. (2011). Evaluation of the Better Access to Psychiatrists, Psychologists and General Practitioners through the Medicare Benefits Schedule initiative: Summative evaluation. Melbourne: Centre for Health Policy, Programs and Economics, University of Melbourne.

Vasiliadis, H.-M., Tempier, R., Lesage, A., \& Kates, N. (2009). General Practice and mental health care: determinants of outpatient service use. Canadian Journal of Psychiatry. 54(7), 468-76.

Weaver, R. K., \& Rockman, B. A. (1993). Assessing the effects of institutions. In Do institutions matter? Government capabilities in the United States and abroad (pp. 1-41). Washington, DC: The Brookings Institution.

Wendt, C., Frisina, L., \& Rothgang, H. (2009). Healthcare system types: A conceptual framework for comparison. Social Policy \& Administration, 43(1), 70-90. 
Wood, G., \& Gough, I. (2006). A comparative welfare regime approach to global social policy. World Development, 34(10), 1696-1712. 
Table 19 Sample Frame

Sample Frame

\begin{tabular}{|c|c|c|c|}
\hline & Australia & $\underline{\text { UK (England) }}$ & Canada \\
\hline Researcher & 4 & 4 & 3 \\
\hline Policy-maker & 1 & 2 & 3 \\
\hline Stakeholder & 2 & 1 & 2 \\
\hline Total & 7 & 7 & 8 \\
\hline
\end{tabular}


Table 20 Key Factors for Policy Reform - Summary of Results

Key Factors for Policy Reform regarding Access to Psychotherapy - Summary of Results

$\underline{\text { Australia }} \quad \underline{\text { UK (England) }} \quad \underline{\text { Canada }}$

$\underline{\text { Factors }}$

\begin{tabular}{|c|c|c|c|}
\hline $\begin{array}{l}\text { Government } \\
\text { structure }\end{array}$ & $\begin{array}{l}\text { Strong } \\
\text { commonwealth } \\
\text { government with } \\
\text { jurisdiction over } \\
\text { Medicare }\end{array}$ & $\begin{array}{l}\text { Unitary state with } \\
\text { jurisdiction over } \\
\text { NHS England }\end{array}$ & $\begin{array}{l}\text { Decentralized } \\
\text { federation with } \\
\text { jurisdictional tensions, } \\
\text { particularly over } \\
\text { healthcare }\end{array}$ \\
\hline $\begin{array}{l}\text { Second key } \\
\text { factor }\end{array}$ & $\begin{array}{l}\text { Survey data } \\
\text { showing high rates } \\
\text { of unmet need }\end{array}$ & $\begin{array}{l}\text { Strong case for } \\
\text { public investment }\end{array}$ & $\begin{array}{l}\text { Related policy legacies } \\
\text { from } C H A \text { and fiscal } \\
\text { constraints on } \\
\text { provincial/territorial } \\
\text { governments }\end{array}$ \\
\hline $\begin{array}{l}\text { Resulting service } \\
\text { system design }\end{array}$ & $\begin{array}{l}\text { Better Access } \\
\text { expanded } \\
\text { Medicare coverage } \\
\text { to psychologists } \\
\text { etc. }\end{array}$ & $\begin{array}{l}I A P T \text { with } \\
\text { targets/standards set } \\
\text { by UK government, } \\
\text { administered by } \\
\text { NHS England }\end{array}$ & $\begin{array}{l}\text { Two-tier, with impact } \\
\text { of new federal transfer } \\
\text { to be determined }\end{array}$ \\
\hline
\end{tabular}

Other key factors Workforce supply; policy champions; growing public support

Lessons learned Align reform with policy levers available in particular government context

Establish strong accountability mechanisms including both statistics and experiential data

Focus the scope of reform rather than trying to do everything at once

Support implementation, including workforce planning 
Table 21 Equity and Access to Psychotherapy - Summary of Results

Equity and Access to Psychotherapy - Summary of Results

$\underline{\text { Australia }}$

Equity impacts

Population-level concerns

Explanation

Serious Mental

Illness (SMI)

concerns

$\underline{\text { Equity efforts }}$ barriers
Rural; socioeconomically disadvantaged regions

Workforce supply/incentives $\underline{\text { UK (England) }}$

BME (black minority ethnic) groups; districtlevel; deprivation $\underline{\text { Canada }}$

Inequities considered selfevident, particularly income-based; federal populations distinct (more coverage but higher needs)

Expanded coverage Using data to of telemental health; improve quality;
Targets provide disincentives; broader social determinants of health

Concerns re. costshifting from SMI to people with mild to moderate mental illness Primary Health Networks with mandate for local planning tailoring to local needs by district commissioning groups
CHA exclusion of non-physician psychotherapy; broader social determinants of health

No data obtained

Improving equity requires making this an explicit objective and tracking progress

Universal approaches increase access at lower-income levels in absolute terms even if equity gaps remain 


\section{Appendix D: CUREB-Approved Materials}

\section{Carleton \\ U N I V E R S I T Y \\ Canada's Capital University}

\section{Recruitment Email}

\section{State governance, service system design and equity in access to psychotherapy: Lessons for Canada from Australia and the UK}

Dear

I am writing to request your participation in a key informant interview regarding the relationship between state governance, service system design and equity in access to psychotherapy, drawing on experiences in Australia, the United Kingdom and Canada. This study is part of a broader research programme toward my dissertation on access to psychotherapy in the Canadian context, under the supervision of Allan Maslove, Distinguished Research Professor Emeritus with Carleton's School of Public Policy and Administration.

Your expertise as a policy-maker [or researcher, or advocacy organization, or professional association] would greatly contribute to understanding these relationships.

Please let me know if you would be willing to participate in a 45-60 minute interview. If you are willing, I will follow up with additional information about the study, and a consent form for you to sign and return. I will also contact you to arrange the logistics of scheduling an interview at your convenience.

This research has been cleared by the Carleton University Research Ethics Board-A (clearance \#105482). Participants in this study will not be exposed to any more risk than they would experience in their daily lives as mental health experts and stakeholders. No compensation will be provided.

Thank you very much in advance for considering this request.

Yours truly,

Mary Bartram, RSW, PhD Candidate

School of Public Policy and Administration

Carleton University

Ottawa, Ontario, Canada 


\title{
Carleton \\ U N I V E R S T Y
}

Canada's Capital University

\section{Information and Consent Form}

\section{State governance, service system design and equity in access to psychotherapy: Lessons for Canada from Australia and the UK}

\author{
Investigator: \\ Mary Bartram, RSW, PhD Candidate \\ School of Public Policy and Administration \\ Ottawa, Ontario, Canada \\ E-mail: mary.bartram@carleton.ca

\section{Purpose of the Study}

As you know, both Australia and the United Kingdom have implemented wide-reaching policies to improve access to psychotherapies/psychological therapies over the past 10-15 years. Changing Directions, Changing Lives: The Mental Health Strategy for Canada was released by the Mental Health Commission of Canada in 2012, with recommendations to improve access to evidence-based psychotherapies. However, a similar initiative has yet to be introduced in Canada. While physician and hospital services are covered by public health insurance, access to psychological services and other non-physician mental health professionals follows a "two-tier" model, with higher income Canadians either paying out-of-pocket or through employment-based insurance, and lower income Canadians facing considerable financial barriers or long waits for limited community-based services.

This study is one component of my doctoral research into access to psychotherapy, under the supervision of Allan Maslove, Distinguished Research Professor Emeritus with Carleton's School of Public Policy and Administration. Its purpose is to gather perspectives from key informants in Australia, the United Kingdom and Canada regarding the following questions: What is the relationship between constitutional structure, service system design, and equity in access to psychotherapy? How much do policy differences regarding access to psychotherapy have to do with differences in the way that national governments are structured? If Canada were to follow suit in introducing a wide-scale initiative to expand access to psychotherapy, what are key lessons learned in Australia and the United Kingdom, particularly in relation to service system design and equity in access?

You have been identified through a literature review as a key informant due to your role in research, policy-making, advocacy and/or service provision regarding to access to psychotherapy. 


\section{Procedures involved in the Research}

The key informant interview will take place via telephone or skype (or equivalent) according to your preference. You are being asked to give informed consent in advance. If you agree to participate, you will be asked to answer questions about your opinions on the relationships between constitutional structure, service system design and equity in access to psychotherapy. The interview is expected to last between 45 and 60 minutes. The researcher will take hand-written notes during the interview. With your permission the interview will also be audio-recorded. The audio-recording will be used to supplement the researcher's hand-written notes.

\section{Potential Harms, Risks or Discomforts:}

It is not likely that there will be any harms or discomforts from/associated with participating in this study. You do not need to answer questions that you do not want to answer or that make you feel uncomfortable and you can withdraw from the study at any time. The steps which will be taken to protect your privacy are described further below.

\section{Potential Benefits}

The research is not expected to provide direct benefit to the participants. The results of the study may be helpful in improving mental health policy and service delivery in Canada. Participants may indirectly benefit from knowing they contributed to a discussion that could lead to such improvements.

\section{Confidentiality}

You are participating in this study confidentially. My intention is to use data gathered from this study in publications and presentations. Any quotes from participant interviews will not be identified by name, but rather identified by primary role and country of origin (for example, Australia_Policy-Maker_\#1, Canada_Researcher_\#2). Electronic notes and audio-recordings taken during the discussion will be stored as password protected files on a password-protected computer. Any hard (paper) copies of the information/data you provide will be kept in a locked desk/cabinet in my office. Electronic notes and hard copies will be kept for a period of 5 years after the study has been completed and then destroyed; audio recordings will only be kept for one year. All paper records will be disposed of in confidential waste or shredded, and all electronic records will be deleted.

\section{Voluntary Participation and Withdrawal}

Your participation in this study is voluntary and you can decide to withdraw from the study and cancel your consent with no consequences to you, by sending an email indicting that you are withdrawing from the study to mary.bartram@,carleton.ca, no later than June 30,2017. As mentioned previously, if you do not want to answer some of the questions you do not have to, but you can still be in the study. If you would like to have some responses struck from the record, you just have to inform the researchers and the information will be removed. You will not receive payment for participating in the study, although you input and perspectives are greatly appreciated. 


\section{Information about the Study Results}

I expect to have this study completed by June 30, 2017. If you would like to receive a summary of the interview discussion or would like to receive a copy of the final manuscript please let me know how you would like the document/updates to be sent to you. There is a space to indicate this on the last page of this consent form.

\section{Questions about the Study}

This letter is yours to keep. If you have questions or need more information about the study itself, please contact the Investigator at mary.bartram@,carleton.ca

This study has been cleared by the Carleton University Research Ethics Board-A (clearance \#105482). If you have any ethical concerns with the study, please contact Dr. Andy Adler, Chair, Carleton University Research Ethics Board-A (by phone at 613-5202600 ext. 4085 or via email at ethics@carleton.ca).

\section{CONSENT FORM}

- I have read and understand the information presented in the information letter about a study being conducted by Mary Bartram of Carleton University.

- I have had the opportunity to ask questions about my involvement in this study and to receive additional details I requested.

- I understand that if I agree to participate in this study, I may withdraw from the study at any time.

- I have been given a copy of this form.

- I agree to participate in the study.

1. I agree that the interview can be audio recorded.

Yes

No

2. I would like to receive a copy of the interview summary.

Yes

No

3. I would like to receive a copy of any published materials (such as journal articles and reports) drawing on this study.

No

.Yes

If yes, where would you like the materials sent:

Email:

Mailing address: 


\section{Signatures:}

Participant's Name (Please Print)

Participant's Signature

Date

\section{Investigator Statement:}

I have carefully explained to the research participant the nature of the above research study. To the best of my knowledge, the research participant signing this consent form understands the nature, demands, risks and benefits involved in participating in this study. I acknowledge my responsibility for the well-being of the above research participant, to respect the rights and wishes of the research participant.

Name of Investigator/Delegate (Please Print)

Signature of Investigator/Delegate Date 


\section{Interview Guide}

\section{State governance, service system design and equity in access to psychotherapy: Lessons for Canada from Australia and the UK}

The purpose of this interview guide is to gather your perspective regarding the relationship between state governance, service system design, and equity in access to psychotherapy in Australia, the UK and Canada, with a view to informing policy development in the Canadian context. In Canada the governance structure is highly decentralized, with provincial governments having jurisdiction over health service delivery. The federal government provides 20-25\% of funding for health services through fiscal transfers on the condition that provincial governments maintain first-dollar universal coverage of physician and hospital services. However, mental health services that are provided by psychologists and other non-medical mental health professionals are generally not covered by public insurance, resulting in what is known as a "two-tier" system: lower-income citizens need to queue for limited public services offered through community mental health services, while those with employment-based benefits or the means to pay out-of-pocket access private services. Psychotherapy is defined broadly here, to include psychotherapy, psychological therapies, clinical counselling, and talk therapy. Depending on your expertise, you may speak to policy development in Australia, the UK, and/or Canada.

1. How are psychotherapy services provided in Australia/the UK?

Prompts: insurance coverage, public/private split, service provider roles and regulations, specific programs

2. What were the key factors that enabled Australia/the UK to introduce wide-scale initiatives to expand access to psychotherapy in the past 15 years?

Prompts: stakeholders, evidence, professionals, stigma, business case, constitutional structure, economic context, political context

3. To what extent is access to psychotherapy on a par with access to services for physical health problems? Does this parity include choice, that is to say, having the ability to choose from amongst a range of evidence-based treatments? 
4. What are the equity impacts of the design of psychotherapy services in Australia/the UK? To what extent is access to psychotherapy determined by need as opposed to by other factors? Prompts: income, rurality, education, cultural background, language spoken

5. What other factors (other than service system design) might account for inequities in access to psychotherapy in Australia/the UK?

6. What efforts are being made to improve access to psychotherapy overall in Australia/the UK? What efforts are being made to reduce inequities in access to psychotherapy?

7. What is working well with these efforts? What is not working well? Have mental health outcomes improved as a result? Can you suggest any sources that I may go to for corroborating evidence?

8. What are the key challenges and opportunities ahead for improving and reducing inequities in access to psychotherapy in Australia/the UK?

9. What were the key factors that influenced the design of psychotherapy services (i.e. the insurance model, public/private split, financing, eligible service providers) in Australia/the UK?

Prompts: stakeholders, evidence, professionals, stigma, business case, constitutional structure, economic context, political context, other

10. On reflection, what are the key lessons learned from Australia/the UK's efforts to improve and reduce inequities in access to psychotherapy?

Prompts: workforce development, scopes of practice, demand-driven insurance vs direct government funding, targeted vs universal, accountability mechanisms, income-based and rural/remote inequities, other

11. Do you have any suggestions for how these lessons learned could be adapted to the Canadian context (i.e. highly decentralized, narrow but deep coverage)?

12. Do you have any other thoughts on the relationship between state governance, service system design and equity in access to psychotherapy that you would like to share before we end the interview?

Thank you very much for sharing your perspective.

Mary Bartram, RSW, PhD Candidate

School of Public Policy and Administration

Carleton University

mary.bartram@,carleton.ca 


\section{Conclusion}

This dissertation has demonstrated that income-based inequities in access to psychotherapy are a significant problem in Canada, and further that Canada's decentralized government structure has played a central role in creating and sustaining these inequities. As this structure is unlikely to change, what then can be done? Can any of the lessons learned from the United Kingdom (UK) and Australia really be helpful here? Before turning to a consideration of this question and the broader policy implications of these findings, the limitations and strengths of this dissertation are first summarized below.

As with the Canadian health system, the strengths and limitations of this dissertation arise from trade-offs between depth and breadth. The strengths of this dissertation are its breadth and comprehensiveness. Access to psychotherapy in the Canadian context is analysed from multiple angles, using a variety of methodologies to make original contributions to the evidence regarding this increasingly high-profile policy challenge. First, qualitative methods were used to trace the mental health narrative throughout the Canadian health insurance and health reform debates. Second, needstandardized concentration indices calculated from health survey data to measure incomebased inequities in access to psychotherapy and other mental health services, both in Canada and in comparison with Australia just after it had introduced major reforms to improve access. Finally, this comparative approach was expanded by conducting interviews with key informants in Australia, Canada and the UK, another country that has introduced major reforms, with a view to enriching the evidence regarding the 
relationship between government structure, service system design, and equity in access to psychotherapy.

Conversely, the limitations of this dissertation relate to the lack of depth in any one study. The historical analysis in the first paper could have been deepened through consideration of provincial and territorial policy records, or through a comparative tracing of the mental health policy narrative through the development of health insurance in other countries such as the UK and Australia. Similarly, the findings from comparative study of key informant interviews in Australia, the UK and Canada could have been expanded to include other countries with similarly interesting government structures and policy reforms, such as the U.S. and the Netherlands. Moreover, the findings from both of these qualitative studies would have been more reliable if coding had been done by more than just the author. The depth of the quantitative analyses was limited by the lack of sufficient data regarding attitudinal barriers, such as stigma and lack of confidence in the service system. Further, qualitative data from service users in all three countries would help to better understand how financial, attitudinal and other barriers interact at the level of individual decision-making. In particular, such qualitative data could help to probe the possibility of a backlog effect with the introduction of reforms.

Despite these limitations, the main strength of this dissertation may well be its policy relevance, particularly in the Canadian context. While the decentralized nature of Canada's federal system is unlikely to change, windows for reform do open from time to time. First published in October 2016, the first paper accurately forecast the prospects for the new targeted federal mental health transfer that was finalized in the March 2017 federal budget (Bartram, 2016; Finance Canada, 2017). This paper also lays the ground 
work for consideration of policy options going forward (Bartram \& Lurie, 2017). An historic window of opportunity opened for improving access to psychotherapy and other mental health services. However, the long-standing challenges arising from jurisdictional tensions, fiscal constraints, and stigma will continue to constrain the potential impact of this new transfer, whether by watering down accountability or weakening the priority status accorded to mental health.

The dissertation also points to the importance of making equitable access to psychotherapy an explicit priority, particularly in Canada where both the quantitative and qualitative studies found evidence of income-based inequities. While the fourth paper demonstrated that more centralized governments are in a stronger position to implement reforms and monitor progress, provincial and territorial governments in Canada actually have a nearly full suite of policy levers, from revenue-raising and setting targets, to delivering services and monitoring progress. While they are challenged by fiscal constraints that are in turn shaped by fiscal federalism, closing the estimated $\$ 3.1$ billion gap in mental health funding would require a relatively small increase of provincial and territorial spending ( $\$ 2.6$ billion annually on top of the new $\$ 500$ million annual federal transfer; Bartram \& Lurie, 2017). To date, only Ontario has announced its intention to expand access to psychotherapy by investing $\$ 73 \mathrm{M}$ over three years into a new Structured Psychotherapy Program (Ontario, 2017). It remains to be seen to what extent this new program will make equitable access an explicit objective, and how progress will be monitored.

With the new federal transfer, ideally jurisdictions will have flexibility under each bilateral agreement to implement a range of approaches, with different mixes of 
universal, targeted, insurance-based and programmatic elements (Marchildon, 2016). Learning across jurisdictions can be fostered by marshalling the resources of provincial quality councils and pan-Canadian health organizations such as the Canadian Institute for Health Information, the Mental Health Commission of Canada, and the Canadian Foundation for Healthcare Improvement.

The Canadian Institutes for Health Research could work with the health services and policy research community to develop a focused research agenda, and put out a special priority-driven call on the impact of the targeted mental health federal transfer. At the most basic level, it will be important to track how much provincial and territorial governments actually spend on mental health services over the next ten years, and what they spend it on. Tracking changes in unmet need, service utilization, equity, and mental health outcomes is also basic information required to assess the impact of the new funding. Keeping track of changes in stigma will help to contextualize this information, as declining stigma could drive up demand and unmet need even as service availability is expanding. Particular attention needs to be paid to factors that support successful implementation of reforms at the service delivery level, including the leadership of both service users and service providers.

Generations of Canadians have been affected by gaps and inequities in mental health services, including psychotherapy. The new $\$ 5 \mathrm{~B}$ federal transfer is a major breakthrough and a testament to political will and decades of advocacy, even if it will only go so far in closing gaps in funding. Without rigorous accountability mechanisms, and careful consideration of lessons learned in Australia and the UK, this opportunity could slip through Canada's fingers. Stigma may be declining but it is still a significant 
social problem, and fiscal and jurisdictional pressures in the Canadian context are as intense as ever. As a first step toward making the most of these new investments, governments should invite innovation and vigilance by making the bilateral transfer agreements public (Bartram, 2017). 


\section{References}

Bartram, M. (2016). A targeted federal mental health transfer: Are prospects better under the Trudeau Liberals? In G. B. Doern \& C. Stoney (Eds.), How Ottawa Spends 20162017 (pp. 216-239). Ottawa: Carleton University.

Bartram, M. (2017). Making the most of the new \$5 billion for mental health. Canadian Medical Association Journal, 189(44), E1360-E1363.

Bartram, M., \& Lurie, S. (2017). Closing the mental health gap: The long and winding road? Canadian Journal of Community Mental Health, 1-14.

Finance Canada. (2017). Building a strong middle class. Ottawa, ON: Author. Marchildon, G. (2016) Bilateral health agreements between the Federal and Provincial/Territorial Governments in Canada. IRPP Insight, 13, 1-20.

Ontario. (2017). A stronger, healthier Ontario. Toronto: Author. Retrieved from http://www.fin.gov.on.ca/en/budget/ontariobudgets/2017/ch4a.html 